INVESTIGATING THE ROLE OF PUBLIC PARTICIPATION IN WIND ENERGY PROJECT DEVELOPMENT IN ONTARIO

\author{
by \\ Anahita Asadolahniajami \\ MASc. in Environmental Applied Science and Management, Ryerson University, 2011 \\ MSc. in Urban Management, Allameh Tabatabaei University, 2008 \\ BSc. in Chemistry, Shahid Beheshti University, 2000
}

\author{
A dissertation \\ presented to Ryerson University \\ in partial fulfillment of the \\ requirements for the degree of \\ Doctor of Philosophy \\ in the Program of \\ Environmental Applied Science and Management \\ Toronto, Ontario, Canada, 2016 \\ (C)Anahita Asadolahniajami 2016
}




\section{Author's Declaration}

I hereby declare that I am the sole author of this dissertation. This is a true copy of the dissertation, including any required final revisions, as accepted by my examiners.

I authorize Ryerson University to lend this dissertation to other institutions or individuals for the purpose of scholarly research.

I further authorize Ryerson University to reproduce this dissertation by photocopying or by other means, in total or in part, at the request of other institutions or individuals for the purpose of scholarly research.

I understand that my dissertation may be made electronically available to the public. 


\title{
Investigating the Role of Public Participation in Wind Energy Project Development in Ontario
}

\author{
Anahita Asadolahniajami \\ Doctor of Philosophy, 2016 \\ Environmental Applied Science and Management, Ryerson University
}

\begin{abstract}
Over the past several decades, the scope of decision-making in the public domain has changed from a focus on unilateral regulatory verdicts to a more comprehensive process that engages all stakeholders. Consequently, there has been a distinct increase in public participation in the environmental decision-making process. While the potential benefits of public engagement are substantial in terms of identifying synergies between public and industry stakeholders that encourage project development, this participation does not come without its challenges. To meet global energy demands and fulfill ambitious targets for greenhouse gas reduction, renewable energy has received increased attention as a feasible alternative to conventional sources of energy. However, current literature on renewable energy, particularly on wind power, highlights potential social barriers to renewable energy investment. This study investigates the role of public participation by reviewing two case studies of the Ontario wind power generation market to identify the facilitators and constrainers that affected public input into wind project development in Ontario and recommends a participatory framework in the hope of improving public engagement in the wind project development decision-making process. The recommended framework in this research requires all stakeholders to reconsider their current roles in the decision-making process. The public should engage in project planning and monitor the
\end{abstract}


decision-making processes to ensure that their concerns have been addressed. Developers should address public concerns through a consensus building process initiated early in their planning process. Federal and provincial governments have to reclaim their role of ongoing leadership and provide better criteria for implementation and evaluation of the public participation processes. Finally, the process requires a third party who is not only an intermediary, but also plays the role of a knowledge-broker to connect with stakeholders, share and exchange knowledge, and work on overcoming barriers. The knowledge-broker helps to fulfill the main requirement of the collaborative decision-making, which is effective communication. 


\section{Acknowledgement}

I would like to thank the participants. I am greatly indebted to them for their contribution and dedication to this research. They took time from their demanding schedules and opened their door to a student to help her understand their reality.

The process of developing this dissertation represents countless hours of contemplation, reflection, and intellectual and personal discovery. I would like to appreciate the constant kindness, patience, and support from my supervisor throughout this journey. Huge thanks to Dr. Philip Walsh who inspired me, challenged me, kept me going when times were tough, and helped me find my way.

Gratitude is also expressed to Dr. Pushchak for all his support, invaluable advice, and constructive criticism throughout my graduate studies. 


\section{Table of contents}

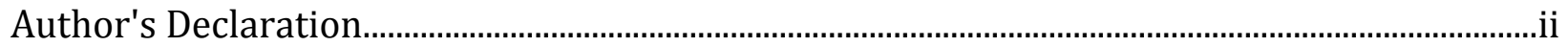

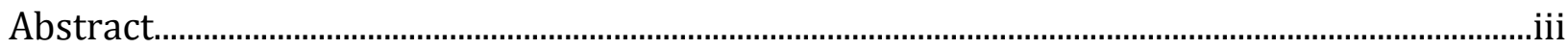

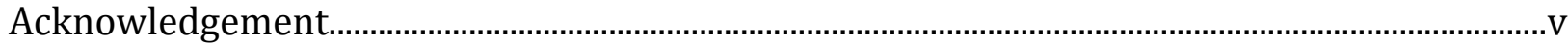

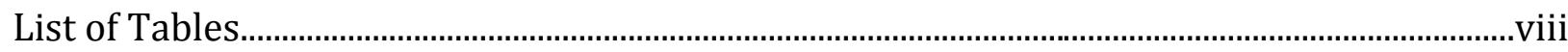

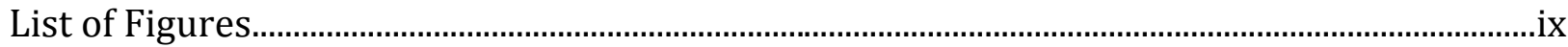

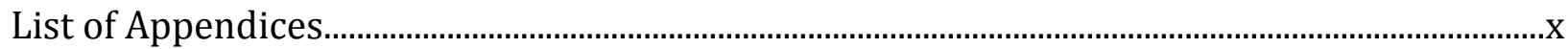

List of Abbreviations......................................................................................................................

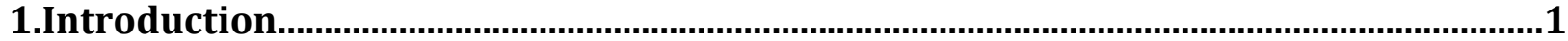

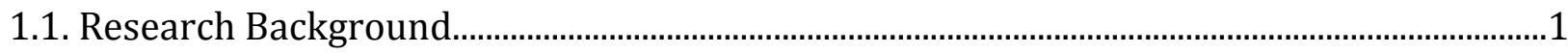

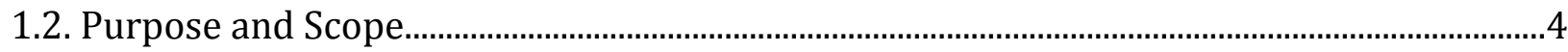

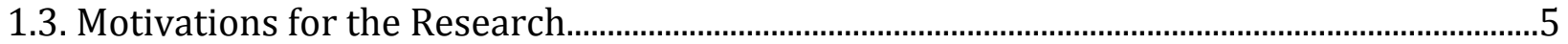

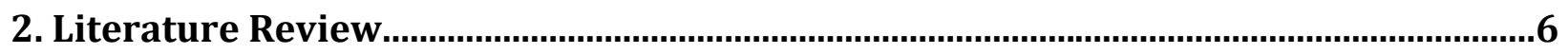

2.1. Public Responses to Wind Power.............................................................................................6

2.1.1. Factors Influencing Project Success..................................................................................

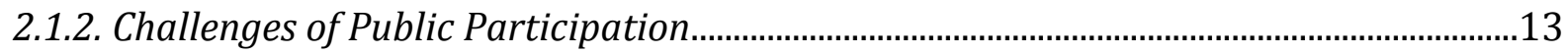

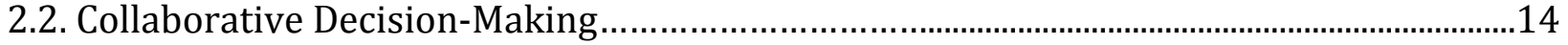

2.3. The Participatory Techniques: From Information Provision to Collaboration..................18

2.4. The Role of a Trusted Third Party in Collaborative Decision-Making..................................22

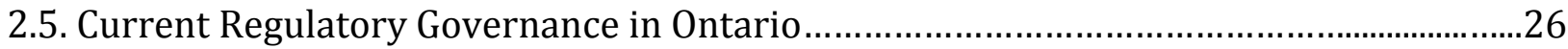

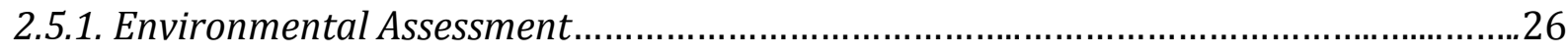

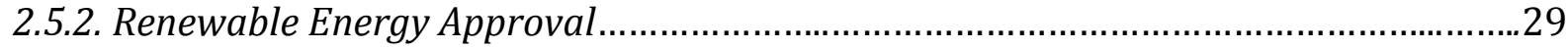

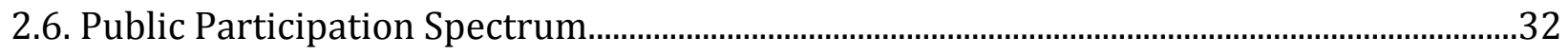

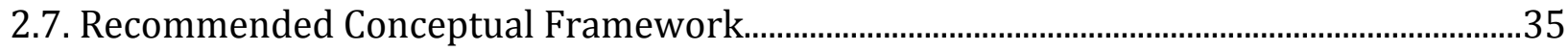

3. Research Methodology

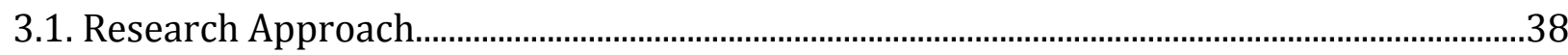

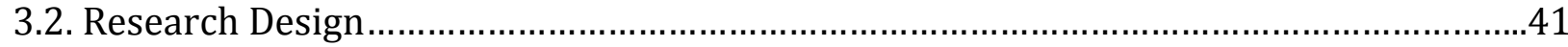

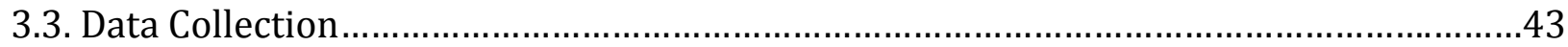

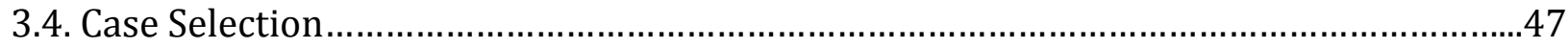

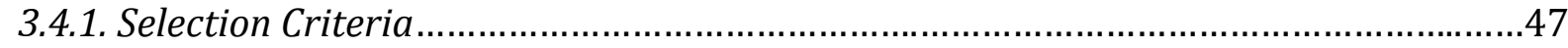




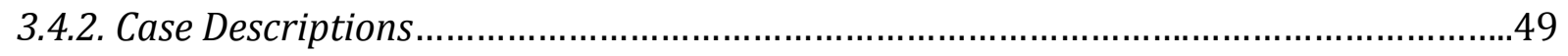

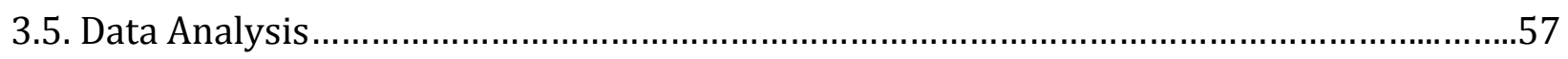

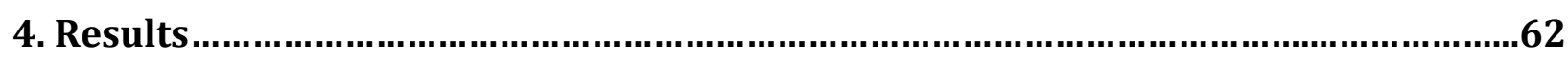

4.1. Themes Related to the Core Question......................................................................63

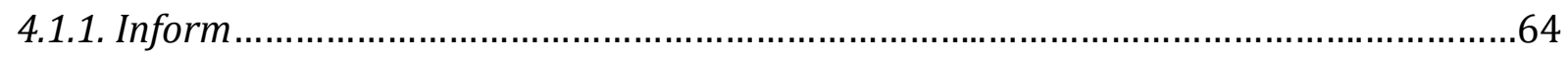

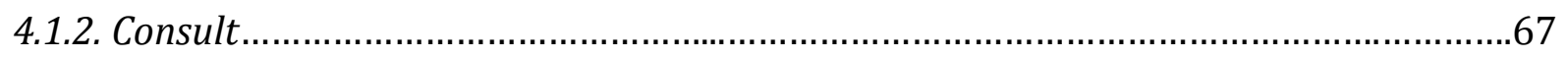

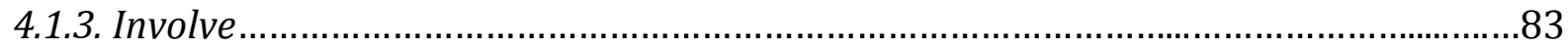

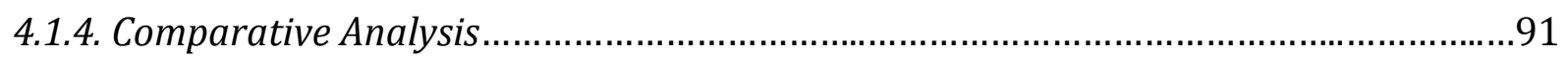

4.1.5. Summary of Existing Participation Levels ................................................................97

4.2. Themes Related to the Sub-Questions......................................................................105

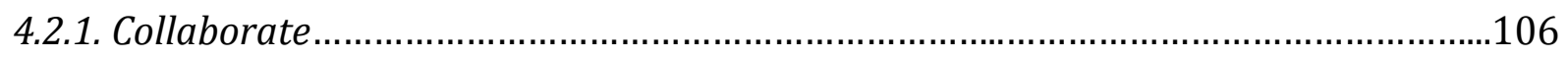

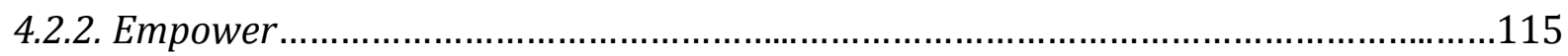

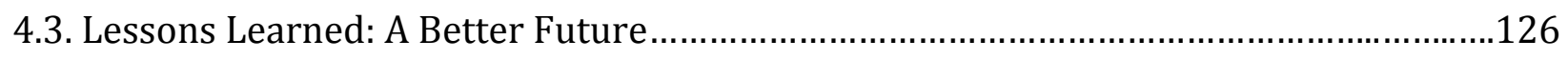

4.4. Updated Conceptual Framework................................................................................134

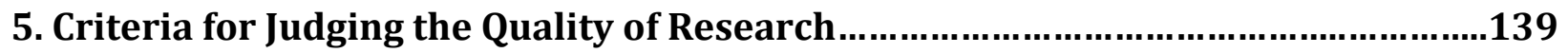

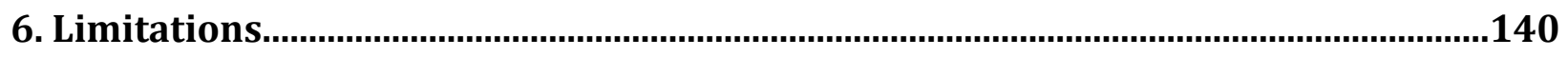

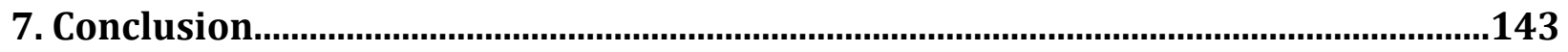

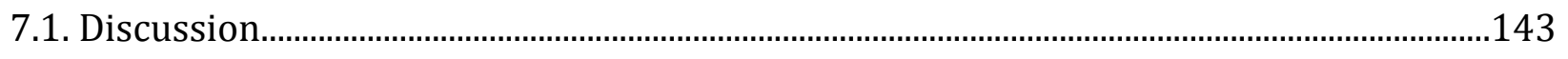

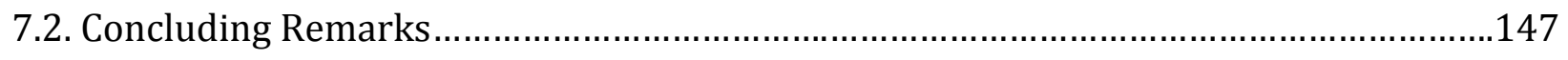

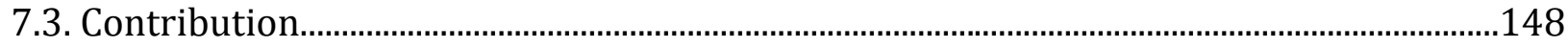

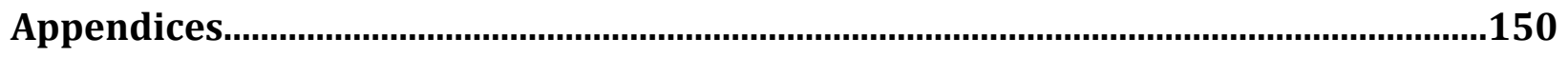

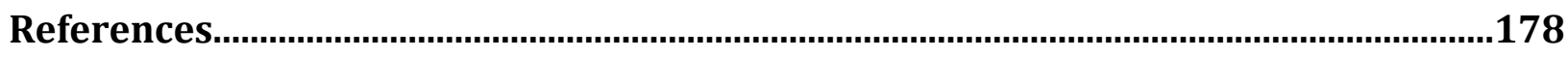




\section{List of Tables}

Table 1: Advantages and challenges of the collaborative approach....................................17

Table 2: Public participation techniques.......................................................................20

Table 3: Case study methodology as opposed to other research methods...........................39

Table 4: Advantages and disadvantages of three interview techniques.............................45

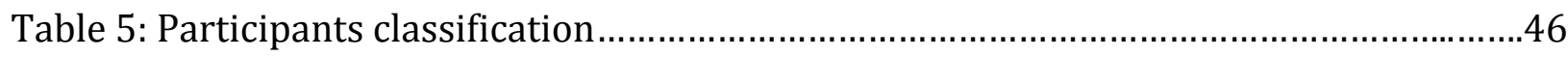

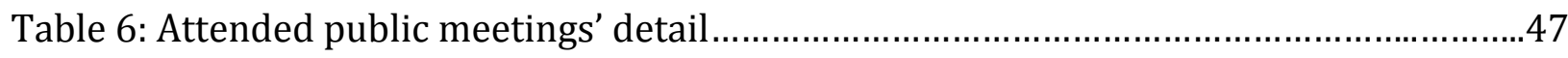

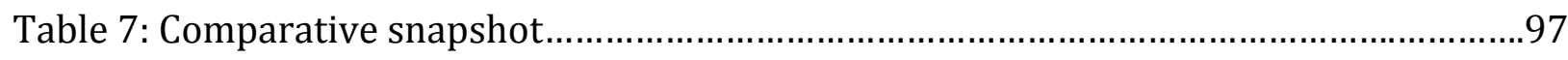

Table 8: Participants' comments on the notion of a knowledge-broker.............................109

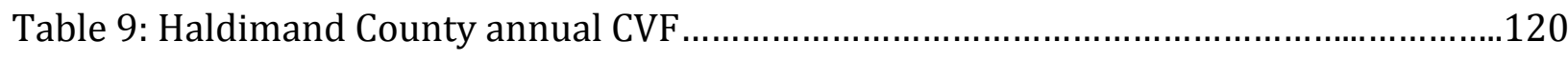

Table 10: Summary of results................................................................................ 130

Table 11: Test and tactics for establishing reliability and validity..........................................139 


\section{List of Figures}

Figure 1: Drivers for public participation in renewable energy projects................................

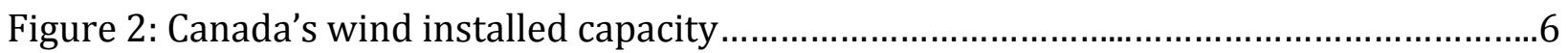

Figure 3: Major factors for success in wind energy project deployment...............................12

Figure 4: Different phase and steps of collaborative decision-making................................16

Figure 5: Criteria for effective public participation..........................................................21

Figure 6: The role of a knowledge-broker in connecting different stakeholders....................26

Figure 7: Ontario EA legislation and public participation...................................................28

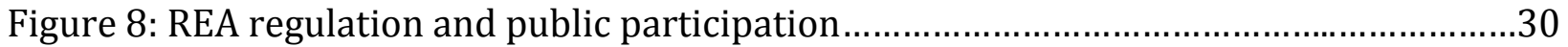

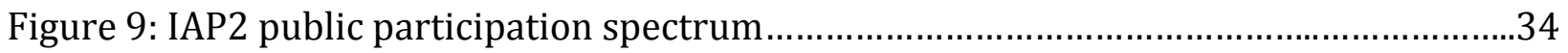

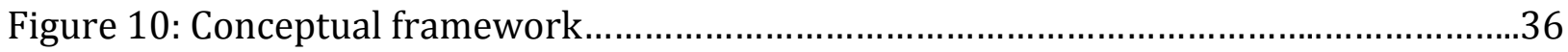

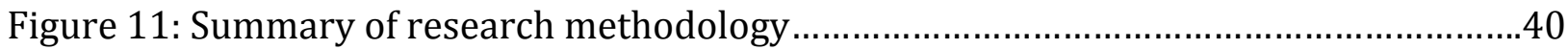

Figure 12: Embedded case design .............................................................................4

Figure 13: Location of Haldimand Projects and Ernestown Wind Park................................ 49

Figure 14: Haldimand Renewable Energy Projects map......................................................50

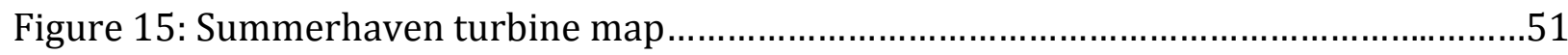

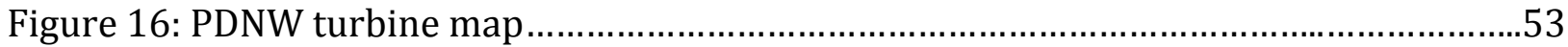

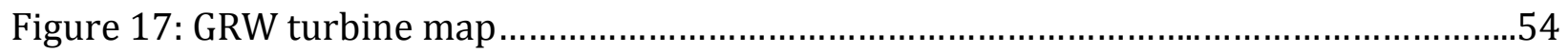

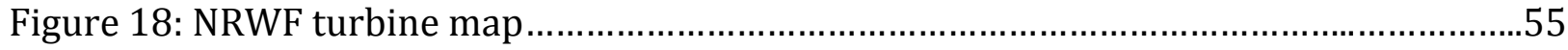

Figure 19: Ernestown Wind Park turbine map ..................................................................

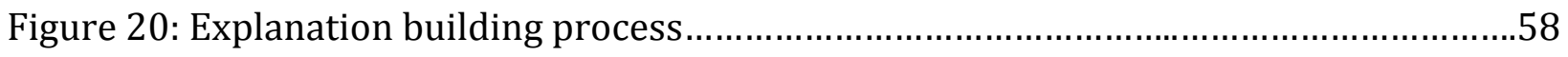

Figure 21: Stages of conducting the research and data analysis............................................60

Figure 22: A summary of interactions between local community and developers..............104

Figure 23: Updated conceptual framework...................................................................135 


\section{List of Appendices}

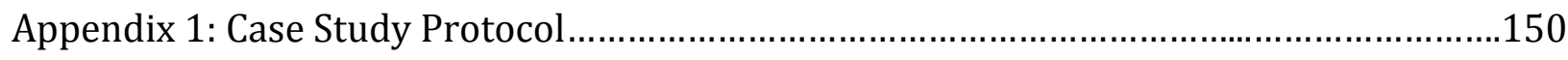

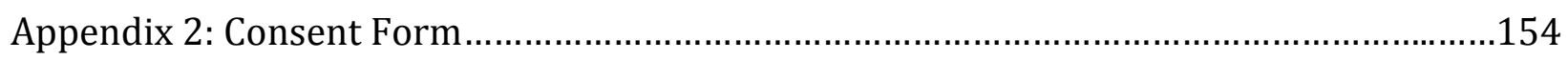

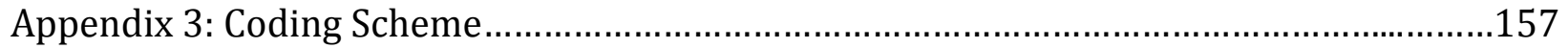

Appendix 4: Joyce Smith's Letter to the Ontario Energy Board..........................................160

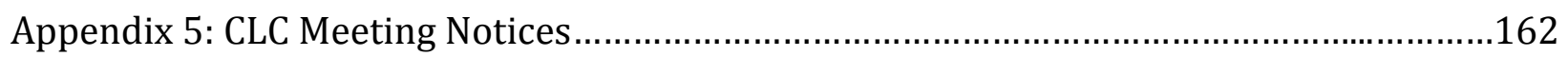

Appendix 6: Sample of Leaflets and Signs Distributed by the Opposition Groups...............164

Appendix 7: Email From the Spokesperson of an Opposition Group...................................165

Appendix 8: CanWEA Fact Sheets.......................................................................................166

Appendix 9: Letter of Melancthon Township Mayor to the Premier Of Ontario...................171 


\section{List of Abbreviation}

APPEC: Alliance to Protect Prince Edward County

CanWEA: Canadian Wind Energy Association

CBO: Community Base organization

CEA: Canadian (Federal) Environmental Assessment

CEAA: Canadian Environmental Assessment Act

CLC: Community Liaison Committee

CP: Collaborative Planning

CVF: Community Vibrancy Fund

EA: Environmental Assessment

ERT: Environmental Review Tribunal

FIT: Feed-In-Tariff

GEA: Green Energy and Green Economy Act

GHG: Greenhouse Gas

GRW: Grand Renewable Energy

IAP2: International Association for Public Participation

IESO: Independent Electricity System Operator

IPPR: Institute of Public Policy Research

kW: Kilowatts

LRP: Large Renewable Procurement

MOECC: Ministry of Environment and Climate Change

MW: Megawatts

NEPDA: Niagara Escarpment Planning and Development Act

NGO: Non-governmental Organization

NIMBY: Not In my Backyard

NRWC: Niagara Region Wind Corporation

NRWF: Niagara Region Wind Farm

OEB: Ontario Energy Board

OPA: Ontario Power Authority

PDNW: Port Dover Nanticoke Wind

PECFN: Prince Edward County Field Naturalists

REA: Renewable Energy Approval

RES: Environmental Screening Report

RES: Renewable Energy Supply

SLAPP: Strategic Lawsuit Against Public Participation

WCO: Wind Concerns Ontario 


\section{Introduction}

\subsection{Research Background}

The nature of governments' contribution to society has changed in response to the external pressures of globalization, international social movements, and managing their own domestic affairs. Delegation and decentralization of governments' role and responsibilities in providing services and the influence of a growing number of community-based organizations ( $\mathrm{CBO}$ ) have resulted in increased citizen participation in the regulatory decision-making process (Figure 1). In other words, there has been a shift in political approach from governing to governance. Over the past several decades, the scope of public decision-making has changed from a focus on state officials and experts' verdicts to comprehensively addressing stakeholders' demands and engaging citizens (Savan et al., 2004).

Consequently, there has been a distinct increase in public participation in environmental decision-making processes. This may be due to: public awareness and citizens' demands to have a greater role in decisions that affect their welfare; a recognition of the benefits (e.g. citizen's accountability and responsibility) of involving citizens in decision-making processes by public officials; compliance with new regulations, which have made it necessary to include public opinion, specifically in risk arenas; improvement of the quality of decision-making by avoiding unpopular policies; and the achievement of a key principle of a democratic society to acknowledge the basic human rights regarding procedural justice (Charnley and Engelbert, 2005; Rowe and Frewer, 2000; Wesselink et al., 2011). According to Bijlsma et al. (1988, pg. 397) "if decision-making concerning the use and development of 
science and technology is to be truly democratic, then the various actors must have equal opportunities to participate in the decision-making process."

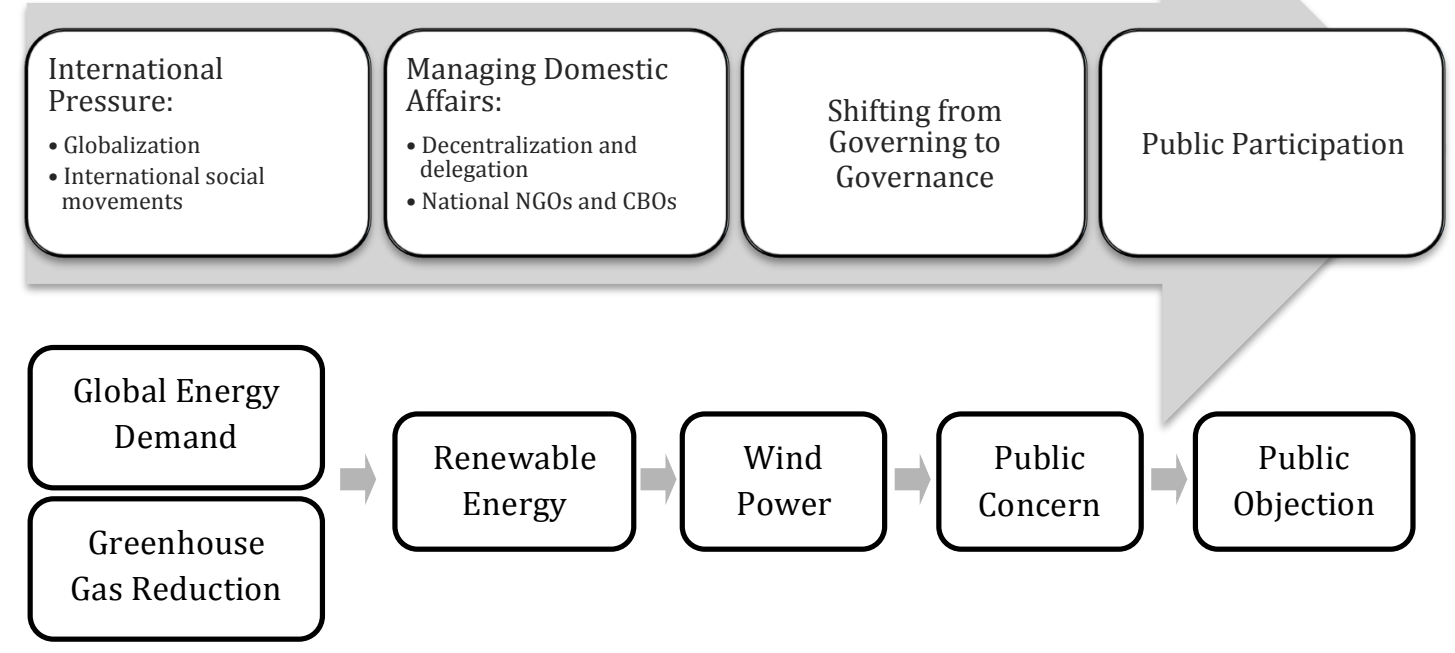

Figure 1: Drivers for public participation in renewable energy projects

While the potential benefits of public engagement are substantial, this participation does not come without its challenges. Some of these key challenges include: a lack of knowledge in the case of complex technical issues; a more time-consuming process; an incomplete understanding of issues by citizens, potentially resulting in a different interpretation of action consequences; a different perception of risk by citizens and experts; and finally, individual differences in values, beliefs, motivations, and conflicts of interest that may prevent reaching a consensus (Fischer, 2009; McCallum and Santos, 1997; Rowe and Frewer, 2000). These factors can limit the benefits of public participation in making complex policy decisions.

To meet global energy demands and fulfill ambitious targets for greenhouse gas reduction, renewable energy has received increased attention as a feasible alternative to 
conventional sources of energy (Corscadden et al., 2012; Haggett, 2011; McLaren Loring, 2007). Current literature on renewable energy, particularly on wind energy, highlights potential technological, economic, social, or public barriers to renewable energy investment (Richards et al., 2012). What distinguishes wind power from other renewable energy sources is its visibility in the landscape, which remains the key factor in public opposition (Coleby et al., 2009). In the case of developing a new wind energy project, public officials must balance the needs and views of the local public with the larger jurisdictional targets and interests. As McLaren Loring (2007, pg. 2648) states, "members of the local communities often object to proposed wind turbines on the grounds of visual intrusion, noise pollution or local environmental disturbance. In many cases, well-organized local opposition groups form."

Wright (2012, pg. 6) referenced Breukers and Wolsink (2007) in describing public participation as "a non-specific term that is open to interpretation, however in the context of wind energy, there is precedent to accept the following idealized definition: direct involvement by residents in plan making beyond that of formal consultation, i.e. facilitating citizens with an opportunity to influence the planning process".

For the purposes of this study, public participation will generally be understood as the contribution of groups or individuals (independent of project developers and governmental agencies) to the decision-making process. The public usually has an interest in the outcome of such a decision, because they may be affected by the outcome of that decision, either directly or indirectly (Wouters et al., 2011). Public participation encourages decisions that are in line with citizen preferences, resulting in increased levels of support from the public and less reluctance to the acceptance of the proposal (Irvin and 
Stansbury, 2004). However, incorporating the public's view into the decision-making process is not without cost.

\subsection{Purpose and Scope}

With that in mind, the two main objectives of this study are: (1) to identify facilitators and the constraints that affect public input into wind project development; and (2) to provide guidance to improve the practice of public consultation in a wind project development decision-making process. This study aims to answer the core question: "How does public participation affect the public decision-making process of developing a wind energy project?" To answer this core question, two sub-questions must be addressed: "What are the major social conflicts of wind power development?" and "What is the role of a knowledge-broker (trusted third party) in resolving these conflicts?"

In order to answer the core question, there is a need to investigate the role of local/provincial authorities in managing such participation in order to reach a consensus. The Ontario wind energy sector provides an appropriate context within which to explore the advantages and disadvantages of public participation and the influence of knowledgebroker. This is because the sector is: (1) in a process of growth in response to government initiatives, most notably through the Green Energy and Green Economy Act (GEA); and (2) it has active actors and networks of opponents. This research provides two case studies of the Ontario, Canada wind power generation market. The cases are built using qualitative methods of data collection primarily from documents, observation, and interviews. 


\subsection{Motivations for the Research}

Much of the existing literature focuses on the rationale, motivations, benefits, limitations, and challenges of public participation and how the public may be involved in the decisionmaking process in order to reach a consensus. Despite the established need for public engagement in wind energy project approvals, improving the practice of public consultation in a wind project development decision-making process requires a review of the literature that describes the various strategies that could be adopted for public participation. A conceptual framework for effective public participation can then be derived from the integration of these strategies. Most available literature on wind energy development discusses the economic and political barriers, while relatively little research has specifically focused on effective communication and the role of a trusted third party (whom for the purpose of the research will be referred to as a knowledge-broker) in the decision-making process. Therefore, there is still a need for further research on the role of knowledge-brokers in resolving social conflicts of wind project development.

This study contributes to academic knowledge by seeking to address these gaps through a participatory framework that highlights the role of a knowledge-broker in regulatory governance. To examine the role of public participation and the trusted third party in the wind energy industry, there is a need to conduct exploratory case studies. It is a sincere hope that this study will support developers' activities by providing a participatory framework for public participation that may help guide and encourage developers to undertake an effective and morally justified approval process for renewable energy projects. 


\section{Literature Review}

\subsection{Public Responses to Wind Power}

Wind power currently accounts for nine percent of Ontario's installed generation capacity; it is the fastest growing renewable energy source and will continue to play an increased role in supplying electricity $\left(\mathrm{IESO}_{\mathrm{a}}, 2015\right)$. Figure 2 demonstrates that Ontario is at the forefront of wind energy in Canada, with a wind power installed capacity exceeding 4,361 Megawatts (MW). There are currently more than 79 wind facilities in Ontario, with a number of additional wind projects being developed (CanWEA, 2015).

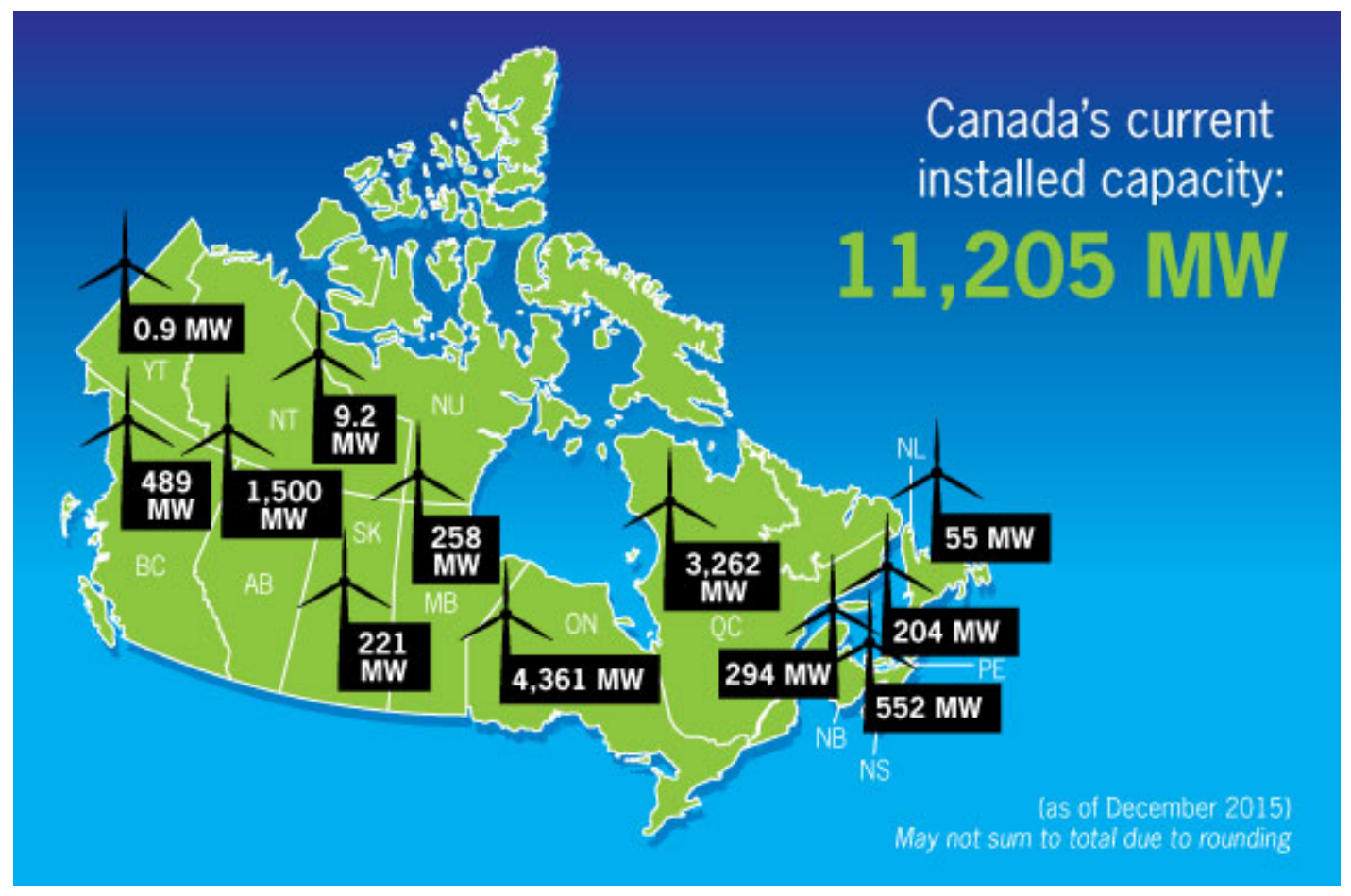

Figure 2: Canada's wind installed capacity (adapted from CanWEA)

Opinion polls have indicated that the majority support switching from conventional fossil fuels to wind energy development in Canada (Bell et al., 2005). However, the gap between plan and practice appears wide. While many people at the national level have 
expressed the desire to utilize wind energy, there has been conflict at the local level (Wright, 2012). Some scholars (Bell et al., 2005; Devine-Wright, 2005; Wolsink and Breukers, 2010) describe this social gap as NIMBYism (Not In My Backyard). The NIMBY perceptions of wind farms have been used as a means of describing the tension between the general support for wind energy and local opposition to specific developments. This opposition is attributed to the self-interest of local residents whose NIMBY sentiments are driven by their determination of the net costs and benefits (Wolsink, 2000). These negative attitudes often result from fears relating to the perceived impact on human health, the local environment, and individual property value (Coleby et al., 2009). However, the NIMBY explanation has been characterized as being overly simplistic and the empirical research on communities has been lacking in specifics related to the influence that social networks, social representations, and social identities have on a community's attitude to a wind farm (Devine-Wright, 2005).

\subsubsection{Factors Influencing Project Success}

Public objections raise questions regarding the factors that inhibit community acceptance of wind energy projects. In developing a wind energy project, stakeholders, who feel they have not been consulted or their perspectives have not been considered, usually form a strong opposition to renewable energy policy initiatives that can prevent them from being implemented. A proposed solution by many scholars is an environmental assessment (EA) during the development process, which considers the involvement of the community in addressing possible environmental impacts, not only to identify key local environmental knowledge, but also to reach mutual support between the project developers and the 
public. EA is a proactive planning tool that enables developers, authorities, and the public to identify, evaluate, and control the potential environmental damages from a proposed project before implementation (Fitzpatrick and Sinclair, 2003). However, this method can be expensive and time-consuming (Coleby et al., 2009; Gibson et al., 2005; O'Faircheallaigh, 2010; Webler and Tuler, 2006).

McLaren Loring (2007) compared wind energy planning using 18 case studies in England, Wales, and Denmark. McLaren Loring articulated several major factors that affect the success of developing wind projects with a higher level of public participation. These include: the involvement of a full range of potential stakeholders; minimizing the involvement barriers (e.g. time and location of the public meetings); collaborative decisionmaking by planners and local community members; financial ownership of the project; initiation of the project by a local group or individual instead of an outsider; the continued involvement of the local community even after construction; a strong relationship among actors within a network (this is applicable for both supporters and opponents); excellent communication within the network; charismatic critical actor; and positive media coverage, which could be directed by both supporters and opponents. Based on the data analysis results of these case studies, McLaren Loring (2007, pg. 2658) concluded, "projects with high levels of participatory planning are more likely to be publicly accepted and successful. In addition, stable supporting networks are more likely to form. Although the presence of a stable network of supporters is not related to project acceptance and success, the absence of a stable network of opponents is necessary for project acceptance and success in receiving planning permission." 
Another study, conducted by Corscadden et al. (2012), also put emphasis on the importance of high-level consultation and early communication with communities. Based on the results of a survey undertaken in Nova Scotia, which identified public perception related to community-scale wind energy projects, Corscadden et al. emphasized that such consultation provides a forum for increased social acceptance and reduced conflict.

It is important to note that both regulatory policies and regulatory governance are important factors in the success or failure of a wind project. Holburn et al. (2010) describe regulatory governance (the decision-making process) as a mechanism that constrains regulatory discretion and the resolution of resulting conflicts despite the introduction of regulatory incentives (policy instruments) such as renewable energy pricing and grid connection rights, which in Ontario include the Feed-In-Tariff (FIT) program, completive procurement auctions, and a termed Renewable Energy Supply (RES) program. Holburn et al. (2010, pg. 469) contend that, "in the case of Ontario, despite large market potential and comparatively strong regulatory incentive policies, weak regulatory governance is one factor that has accounted for the challenges in implementing large-scale private investment in power generation at a reasonable cost."

The lack of stakeholder or public consultation, the future instability of existing policies, and politicized policy-making processes - where an elected minister has greater control over regulatory policies rather than independent agencies - has resulted in relatively lesscredible regulatory governance in Ontario as compared with Germany and Texas, both of which have established stable regulatory frameworks arising from comprehensive legislation and specific commitments to renewable capacity targets (Holburn et al., 2010; Jacobsson and Lauber, 2006; Langniss and Wiser, 2003). 
Pasqualetti et al. (2002) also believe that the success of wind projects depends on how well the industry learns to consolidate public opinion in the decision-making process by addressing concerns and incorporating suggestions. This concept is in line with participatory planning theory, which argues that if people are informed early on of the project's development, they do not feel threatened, they are able to consider or predict benefiting from the project, and they are more likely to react positively to the project (McLaren Loring, 2007). This, in turn, could enhance the democratic legitimacy of the process and outcome (Wells, 2009).

Wells (2009) categorized factors of a community's acceptance of wind projects into three groups. The first factor is procedural justice, referring to public participation. In other words, public participation is the degree of public involvement in the developmental phase of the decision-making process, which is not only restricted to consultation, but, in some cases, should include a more direct engagement of citizens. The second factor is distributional justice, referring to the financial and economic concerns of the local community. The equitable distribution of cost and the benefits of a wind project play an important role in public acceptance. This obstacle can be tackled in two ways: compensation (e.g. tax credits) and local or shared ownership. The third factor is trust, a key factor in the decision-making processes. Consulting with the public in siting of wind turbines and receiving information from the local community through transparent communication are essential to a confidence-building process.

Wind project developers not only need to encourage public participation in the early stages of wind energy projects, but must also find ways to address the strong networks of opponents to these projects (Corscadden et al., 2012; Devine-Wright, 2005; McLaren 
Loring, 2007). According to Eltham et al. (2008), collaborative approaches with public involvement in decision-making are shown to be more effective in reducing the opposition to the project than top-down imposed ones. As wind turbines have a direct and visible impact on the people who live in the local area, local community participation becomes crucial to the public acceptance and development of the project.

Wouters et al. (2011) stipulate that the public should not only be listened to when making decisions that could affect their quality of life, but also the public participation process should reassure the public that their contribution will have an influence on the decision. The needs and interests of all participants should be addressed during the decision-making process and acquired information should be provided to participants through effective communication. The optimum results or a consensus arise from fulfilling these primary principles.

The benefits arising from public participation include: improved understanding of stakeholders' expectations; integration of lay and expert knowledge to reach higher-quality decisions; improved public understanding of the agency's responsibilities and barriers (social, financial, political, and legal); the creation of a transformative tool for social change; reducing conflicts; increasing the likelihood of implementation; greater compliance through increased ownership of a solution; providing the opportunity for communication between agencies that make decisions and the public; an early warning system for public concerns; building trust and improving agency credibility within the community; and educating community about complex technical issues. Finally, public participation can be used for distributing accurate information in a timely manner (Aitken, 2009; Aitken, 2010; 
Coenen, 2009; Irvin and Stansbury, 2004; Wouters et al., 2011). Figure 3 summarizes the major factors for success in wind energy project deployment.

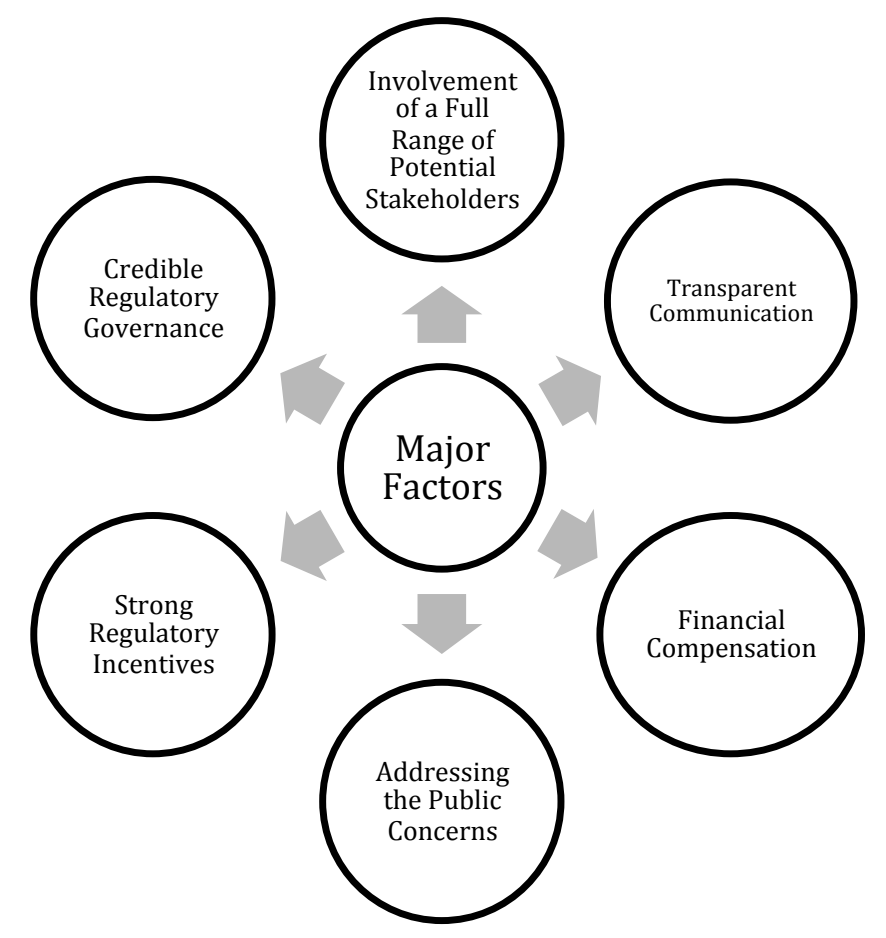

Figure 3: Major factors for success in wind energy project deployment

While the extant literature supports the role of increased public participation in improving the likelihood of public acceptance leading to wind energy project success, it is important to note that if public participation is not linked to the financial viability of the project or a contributor to project deployment success, it is unlikely to motivate developers to spend money on costly public participation activities (Wright, 2012). Furthermore, public acceptance of a wind energy project can be extremely challenging, if the primary principles of public participation are not met. 


\subsubsection{Challenges of Public Participation}

While there are numerous advantages associated with public participation in planning and decision-making processes, the literature notes that there are some challenges. Public participation is time consuming and a poorly-managed public participation process can result in the loss of creditability. Power imbalances among participants (e.g. those who can afford the time and resources to participate) can bias decisions. In some cases, important expert knowledge can be underemphasized or overlooked. For the developer, allocating resources to the public participation process may leave fewer resources for the project implementation phase and there can be a sense of a loss of decision-making control by officials. Public participation can lead to increased tension between the public and government and, in some situations, implementation of favorable decisions by authorities is not guaranteed (Coenen, 2009; Irvin and Stansbury, 2004; OECD, 2009; O'Faircheallaigh, 2010; Wouters et al., 2011).

Despite all of the drawbacks, citizens' participation in decision-making processes seems inevitable, as the role of government has been changing from governing to governance. For the purpose of this paper, governance in the environmental domain refers to the relationships between government and societal actors, which influence environmental decision-making processes. As collaborative relationships increase, there is a need for structural changes and framework modifications by governments to cope with new situations (Savan et al., 2004). 


\subsection{Collaborative Decision-Making}

A recent approach to public participation is collaborative planning (CP) or communicative planning. The collaborative behavior is strongly desirable as a way to manage and resolve conflicts and also for the achievement of integrative agreements (Fisher and Ury, 2011). Forester (1989) and Healey (1997) are pioneers in developing collaborative planning. Allmendinger and Tewdwr (2002, pg. 209) describe the difference between Healey and Forester's work as “Healey's collaborative planning is more concerned with the transformative influence on existing structure, while Forester's communicative planning focuses more on agency and mechanisms, and outcomes of interpersonal relations." Healey (1998) who coined the term "collaborative planning" defines it as a collective process for resolving conflicts and advancing shared visions involving a set of diverse stakeholders.

Collaborative planning seeks to involve the key (if not all) stakeholders in the decisionmaking process in order to achieve consensual policy outcomes and balanced solutions for the benefit of all. This is achieved through debate and under the conditions of effective communication. Collaborative planning is based on an interactive and interpretive process; therefore, interaction, communication, and negotiation among stakeholders are vital elements of CP (Healey, 1998). As highlighted by the literature, effective communication should meet four criteria: comprehensibility, sincerity, legitimacy, and truthfulness (Kumar and Paddison, 2000). Wolsink (2007) also places emphasis on the importance of communication in the wind energy context. He states that a principal problem to be dealt with during the decision-making process on developing wind facilities is communication. Communication misses its targets when it does not provide meaningful information to the 
public, does not address the real concerns of people, and does not provide them with timely feedback.

Since the public is one of the key stakeholders in any large-scale renewable energy project, public participation in a friendly and supportive environment becomes an essential factor in collaborative planning to ensure full consideration of the public interest. It is important to note that: (1) stakeholders are those who are affected by the planning or decision-making and that they share risks, costs, and benefits; (2) they have a right to participate; and (3) they can affect the decision-making process both negatively and positively. Other important components of collaborative planning are: integrating different forms of knowledge (e.g. local and expert knowledge); mutual and social learning; criticism with respect; and trust (Kumar and Paddison, 2000). The latter is so important because only trusting stakeholders can begin effective communication toward collaboration. The starting point is sharing meaningful information among stakeholders and getting feedback. Trust begins to grow by considering all stakeholders' comments and concerns when choosing alternatives, planning, and making a final decision.

As indicated in Figure 4, a collaborative approach is comprised of three main phases of negotiation, in which there are different steps (Day and Gunton, 2003). Negotiation is a powerful method for conflict resolution, which requires special skills and experience. It is most frequently deployed when important issues must be agreed upon and is necessary when one party requires the other party's agreement in order to achieve a mutually satisfactory resolution. The aim of negotiation is to create shared goals or positions leading in some cases to long-term relationships (Fisher and Ury, 2011). Negotiation sometimes 
involves a more or less neutral third party to extract the issues from manifesting emotions; thereby, keeping the parties focused on the resolution of those issues (Zartman, 1975).

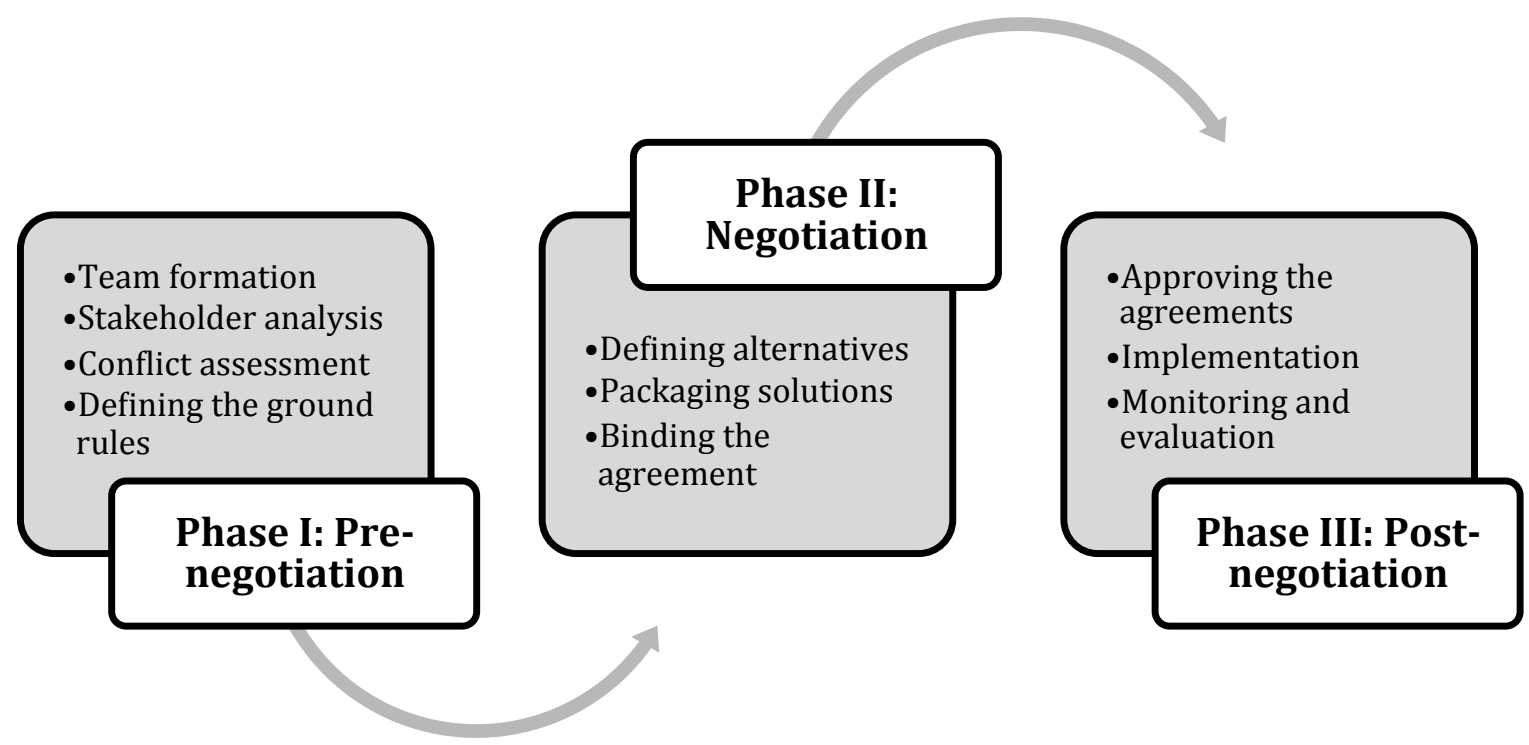

Figure 4: Different phase and steps of collaborative decision-making

Negotiating parties may represent themselves or clients (constituents). Consequently, the negotiation structure often has numerous sets of players, plus at times, an independent third party. Lewicki et al. (1992) explain that third parties usually do not have a strong partisan position on the issues in dispute; instead, they attempt to help parties reach a settlement. There are different types of third parties, for instance a mediator, arbitrator, conciliator, or consultant (Wall and Blum, 1991). Regardless of their classification, third parties have a common objective: to affect an agreement between the negotiating parties. There are many fragmented studies (largely by discipline) about third party's role and style (refer to section 2.4). However, there is still no universally accepted definition of a third party.

Many authors have identified the benefits of adopting a collaborative approach to resolve disputes and to reach a consensus. Table 1 indicates some advantages and 
challenges of the collaborative approach cited in the literature and summarized by Day and Gunton (2003) and Finnigan (2003):

Table 1: Advantages and challenges of the collaborative approach

\begin{tabular}{|c|c|}
\hline Advantages & Challenges \\
\hline $\begin{array}{l}\text { Reducing conflicts: collaborative planning is } \\
\text { more likely to reach a decision because } \\
\text { stakeholders are constructively incorporated } \\
\text { into a collaborative process to reach a } \\
\text { consensus, instead of remaining as critics } \\
\text { outside the process. }\end{array}$ & $\begin{array}{l}\text { Motivation and skills: all stakeholders (both } \\
\text { proponents and opponents) should be } \\
\text { motivated to participate. However, the } \\
\text { asymmetrical distribution of negotiating skills } \\
\text { and technical knowledge can result in } \\
\text { inequitable outcomes. }\end{array}$ \\
\hline $\begin{array}{l}\text { Creative solutions: integration of local and } \\
\text { expert knowledge may result in more creative } \\
\text { alternatives. }\end{array}$ & $\begin{array}{l}\text { Representativeness: stakeholder groups } \\
\text { willing and able to participate in collaborative } \\
\text { planning may represent a narrow spectrum of } \\
\text { special interests that exclude broader public } \\
\text { interests and can therefore result in biased } \\
\text { decisions. }\end{array}$ \\
\hline $\begin{array}{l}\text { Reaching efficient decisions: the broad and } \\
\text { diverse group of stakeholders improves the } \\
\text { quality of decisions by incorporating interests of } \\
\text { all parties in the final plan. Therefore, solutions } \\
\text { to problems are better supported for } \\
\text { implementation. }\end{array}$ & $\begin{array}{l}\text { Logistical challenges: organizing a process } \\
\text { around a large group of potentially resistant } \\
\text { stakeholders requires substantial resources } \\
\text { and time. }\end{array}$ \\
\hline $\begin{array}{l}\text { Creation of social capital: the development of } \\
\text { improved skills, knowledge, and stakeholder } \\
\text { relationships that benefit the community in } \\
\text { ways beyond preparation of the specific project. }\end{array}$ & $\begin{array}{l}\text { Compromise: stakeholders may agree on the } \\
\text { second-best solution in order to achieve } \\
\text { consensus. In some cases, even important } \\
\text { expert knowledge can be underemphasized or } \\
\text { overlooked. }\end{array}$ \\
\hline $\begin{array}{l}\text { Increased equity, building trust, improving } \\
\text { officials' credibility within the community, and } \\
\text { improved public understanding of the agency's } \\
\text { responsibilities and limitations are among } \\
\text { advantages. }\end{array}$ & $\begin{array}{l}\text { A collaborative approach may not be } \\
\text { appropriate in many situations that involve } \\
\text { fundamental value and belief differences. }\end{array}$ \\
\hline
\end{tabular}


The greatest barriers for the public are time commitments, financial resources required for effective participation, and the power imbalances that may exist. However, a collaborative approach can provide unique opportunities for stakeholders to present ideas within an equitable and respectful environment. Innes and Booher (2005) put an emphasis on the importance of information in a decision-making process. They believe the biggest issue in participation is the trustworthiness of information and who controls it. In collaborative participation, joint fact-finding is conducted in which the parties can question data and present their own. If this dialogue goes well, even when someone does not like the final result, they may accept the fairness of the decision if they can see the transparency of the process (Innes and Booher, 2005).

\subsection{The Participatory Techniques: From Information Provision to Collaboration}

While Ontario is the leading Canadian province in terms of installed wind facilities (Wells, 2009) and was the first to introduce a FIT for renewable generation in North America (Holburn et al., 2010), its wind power development has encountered considerable community opposition. In fact, despite market potential and strong regulatory incentive policies, weak regulatory governance that limits public participation to only consultation is considered the main reason for the challenges in the deployment of wind energy. Largescale projects have been cancelled or delayed and the future of wind energy is becoming uncertain. Cancelled projects in Ontario include Kingsbridge II in Goderich, Huron County, and Blue Highlands wind development in Blue Mountain. Each of these projects received excessive municipal approval delays because of appeals by individuals opposing the development (Wells, 2009), ultimately resulting in their cancellation. 
There is a growing consensus among scholars on the importance of public participation, with the underlying assumption that if citizens become actively involved in the decisionmaking process, the outcome will be more acceptable and democratic. The public may be involved in the decision-making process in different ways and levels. The lowest level might involve top-down communication and a one-way flow of information between regulators and the public, whereas the higher level is a two-way information exchange, which seeks some degree of public input and more direct involvement. This means that meaningful information should be provided to the public and their feedback incorporated into the decision-making process.

Rowe and Frewer (2000) highlight that more knowledge-based decisions require lower levels of involvement than value-based decisions. The most appropriate method depends on the specific circumstances of each particular case. There are a variety of methods (see Table 2) that might come under the public participation techniques, ranging from those that obtain input in the form of opinions (e.g. public opinion surveys and focus groups) to those that require judgments and decisions that actually affect decision-making process (e.g. consensus conferences and citizens' juries).

In determining whether a method will be effective, a variety of contextual and environmental factors interact with the characteristics of a technique to determine effectiveness. Hence, while one method may work in one situation, it may or may not work in another. In other words, one size does not fit all in this context. The main problem in the evaluation of participation methods is the absence of an effective benchmark and confusion as to what effectiveness really means. Rowe and Frewer (2004) clarify that given the variety of perspectives and interpretations of the participation concept, it is unlikely that 
all researchers would agree on a single universal definition of effective participation. Therefore, the suggested criteria depend on the authors' perspective. From a democratic perspective, an effective participation exercise might be fairness and a number of related criteria would be developed. From a pragmatic perspective, effective participation means reaching better decisions. An economic perspective is concerned with cost or resources.

Table 2: Public participation techniques

\begin{tabular}{|c|c|}
\hline Method & Description \\
\hline Referenda & $\begin{array}{l}\text { A vote is usually the choice of one of two options - all participants } \\
\text { have equal influence. }\end{array}$ \\
\hline Public hearing & $\begin{array}{l}\text { True participants are experts and politicians making presentations, } \\
\text { public may voice opinions, but have no direct impact on } \\
\text { recommendation. }\end{array}$ \\
\hline Public survey & $\begin{array}{l}\text { Sample of the interested and participating population segments, often } \\
\text { achieved through written questionnaire or telephone survey. }\end{array}$ \\
\hline Negotiated rule making & $\begin{array}{l}\text { Small number of representatives of stakeholder groups (may include } \\
\text { public representatives) are major participants. Consensus required } \\
\text { on specific question/regulation. }\end{array}$ \\
\hline Consensus conference & $\begin{array}{l}\text { Lay panel where an independent facilitator questions expert } \\
\text { witnesses chosen by a stakeholder panel; meetings are open to wider } \\
\text { public. Conclusions on key questions made via report or press } \\
\text { conference. }\end{array}$ \\
\hline Citizen jury/panel & $\begin{array}{l}\text { Generally, twelve to twenty members of the public selected by a } \\
\text { stakeholder panel to be roughly representative of the local } \\
\text { population. Similar to consensus conference, but meetings are not } \\
\text { generally open. }\end{array}$ \\
\hline $\begin{array}{l}\text { Citizen/public advisory } \\
\text { committee }\end{array}$ & $\begin{array}{l}\text { Small group selected by sponsor to represent views of various groups } \\
\text { or communities to examine some significant issue and interaction } \\
\text { with industry representatives. }\end{array}$ \\
\hline Focus groups & $\begin{array}{l}\text { Small group of five to twelve selected to be representative of public, } \\
\text { free discussion on general topic with video/tape recording and little } \\
\text { input/direction from facilitator to assess opinions/attitudes. }\end{array}$ \\
\hline
\end{tabular}

Since public participation requires substantial resources, authorities may only support public participation programs if it can be demonstrated through evaluation that they are 
useful for improving decisions or reducing conflicts. Evaluation is also a learning tool to determine how public participation programs can become more effective in the future. Furthermore, evaluation makes it possible to measure the gap between plan and practice. It shows how well government policies regarding public participation correspond to government practices for involving citizens in the decision-making process.

The first step in determining if the public participation process is successful is the development of a common set of evaluative criteria to assess the performance of the public participation processes. A number of authors have made specific suggestions about the criteria that need to be considered for effective public participation in decision-making processes. Figure 5 demonstrates some of these suggested criteria to predict and measure the effectiveness of public participation (Charnley and Engelbert, 2005; Irvin and Stansbury, 2004; OECD, 2009; Wolsink and Breukers, 2010; Wouters et al., 2011).

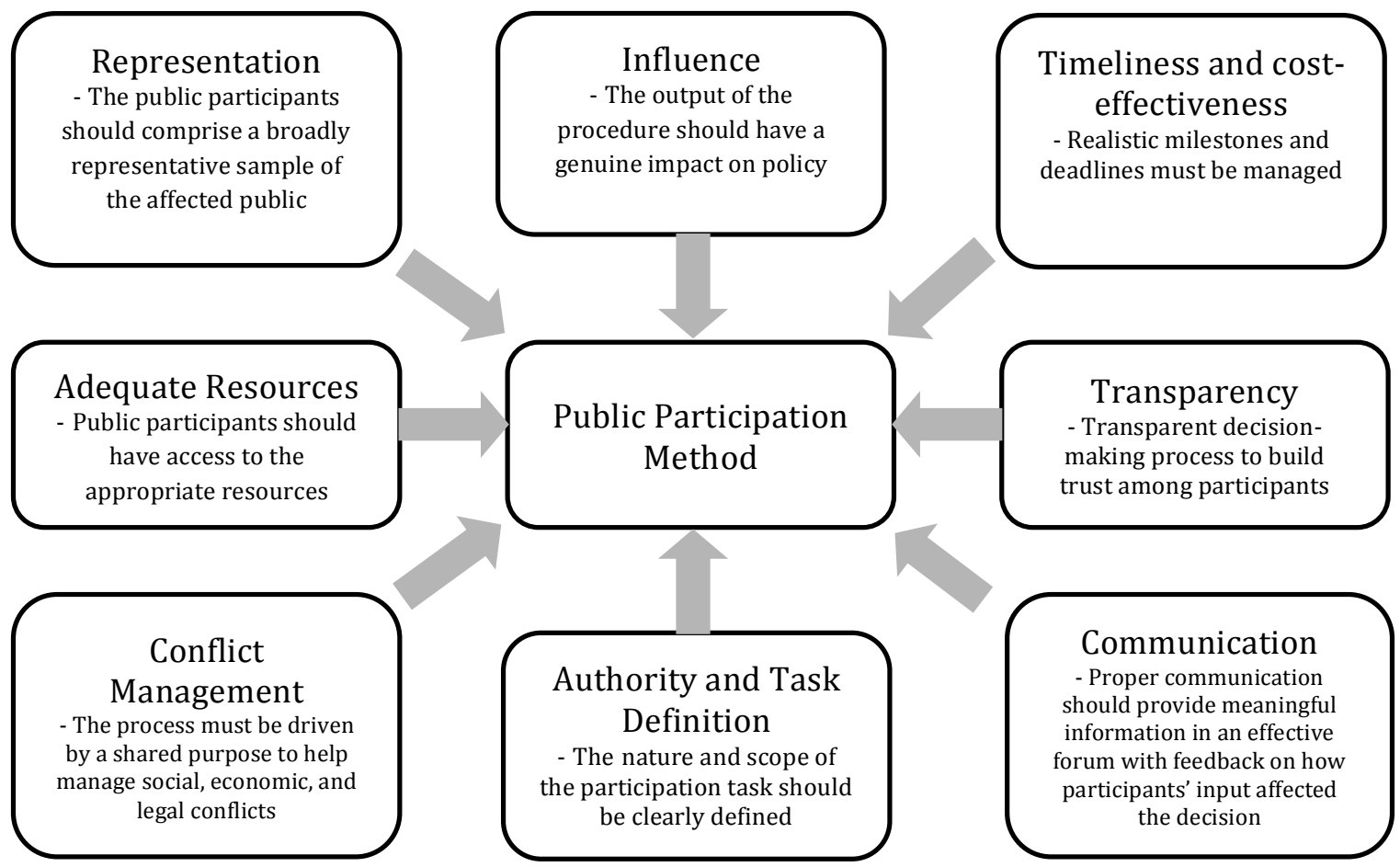

Figure 5: Criteria for effective public participation 
These criteria can assist officials in selecting and conducting the most effective public participation method. However, the decision-making process is not linear and a systematic evaluation is required to identify corrective actions leading to continual improvement of the existing process and the attainment of a benchmark pattern for future projects. This evaluation has to be done by independent, unbiased experts. Since different actors may have different objectives in participating, an evaluation has to consider the responsibility of the government or regulator to balance interests of the public as a whole.

Rowe and Frewer (2000) suggest that a potentially effective approach to participation might be the integration of different techniques to overcome the shortcoming of one and take advantage of the benefits of another. Therefore, there is a need for a quick evaluation to define the most appropriate techniques. It is essential to develop criteria to assess what effective participation actually is in order to help determine what should be expected from the authorities, public, and other participants.

\subsection{The Role of a Trusted Third Party in Collaborative Decision-Making}

As referenced earlier, there is growing agreement that there are advantages to authorities collaborating with the public from the start of a decision-making process. This collaboration may be reached through a trusted third party. His or her role would be to act as a bridge between the various stakeholders by conducting effective communication - the most important element of a collaborative approach. Many terms that describe this third party are often used interchangeably such as mediator, knowledge-broker, facilitator, boundary spanner, change agent, collaborative entrepreneur, intermediary, arbitrator, conciliator, consultant, and so on. Early studies focused on mediation, arbitration, and 
consultation, while more current studies have a more integrated and knowledge-based approach towards the understanding of the causes, factors, and dynamics of conflict itself and the role of a third party to resolve the conflict and reach a consensus.

Partidario and Sheate (2013, pg. 27) define knowledge brokerage as "a mechanism for transferring research evidence into policy and practice, and as a way of breaking down barriers that impede interaction, healthy communication and collaboration. Through knowledge sharing and exchange, mutual learning processes can be stimulated, increasing the potential to build capacity among stakeholders and improve outcomes." The knowledge brokerage concept was born in the health sector and rapidly expanded to the business world and environmental field where policy problems are increasingly associated with complexity, uncertainty, and public opposition.

Cooper (2010) describes that the exact role and function of the third party are conceptualized differently in different sectors and contexts; however, a common key feature is the facilitation of information exchange among various stakeholders. For the purpose of this research, this third party will be referred to as a knowledge-broker and defined as a skilled third party who attempts to facilitate creative problem solving through communication and analysis, aided by social-scientific knowledge of the conflict. In other words, a knowledge-broker is the catalyst for effective communication who nurtures the relationships among stakeholders by linking them and providing meaningful information. Information exchange can occur mutually with specific attention to opportunities that maximize the benefit of all stakeholders, which highly depends on the expertise of the knowledge-broker (Choi et al., 2005). 
Fullan (1999) found that psychologically, people are more likely to exhibit helpful behavior to those similar to themselves. In this way, ideas are more likely to be exchanged and modeled in an easier and effective manner. This highly depends on developing an equal partnership between the knowledge-broker - who has a credible and reliable reputation in the community - and the recipients. However, there is an inherent inequality in this relationship, since the knowledge-broker may have an elevated status due to her/his expertise (Rogers, 2003).

Bandura (1986) frames the importance of the role of a knowledge-broker in the knowledge transfer process. He believes that knowledge utilization begins when the knowledge-broker establishes a social relationship with the end-users and initiates knowledge use within a network of social influences.

Choi et al. (2005) argue that not only the public and policy-makers, but also scientists and politicians have different goals, languages, attitudes toward information, and perception of time. "Important issues affecting their working together include lack of mutual trust and respect, different views on the production and use of evidence, different accountabilities, and whether there should be a link between science and policy" (Choi et al., 2005, pg. 632). In the case of wind power development and with regards to health and ecological concerns, links between scientists and policy-makers appear vital in order to educate people about the health concerns of wind turbines. This may prevent delay or cancellation of negotiated projects, which can significantly impact the economics of a project and discourage investors. The suggested solution is to use a trusted and knowledgeable third party (as we call him/her in this study: knowledge-broker) to bridge the gap between policy and academic communities and simplify the information for both 
public and politicians. Therefore, as depicted in Figure 6, a knowledge-broker could act as an intermediary between three communities: the public, politicians, and scientists, in order to nurture the relationship amongst the three groups and serve as a catalyst for effective communication. Hence, it is crucial that the knowledge-broker be well informed and knowledgeable about the project and trusted by the community.

Another critical role of the knowledge-broker is to translate the demand for evidence (from the public) and retranslate information that comes from either politicians or scientists in a way that is understandable and transparent (Choi et al., 2005).

In his study, Nishimura (2012) analyzed a multi-stream collaborative model. This model is adjusted to help analyze the collaboration of actors from different sectors in solving environmental issues. He believes a knowledge-broker or collaborative entrepreneur is a critical catalyst in the formation of collaboration in that they provide information that is highly accurate and reliable, allowing quality decisions to be based on quality information.

According to Rogers (2003), in the knowledge transfer process, the success of the diffusion of proper ideas and technologies relies on the existence of change agents (knowledge-broker) to tackle the conflicts and influence the decision-making processes in a direction deemed desirable by all stakeholders in order to reach a consensus. Therefore, they function as linkage agents in moving knowledge, skills, or fact-based information from the producer of the knowledge to the users of that knowledge, and conveying feedback from the users to the producer. 


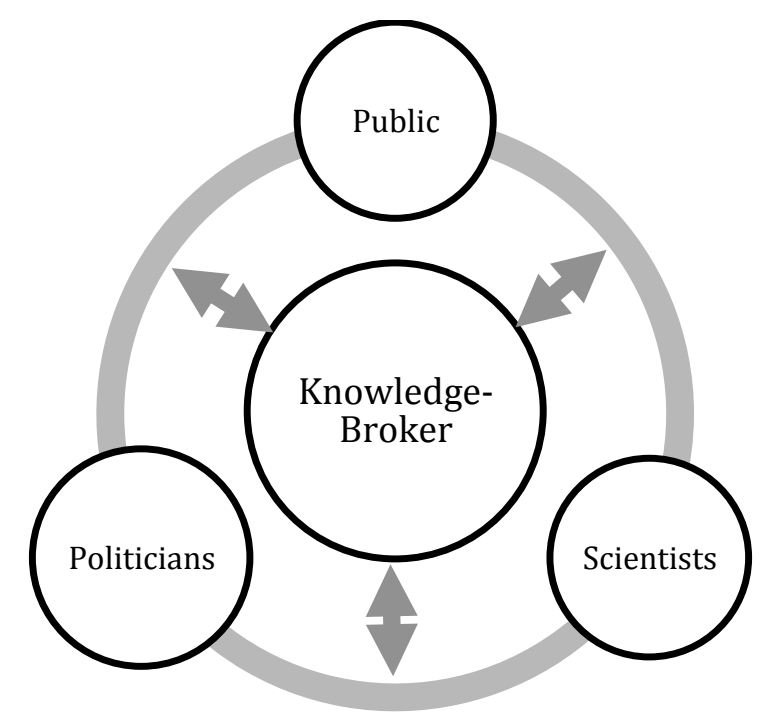

Figure 6: The role of a knowledge-broker in connecting different stakeholders

The factors that could affect the knowledge-broker success include, but are not limited to: having enough knowledge; understanding local needs; matching local needs with proposed solutions; raising awareness through the introduction of solutions; information sharing and transparency; strength of the interpersonal communication skills; effectiveness of communication skills; and creditability (Kramer, 2002; Nishimura, 2012).

\subsection{Current Regulatory Governance in Ontario}

In Ontario, all renewable energy projects are subject to one of the following approval streams: the Environmental Assessment process or the Renewable Energy Approval process (REFO, 2012).

\subsubsection{Environment Assessment}

Prior to the introduction of the Renewable Energy Approval (REA) process in 2009, wind projects over 2 megawatts (MW) and less than $200 \mathrm{MW}$ were required to complete an 
Environmental Screening Report (ESR) pursuant to the Electricity Projects Regulation (O. Reg. 116/01) associated with the Environmental Assessment Act. Following the completion of an ESR, municipal zoning approval was also required. In some cases, the Canadian Environmental Assessment Agency determines a federal EA (CEA) on a specific project is required. An environmental assessment under CEAA 2012 (Canadian Environmental Assessment Act, 2012) is required for each project designated by the Minister of the Environment and Climate Change and also projects described in the Regulations Designating Physical Activities (CEAA, 2015).

One of the purposes of the EA is to ensure that opportunities are provided for public participation. However, project proponents are mainly responsible for managing public involvement programs, yet have no clear guidance as to how manage them. There are no criteria or standards available for gauging the adequacy of public involvement programs (Sinclair and Diduck, 2001). Therefore, public engagement in the EA is typically restricted to providing public notification about proposed developments and the submission of written comments by the respondents. While this may seem a good starting point for public engagement, in practice it is not easy for the public to make substantive comment(s) about complex technical and scientific issues; this becomes more challenging when information on environmental assessment is not available in plain language. Even after submitting their comments - despite all challenges and difficulties - there is no guarantee that feedback will be provided to participants (Gibson et al., 2005).

The spectrum of participation ranges from providing information to the public to actual empowerment that places final decision-making in the hands of the public (see section 2.6). Figure 7 demonstrates that in Ontario, public participation in wind project development 
processes generally falls within the "inform" and "consult" areas of the spectrum. The statutory requirements of Ontario's EA legislation (Environmental Assessment Act, RSO 1990, Chapter E18: Consultation in Ontario's Environmental Assessment Process: Code of Practice) have led to initial decisions being made by developers, announced to the public, and then defended against public criticism. The defined role of the public in this "decideannounce-defend" model of decision-making is to provide criticism rather than support.

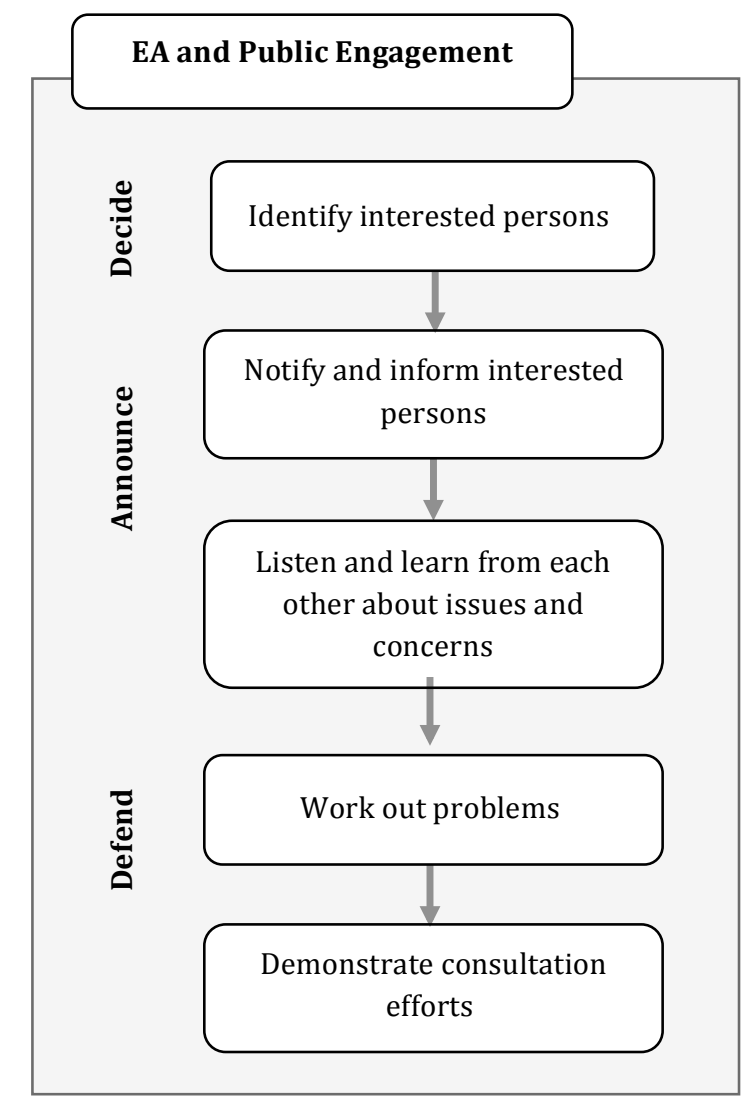

Figure 7: Ontario EA legislation and public participation

Many scholars point out that involvement typically happens in the late stages of project planning when different potential alternatives are already narrowed down prior to consulting with the public. One of the fundamental challenges of Ontario's EA is to achieve meaningful public participation leading to sustainable decision-making (Doelle and Sinclair, 2006). Sustainable decision-making generally involves a range of social, 
environmental, economic, political, and ethical factors, which need to be in balance with each other in order to reach a consensus and in turn, a sustainable society (Hersh, 1999). However, since the introduction of the Environmental Assessment Act, the EA has been a source of criticism and disappointment in this regard.

\subsubsection{Renewable Energy Approval}

As part of the Green Energy and Green Economy Act, the Ministry of Environment and Climate Change (MOECC) established a new Renewable Energy Approval (REA) process. The Renewable Energy Approval Regulation under the Environmental Protection Act (O. Reg. 359/09) came into force on September 24, 2009. The REA process has had an impact on the development of wind projects. Only turbines 3 kilowatts $(\mathrm{kW})$ or less are exempt from preparing a REA. Any facility over $50 \mathrm{~kW}$ with a sound power rating of $102 \mathrm{~dB}$ or greater is required to meet an absolute minimum setback of $550 \mathrm{~m}$ from the nearest receptor. Furthermore, the municipal zoning approval is no longer required leaving municipalities to be included in the general consultation process only.

The REA regulation is not an amendment to the Environmental Assessment Act. It enacts under the Environmental Protection Act. Therefore, all wind projects are removed from the existing federal-provincial environmental assessment coordination agreement. If a CEA is required, two separate and distinct documents must be submitted. To meet the obligations of the REA regulation regarding public engagement, developers only need to provide notifications and hold two public meetings (Figure 8). The purpose of the meetings is to provide the general public with information about their project and to gather feedback. 
Local communities can appeal the REA decisions through Ontario Environmental Review Tribunal (ERT). ERT is an administrative tribunal established by provincial legislation, which holds hearings and issues decisions, reports, or recommendations based on law, evidence, and a duty to protect the environment (ERT, 2015). The ERT resolves applications and appeals under the following statutes: Environmental Protection Act; Environmental Assessment Act; Clean Water Act; Environmental Bill of Rights; Consolidated Hearings Act; Niagara Escarpment Planning and Development Act (NEPDA); Nutrient Management Act; Ontario Water Resources Act; Pesticides Act; Safe Drinking Water Act; and the Toxics Reduction Act. The ERT also hears matters under the Oak Ridges Moraine Conservation Act and the Greenbelt Act (ERT, 2015).

\begin{tabular}{|c|c|c|c|c|c|c|}
\hline $\begin{array}{c}\text { Notice of } \\
\text { project or } \\
\text { notice of first } \\
\text { public meeting } \\
\text { Draft project } \\
\text { description } \\
\text { report made } \\
\text { available } \\
\text { Municipal } \\
\text { Consultation } \\
\text { Form to } \\
\text { Municipality }\end{array}$ & $\begin{array}{c}\text { First } \\
\text { public } \\
\text { meeting }\end{array}$ & $\begin{array}{c}\text { Draft } \\
\text { reports } \\
\text { made } \\
\text { available to } \\
\text { municipality }\end{array}$ & $\begin{array}{l}\text { Notice of } \\
\text { final public } \\
\text { meeting } \\
\text { Draft reports } \\
\text { made } \\
\text { available }\end{array}$ & $\begin{array}{l}\text { Final public } \\
\text { meeting } \\
\text { Developer } \\
\text { revises and } \\
\text { submits } \\
\text { REA } \\
\text { application }\end{array}$ & $\begin{array}{c}\text { REA } \\
\text { application } \\
\text { accepted } \\
\text { and posted } \\
\text { on the ERB } \\
\text { for } 30 \text { days }\end{array}$ & $\begin{array}{c}\begin{array}{c}\text { Notice of } \\
\text { application } \\
\text { published }\end{array} \\
\text { All reports } \\
\text { posted on } \\
\text { developer's } \\
\text { website } \\
\text { REA } \\
\text { Decision } \\
\text { Issued }\end{array}$ \\
\hline \multirow[t]{2}{*}{30 Days } & & & 60 Days & & 10 Days & \\
\hline & & \multicolumn{2}{|c|}{90 Days } & & \multicolumn{2}{|c|}{6 Months } \\
\hline Aboriginal Consulta & (continu & from an early & s in the project) & & & \\
\hline
\end{tabular}

Figure 8: REA regulation and public participation (adapted from REFO, 2012) 
As witnessed in Ontario, a regulatory framework that limits public participation to consultation as part of a legal obligation leads to public opposition, a lack of municipal support, subsequent delays, and the risk of cancellation of the wind energy project. With a more collaborative approach, where public participation occurs in the early stages of the project, developers can address the concerns of the network of opponents prior to finding themselves in a project with a tight deadline and limited progress. This latter approach is consistent with practices in many European countries, particularly Germany (as a leading jurisdiction in the use of wind and solar power in Europe), which has established a stable regulatory framework, based on strong environmental awareness, comprehensive legislation, and political commitments to renewable energy targets. A project cancellation emboldens the opposition network (regardless of the merits of their concerns), gives stakeholders a negative perception of the decision-making process, which limits their future participation and renders the process unsustainable.

As the degree of participation increases, the need and importance of a structural change by governmental agencies and public officials is more evident in order to construct a robust collaborative framework (Savan et al., 2004). This, in turn, results in a proper understanding of the issues affecting a community which can lead to reaching a consensus. Accordingly, this is more likely to achieve a positive interaction with a community, while the intensity of opposition decreases. 


\subsection{Public Participation Spectrum}

As highlighted by the literature, public participation is a continuum or a ladder with each rung representing a more active role for the public in governance decisions. After reviewing the different typologies of community engagement described in the literature, Arnstein's (1969) ladder of participation appears to be one of the most established and commonly used typologies relevant to examining participation and power in decisionmaking processes in environmental governance (Green and Kreuter, 1999). It distinguishes between the three levels: non-participation, tokenism, and citizen power. Non-participation is a substitute for genuine participation. In other words, the objective of this level is to enable power-holders to educate or cure participants rather than involving them in planning and decision-making processes. Tokenism refers to actions such as informing and consultation; this provides the opportunity for participants to hear and to be heard; however, there is no assurance of feedback and possible changes. Citizen power involves partnership, power delegation, and citizen control; at this level, citizens can negotiate with power-holders and have managerial power to make decisions.

The principal difference between collaborative planning and the other participatory methods is that $\mathrm{CP}$ is based on a higher level of collaboration and involvement of stakeholders through a two-way communication and face-to-face negotiations in order to reach a consensus agreement and resolve disputes (Day and Gunton, 2003). It seems that the collaborative planning fits well within the rungs of Arnstein's (1969) ladder of participation, because it allows for increased participation by citizens. Collaborative planning matches with the "citizen power" level of Arnstein's ladder (Allmendinger and Tewdwr, 2002). In collaborative planning, depending on the regulatory governance, the 
range of stakeholders who are involved and the power relations among them, different rungs of the participatory ladder might be reached - from partnership to citizen control.

Arnstein (1969) suggests that there is a significant difference between giving people the feeling of involvement (while little or nothing has actually changed) and real empowerment, with the former allowing those who hold the decision-making power to claim that all stakeholders were considered. Arnstein explains different levels of participation using a typology of eight levels of participation, arranged in a ladder pattern with each rung representing the level of citizens' power in the decision-making processes. The actual level of public involvement is related to how much social power or control the public has in the decision-making process. This control or power depends on three factors: bargaining power; financial recourses; and the ability to shape interests in a specific direction (i.e. using media). In order to empower individuals and communities to gain mastery over their affairs, there is a need to increase the community's capacity (e.g. selfesteem, supportive culture, and intellectual resources: knowledge and education) and the capacity of formal institutions (e.g. governmental agencies and corporations) to provide the mechanism for involving the public (Schutter and Riemer, 2009).

Based on Arnstein's ladder of participation, the International Association for Public Participation (IAP2) developed a public participation spectrum with different levels of public participation in the decision-making process (Figure 9). 


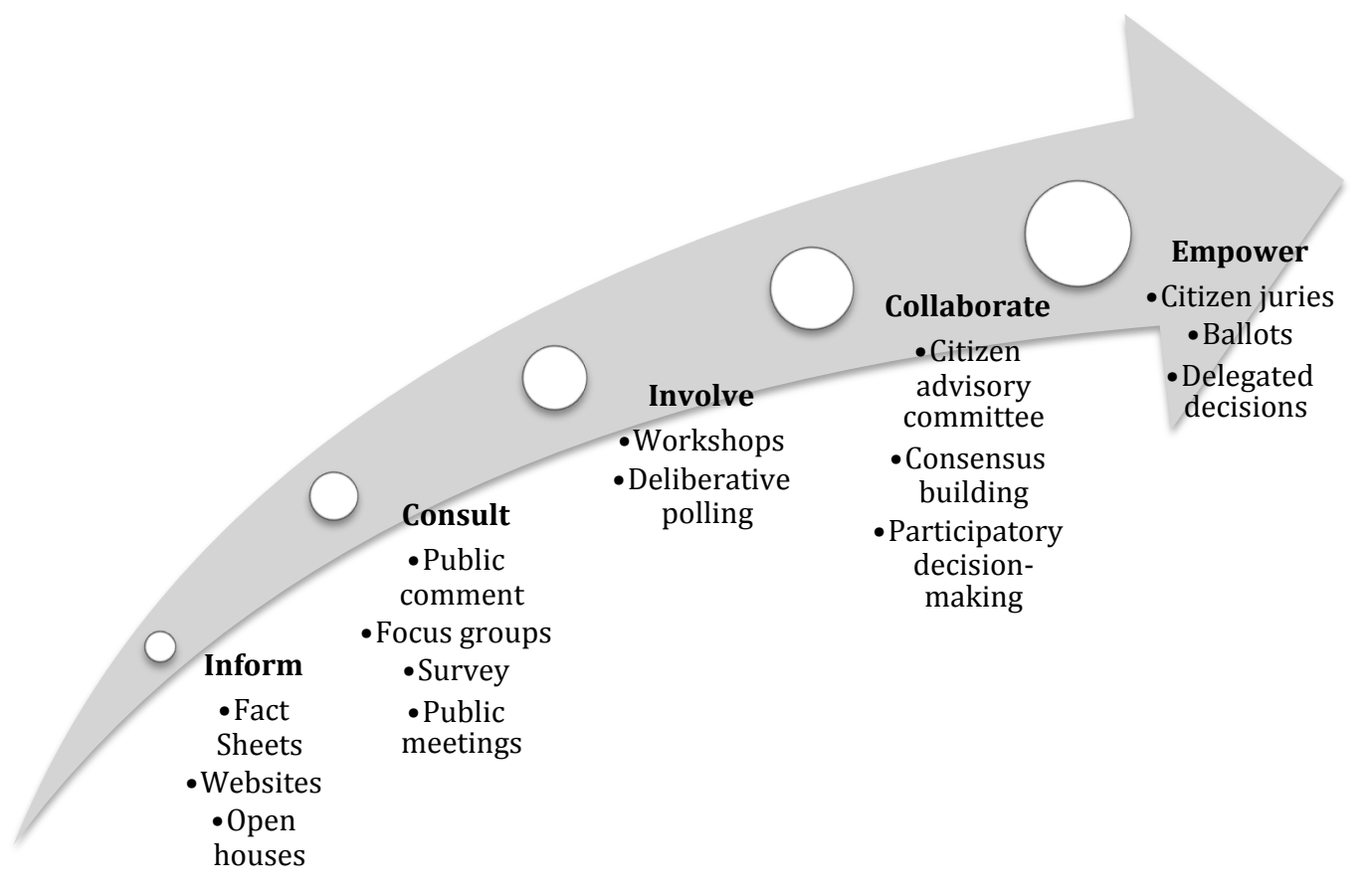

Figure 9: IAP2 public participation spectrum (after Arnstein, 1969)

The public participation spectrum begins with the simple provision of information to the public. The next two levels of "consult" and "involve" include formal consultation to consider public views with the final decision to be made by public officials. At the end of the spectrum, "collaborate" and "empower" require a higher level of co-operation, shared goals, and joint decision-making. At each level, public participation goals will be achieved by selecting one of the participation techniques described in Table 2 .

Under this model, almost all wind energy stakeholders accept that public participation is inevitable, but the debate remains about at what level of the participation spectrum the public should be included. For instance, in Canada, both the federal and provincial governments publicly acknowledge the importance of public input in the environmental management process; however, in practice a limited role for public stakeholders is provided. The only legally regulated mechanisms for public participation are the Environmental Assessment (EA) and Renewable Energy Approval (REA) process (Wright, 
2012). Both processes require public participation in limited circumstances and at the lower end of the participation spectrum (mostly "inform" and "consult") through public comment periods and public meetings (Wright, 2012).

\subsection{Recommended Conceptual Framework}

According to prominent authors in the case study field (Eisenhardt 1989; Stake, 1995; Yin 2009), the development of a conceptual framework is an essential step in research design. The goal is to provide a blueprint for the study to guide the research, facilitate data collection and data analysis, and help the analytic generalizability. The conceptual framework serves different purposes, for instance, to identify who will and will not be included in the study or to describe what relationships may be present based on logic, theory, and/or experience and to provide the researcher with the opportunity to define units of analysis (Baxter and Jack, 2008).

The first draft of the proposed conceptual framework (Figure 10) was organized around the procedural steps of wind project development in Ontario (Gipe and Murphy, 2005), the role of the third party or knowledge-broker, and the main components of the public participation spectrum (inspired by IAP2, 2004). It is important to emphasize that different levels of participation are possible. The spectrum of participation begins with providing information to the public and ends with public empowerment that places final decisionmaking in the hands of the public. Developing a conceptual framework for this research was an attempt to: (1) explore where on the spectrum public engagement in wind energy development in Ontario falls; (2) explore possible ways for stakeholders to climb the ladder of participation, from simply providing information to entering into a collaboration; 
and (3) explore the role of the knowledge-broker in climbing the ladder of participation. The framework continued to develop as the study progressed and the relationships between the proposed constructs emerged as data was analyzed. Section 4.4 provides detailed information on the modifications.

The role of the Knowledge-broker?

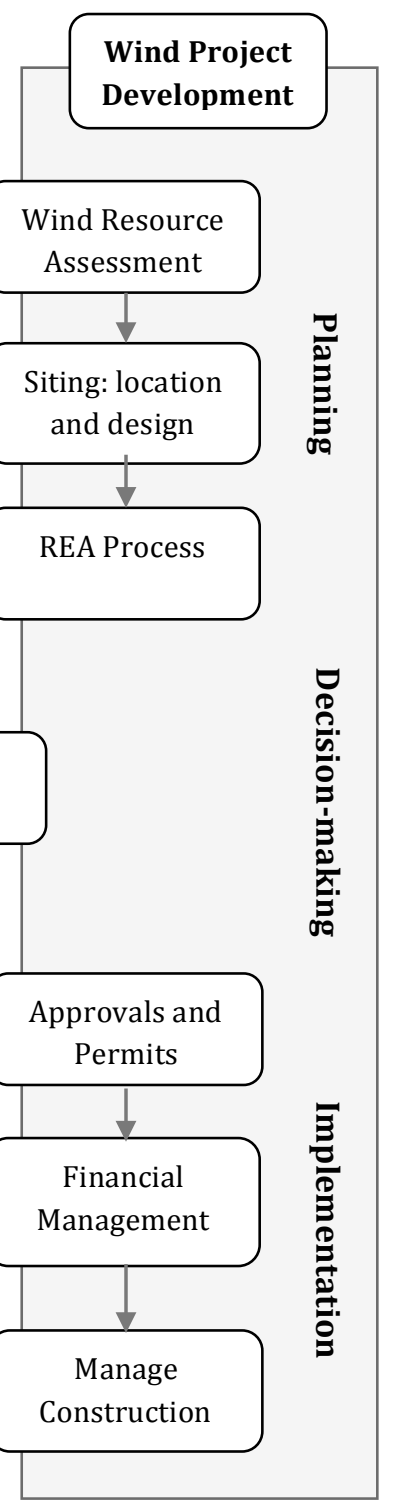

Figure 10: Conceptual framework 
In this framework, the public engagement process starts with carrying out a stakeholder's analysis aimed at the identification of the main actors in the decision-making process, followed by a social network analysis in order to understand the interactions between stakeholders. These two initial steps help explore the existing conflicts and identify a preliminary list of possible solutions (alternative options). In order to reach an agreement, there is a need to re-sort research material, assessment results, and information, so as to package it in a user-friendly manner. An effort is then made to communicate the package so that it is meaningful to all stakeholders. This could be the first step for forming a collaboration to make decisions with the presence of all stakeholders. Such an early involvement of the stakeholders may be considered as a preliminary fulfillment of the requirements of the wind project development in terms of public participation, to be followed by adequate actions to inform interested people about the entire decision process and its outcomes. Information supply and consultation must be ensured in the implementation process, but the decision makers may also decide to bring public participation to the level of active involvement and collaboration on each aspect of the decision including the development of alternatives and the identification of the preferred solution. How a knowledge-broker could help this process and climb the ladder of participation from its current status to a higher rung is discussed in Section 4.2. 


\section{Research Methodology}

\subsection{Research Approach}

Qualitative methodologies categorize, analyze, and evaluate information related to the quality, and/or character of the subject being studied. In other words, qualitative research tries to provide an understanding and explanation of human behavior and social interactions (Silverman, 1997).

A qualitative paradigm has been chosen for this study because it fits with most qualitative research assumptions including: the researcher is the primary instrument for data collection and analysis; this study is concerned primarily with a process rather than outcomes or products; and it is interested in meaning: how people make sense of their lives and the structure of their world (Silverman, 1997).

This study is exploring the nature of a particular contemporary social phenomenon (public participation) within its real-life context, the researcher is dealing with unstructured data, and a particular setting is being studied in detail within a case study scenario. Therefore, case study research methodology seemed the best match for this study. Table 3, summarizes the results of comparisons made by Hiscock (2012) on research criteria that benefit from case study methodology, as opposed to other research methods. As Patton (1987) explains, case studies are extremely useful in situations where in-depth information needs to be understood about a particular problem. As such, this method enabled me to develop an in-depth understanding of the complexities of developing a wind project in which multiple sources for problems existed, i.e. potential technological, economic, and social barriers. This is particularly important given that there have been few 
studies that explore the role of a knowledge-broker in resolving the aforementioned conflicts.

Table 3: Case study methodology as opposed to other research methods (Hiscock, 2012; Yin, 2009)

\begin{tabular}{|c|c|}
\hline Case study methodology & The other possible research methods \\
\hline $\begin{array}{c}\text { Explores a contemporary phenomenon that is } \\
\text { broad and complex }\end{array}$ & $\begin{array}{c}\text { Insights beyond what a survey, historical, or } \\
\text { archival study could provide are required }\end{array}$ \\
\hline $\begin{array}{c}\text { The existing body of knowledge is insufficient } \\
\text { to permit the posing of causal questions }\end{array}$ & $\begin{array}{c}\text { Experimentation is not possible as } \\
\text { relationships are not well enough understood }\end{array}$ \\
\hline A holistic, in-depth investigation is needed & $\begin{array}{c}\text { Some of the criteria of analysis will be } \\
\text { emergent, this could not be leveraged as easily } \\
\text { in survey data collection }\end{array}$ \\
\hline $\begin{array}{c}\text { A phenomenon cannot be studied outside the } \\
\text { context in which it occurs }\end{array}$ & $\begin{array}{c}\text { Experimentation is not possible, as behavioral } \\
\text { variables are outside of the control of the } \\
\text { researcher }\end{array}$ \\
\hline
\end{tabular}

The case was built using qualitative methods of data collection primarily from observation, documents, and interviews. Conducting interviews within this case is a powerful way to gain insight into wind project development barriers and other social issues through understanding the experience of the individuals whose experiences reflect those issues (Seidman, 2006). As King and Horrocks (2010) state, the interview research method is an essential tool for the collection of data in social research as it is all about the direct systematic conversation between an interviewer and the respondent. By this, the interviewer is able to obtain relevant information for a particular research problem both extensively and intensively, and exchange the data and experiences. The aim of this study is to capture aspects of the social world, but this is done in ways that do not rely on numbers as the unit of analysis. As King and Horrocks (2010, pg. 7) explain, "using the term qualitative interviewing situates the methodology and method deliberately within the qualitative domain where a broad and holistic approach is taken to the study of social phenomena". The focus of research was to uncover how people feel about the wind farm 
development and to make sense of their lives from their particular vantage points. Therefore, qualitative interviewing was undertaken. A summary of research methodology is indicated in Figure 11:

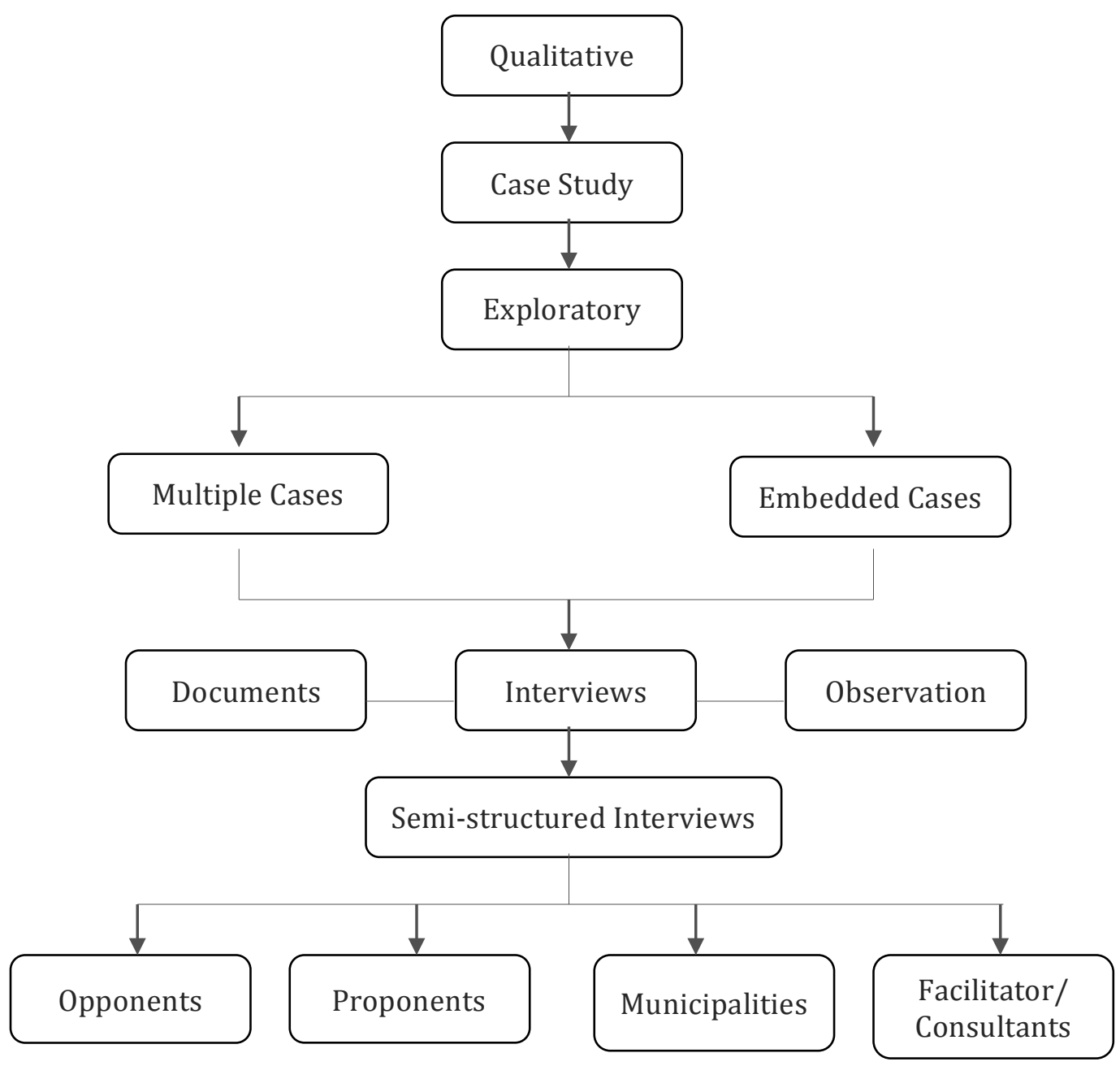

Figure 11: Summary of research methodology 


\subsection{Research Design}

As previously mentioned, by following the Yin (2009) selection criteria, case study research methodology was chosen for this study mainly because: (1) of the type of research question (the focus of the study is to answer "how" questions); (2) the investigator did not have control over actual behavioral events, in other words she/he cannot manipulate the behavior of those involved in the study; (3) the study is about a contemporary as opposed to historical event; (4) the research is an in-depth study of a social phenomenon in its real life context; (5) the boundaries are not clear between the phenomenon and its context; (6) there are few studies that explore the role of a third party in resolving stakeholders conflicts in wind projects and the case study method is a highly relevant approach for exploratory and context-dependent research.

The selection of a specific type of case study (exploratory, explanatory, or descriptive) was guided by the overall study purpose, which is exploratory. The exploratory case study is used "to explore those situations in which the intervention being evaluated has no clear, single set outcomes" (Yin, 2003, pg. 15). Gagnon (2010) highlights that the case method seeks to systematically infer meaning from the events they observe, but this does not necessarily mean they have initial ideas and conceptions about the research question. Therefore, an exploratory study deals with a subject that is clearly important, but has not been previously studied and there is not enough experience or information from the literature. Following Yin (2009) and Gagnon (2010), a multiple case study approach was selected: (1) to explore and understand the similarities and differences within and between cases; (2) to reach either direct (predict similar results) or theoretical replication (predict contrasting results but for predictable reasons); (3) to make it possible to draw conclusion 
from a set of cases; and (4) to provide a rich description of the context in which the events occur and to reveal the underlying structure of social behavior. Yin (2003) states that the evidence from multiple cases is often considered more compelling. Multiple case studies add to the richness of data and enhance the confidence in findings. In the face of analytic benefits and to avoid the vulnerability of single-case design (putting all the eggs in one basket), the goal in this research was to have at least two cases to study.

The nature of the problem and the attributes of the conceptual framework, which is inspired by the current literature on the subject, lend themselves to an embedded case design that allows for multiple units of analysis (Yin, 2009). The embedded design features a single context, which for this research is the Ontario wind energy sector. In addition to matching the framework perspectives - which is developed based on the literature and lessons learned from the current cases - the embedded case design also improves the sensitivity of the case study to emerging themes as the research is conducted. Following Yin's (2009) advice, selecting an embedded case study design helps focus the case study inquiry by using subunits of analysis and avoiding slippage in the nature of the study. Therefore, defining the units of analysis helps to design the research questions. Moreover, the subunits can often add significant opportunities for extensive analysis and enhance insight into the case. The basic units of analysis are shown in Figure 12. 


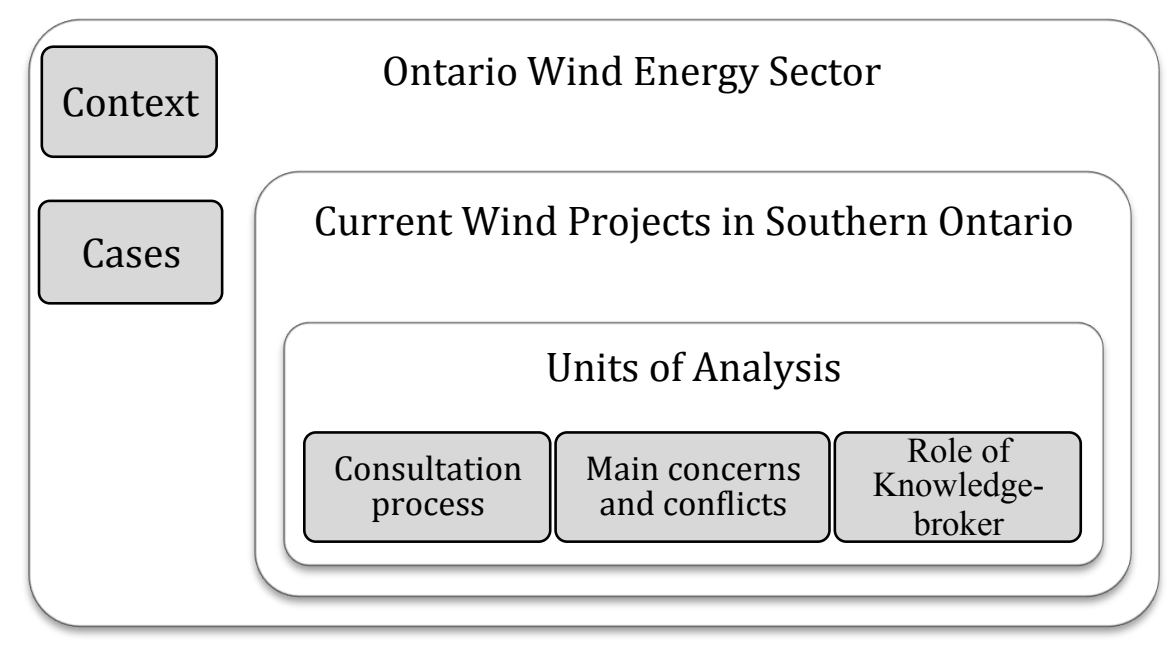

Figure 12: Embedded case design

\subsection{Data Collection}

The general process of constructing case studies begins by assembling the raw case data, constructing a case record of categorized information, then writing the final case study narrative (Patton, 2002). To maximize the contrast between opponents and proponents' perspectives, data was collected from each perspective in two separate stages. The collection started with the developers and public officials' perspective - at the municipality level - in order to gain a broad and comprehensive understanding of the environment that the opponent actors/groups exist within. That way the collection and analysis of data was more targeted along specific lines of enquiry related to the realities of wind project development, and to not spend as much time and effort on learning about the structure of the market environment. Therefore, interviews were directed at municipality officials (planning or renewable energy project managers), developers (wind project or public relation managers), involved third parties (consultant and facilitators), and opposition groups (chairman or spokesperson) or individuals. An interview with a knowledge-broker was not possible, as there is no such role defined in the decision-making process of wind 
power development in Ontario and no evidence found within the cases that one existed. The perspective of the public officials at a provincial level (Ministry of Environment and Climate Change) is incorporated into the study through analyzing available documents and approvals.

Unique characteristics of qualitative interviewing were tempting enough to be picked as a data collection technique. The interview techniques are both descriptive and exploratory tools. In its description function, information received from the respondent provided insight into the nature of social reality. At the same time, the interview was used as an exploration tool that provides insight into unexplored dimensions of the problem (King and Horrocks, 2010).

The definitions of the interview method given by scholars present the interview as a good fit and worthy technique for data collection. Cannell and Kahn (1968) defined an interview as "a two-person conversation, initiated by the interviewer for the specific purpose of obtaining research-relevant information and focused by him on the content specified by the research objectives of description and explanation" (cited by Cohen et al., 2000, pg. 269). Therefore, an interview is a controlled conversation where the interviewer obtains data required for the survey from the respondent by asking serious questions verbally. During the course of the interview, nonverbal messages are also present and need to be interpreted. Complex cognitive, affective, and social feelings are involved in interviews (Cohen et al., 2000). This helps to understand and categorize conflicts and concerns of different stakeholders.

In order to benefit from advantages of both structured interviews and unstructured interviews and to overcome shortcomings of these methods, a semi-structured interview 
was selected for this study. Table 4 demonstrates some advantages and disadvantages of each method based on Holstein and Gubrium's (2001) work. The collaborative framework provides specific lines of questioning which have been incorporated into the interview guide in case study protocol (Appendix 1).

Table 4: Advantages and disadvantages of three interview techniques

\begin{tabular}{|c|c|c|}
\hline $\begin{array}{c}\text { Type of } \\
\text { Interview }\end{array}$ & Advantages & Disadvantages \\
\hline \multirow{3}{*}{ Structured } & $\begin{array}{c}\text { Easy to quantify and analyze } \\
\text { results }\end{array}$ & \multirow[t]{2}{*}{ Cause and effect cannot be inferred } \\
\hline & Replicable & \\
\hline & Fast to complete & $\begin{array}{l}\text { Less valid due to distortion of restricted } \\
\text { answers and closed questions }\end{array}$ \\
\hline \multirow{3}{*}{ Unstructured } & $\begin{array}{l}\text { Provides highly detailed and valid } \\
\text { data }\end{array}$ & Not standardized, so cannot replicate \\
\hline & Extremely flexible & Problem with reliability and generalizing \\
\hline & $\begin{array}{l}\text { Natural and unrestricted, it can } \\
\text { reveal more about the participant }\end{array}$ & Difficult to quantify and analyze results \\
\hline \multirow{3}{*}{$\begin{array}{l}\text { Semi- } \\
\text { structured }\end{array}$} & Large amount of detail generated & \multirow{2}{*}{$\begin{array}{l}\text { Finding the balance between open-ended } \\
\text { and focused interviewing }\end{array}$} \\
\hline & Fairly reliable and easy to analyze & \\
\hline & Fairly flexible and sensitive & Interviewers need some skills \\
\hline
\end{tabular}

To reveal the common narratives, representatives of key stakeholder groups were interviewed. In total, 22 interviews (averaging 50 minutes each) were conducted of Ontario wind industry actors (Table 5). There were 5 interviews with municipalities, 7 interviews with the consultant/facilitators, 5 interviews with the proponents (developers, Canadian Wind Energy Association (CanWEA), and the former Minister of Energy and Infrastructure who presented the Green Energy and Green Economy Act in 2009, and 5 interviews with the opponents (Wind Concerns Ontario (WCO) and the local residents). In addition, 2 opponents emailed their thoughts on wind energy development making a total of 24 subjects who provided data for this study. Of the 22 interviews, notes were taken for one 
because the participant requested not to be recorded. Although the participants gave their personal opinion, they were fully aware of the fact that they were involved in interviews representing their category. Prior to the interviews, the researcher fulfilled all the requirements of the Ryerson Ethics Board for research involving human participants. This included the following: obtaining a signed consent form from participants that explained the purpose and benefits of the research; the voluntary nature of the participation; the right to withdraw or not to answer a specific question; and confidentiality (refer to Appendix 2 for a sample of the consent form). The Ryerson Ethics Board approval was received on December 5, 2013 and renewed on November 17, 2014.

Table 5: Participants classification

\begin{tabular}{|c|c|c|c|}
\hline \multicolumn{2}{|c|}{ Interviewee Category } & $\begin{array}{c}\text { Haldimand Renewable } \\
\text { Energy Project }\end{array}$ & $\begin{array}{c}\text { Ernestown Wind } \\
\text { Park }\end{array}$ \\
\hline \multirow{2}{*}{ Opponents } & Local Resident & $\begin{array}{c}3+2 \text { (responded via } \\
\text { email) }\end{array}$ & 1 \\
\hline & $\begin{array}{c}\text { Wind Concerns } \\
\text { Ontario }\end{array}$ & \multicolumn{2}{|c|}{1} \\
\hline \multirow{4}{*}{ Proponents } & Consultant/Facilitator & 6 & 1 \\
\hline & Developers & 2 & 1 \\
\hline & CanWEA & \multicolumn{2}{|c|}{1} \\
\hline & $\begin{array}{l}\text { Minister of Energy and } \\
\text { Infrastructure in } 2009\end{array}$ & \multicolumn{2}{|c|}{1} \\
\hline \multicolumn{2}{|r|}{ Municipality } & 4 & 1 \\
\hline & Total & \multicolumn{2}{|c|}{$\frac{1}{22+2}$} \\
\hline
\end{tabular}

Interviews were conducted from June 2014 to June 2015. The researcher drafted and sent an email to potential participants. After repeated correspondence (emails and phone calls) to 109 individuals, eventually 22 interviews were obtained. Unfortunately, the balance of potential participants did not respond or declined to contribute. Therefore, in some cases the researcher had to use the snowball sampling or respondent-driven 
sampling where existing participants recommend future participants from among their acquaintances (Salganik and Heckathorn, 2004).

Interviews used a semi-structured approach in which questions elicited descriptions and long answers rather than single words or sentences. Primary question order and follow-up questions were based on the respondent's original answers.

In order to cross-examine the findings of interviews and assess reliability, two public meetings for proposed projects were observed (Table 6).

Table 6: Attended public meetings' detail

\begin{tabular}{|c|c|c|c|}
\hline Project & Description & $\begin{array}{c}\text { Date and } \\
\text { Time }\end{array}$ & Location \\
\hline $\begin{array}{l}\text { Belle River } \\
\text { Wind Project } \\
(100 \mathrm{MW})\end{array}$ & $\begin{array}{l}\text { Located in the Town of Lakeshore, } \\
\text { Essex County, Ontario. Proposed by SP } \\
\text { Belle River Wind. Belle River Wind is } \\
\text { a joint venture limited partnership } \\
\text { owned by affiliates of Pattern } \\
\text { Renewable and Samsung Renewable } \\
\text { Energy, Inc. }\end{array}$ & $\begin{array}{l}\text { May } 20,2015 \\
\text { (5:00 p.m. to } \\
\text { 8:00 p.m.) }\end{array}$ & $\begin{array}{l}\text { Atlas Tube } \\
\text { Centre, Renaud } \\
\text { Room, } 447 \\
\text { Renaud Line } \\
\text { Road, Belle } \\
\text { River, ON N0R } \\
\text { 1A0 }\end{array}$ \\
\hline $\begin{array}{l}\text { Northpoint1 } \\
\text { Wind Energy } \\
\text { Centre (100 } \\
\text { MW) }\end{array}$ & $\begin{array}{l}\text { Located in the North Frontenac } \\
\text { Township, Ontario. Proposed by } \\
\text { NextEra Energy }\end{array}$ & $\begin{array}{l}\text { June } 6,2015 \\
(11: 00 \text { a.m. to } \\
2 \text { p.m.) }\end{array}$ & $\begin{array}{l}\text { Harlowe } \\
\text { Community Hall, } \\
1047 \text { Gull Lake } \\
\text { Road, Harlowe, } \\
\text { Ontario }\end{array}$ \\
\hline
\end{tabular}

\subsection{Case Selection}

\subsubsection{Selection Criteria}

Selection of cases is an important aspect of conducting case studies. Random selection is not a preferable approach, because the total number of cases which can usually be studied is limited. Flyvbjerg (2006) states that the strategic choice of a case would help the generalizability of case studies. The idea is not to form a statistically representative sample 
of population, but rather to find the most informative case to assist in the formation of an analytic or theoretical generalization. The latter depends on using a theoretical framework to establish a logic that might be applicable to the other situations (Yin, 2009). In analytic generalization, a previously developed theory is used as a template to compare with the results of the current case study to see if the data supports the developed theory. As previously mentioned, the first step involves developing a conceptual framework to show how the study findings have guided the relationship between the particular elements and concepts of the initial conceptual framework (Yin, 2009). Hence, the goal of theoretical sampling is to choose cases that are replicable or extend theory to a broader range (Eisenhardt, 1989). Following suggestions by leading authors in this field, the case selection was based on these criteria:

- Conduct screening procedure by consulting with knowledgeable people and/or collecting relevant data from archival sources (Yin, 2003)

- Pragmatic considerations, i.e. feasibility, accessibility, and available data (Seawright and Gerring, 2008; Yin, 2009)

- Sample variation or the presence of several mini-cases within a case (Eisenhardt, 1989; Flyvbjerg 2006; George and McKeown, 1985)

- Deliberate theoretical sampling plan, i.e. choosing polar types relevant to research questions (Eisenhardt, 1989; Seawright and Gerring, 2008)

- Potential to collaborate with the stakeholders (Yin, 2009)

Therefore, this study focused on the developers who are experienced in public participation and have developed projects in Ontario. To fulfill the requirements of deliberate theoretical sampling, polar types of cases were chosen. One is a large wind 
project in southern Ontario with the presence of four national and international companies which have wind projects all over southern Ontario; the other, is a small-scale project by a privately-owned company with only two projects in Ontario. The selected cases Haldimand Renewable Energy Project and Ernestown Wind Park (Figure 13) - are recently completed wind projects - with the exception of one project within the former case (for more information see section 3.4.2). These projects serve as a supporting tool for multiple sources of evidence and help establish a chain of evidence. Availability of information through interviews or reports and documents was a crucial criterion for the case selection.

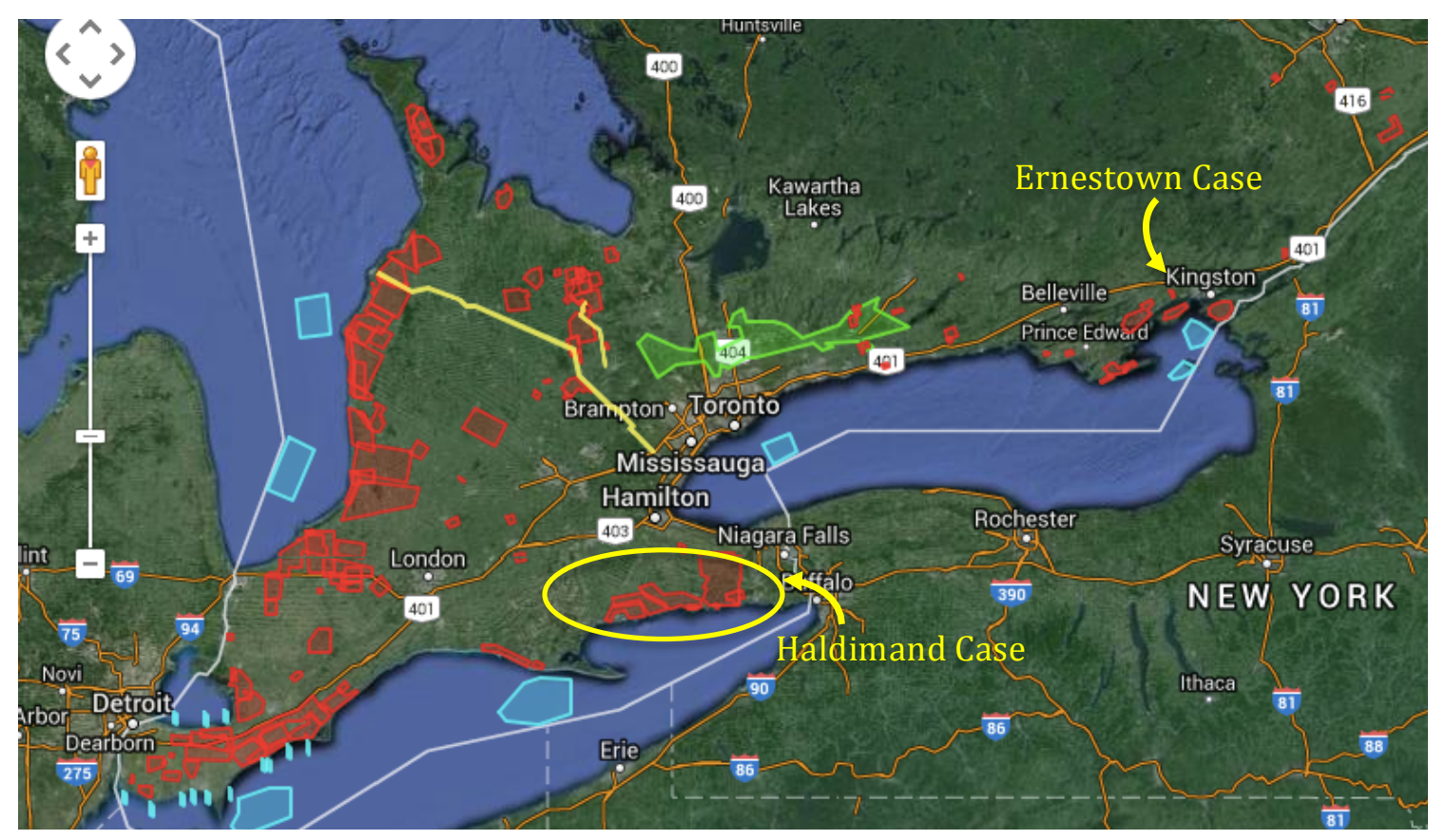

Figure 13: Location of Haldimand Renewable Energy Projects and Ernestown Wind Park (adapted from Ontario Wind Turbines website)

\subsubsection{Case Descriptions}

This section provides background information and project overviews regarding selected cases. Two cases were chosen in two distinct geographical areas. The first case, Haldimand Renewable Energy, comprises four projects, whereas the second case, Ernestown Wind 
Park, is a solo project. Since the public participation process pertains to the five projects indicated in this research, the results are influenced by all of them.

\section{Case \#1: Haldimand Renewable Energy Projects}

Under the Green Energy Act, Samsung, NextEra, Capital Power, and Niagara Region Wind Corporation (NRWC) have located four commercial wind generating projects and one solar energy generating project in Haldimand County with a combined capacity of 553 MW and estimated investment cost of approximately $\$ 1.4$ billion, which makes Haldimand County one of the most active municipalities in Ontario for developing renewable energy. Haldimand County is a small rural community located in southern Ontario on the shore of Lake Erie. More detailed information is provided in Figure 14.

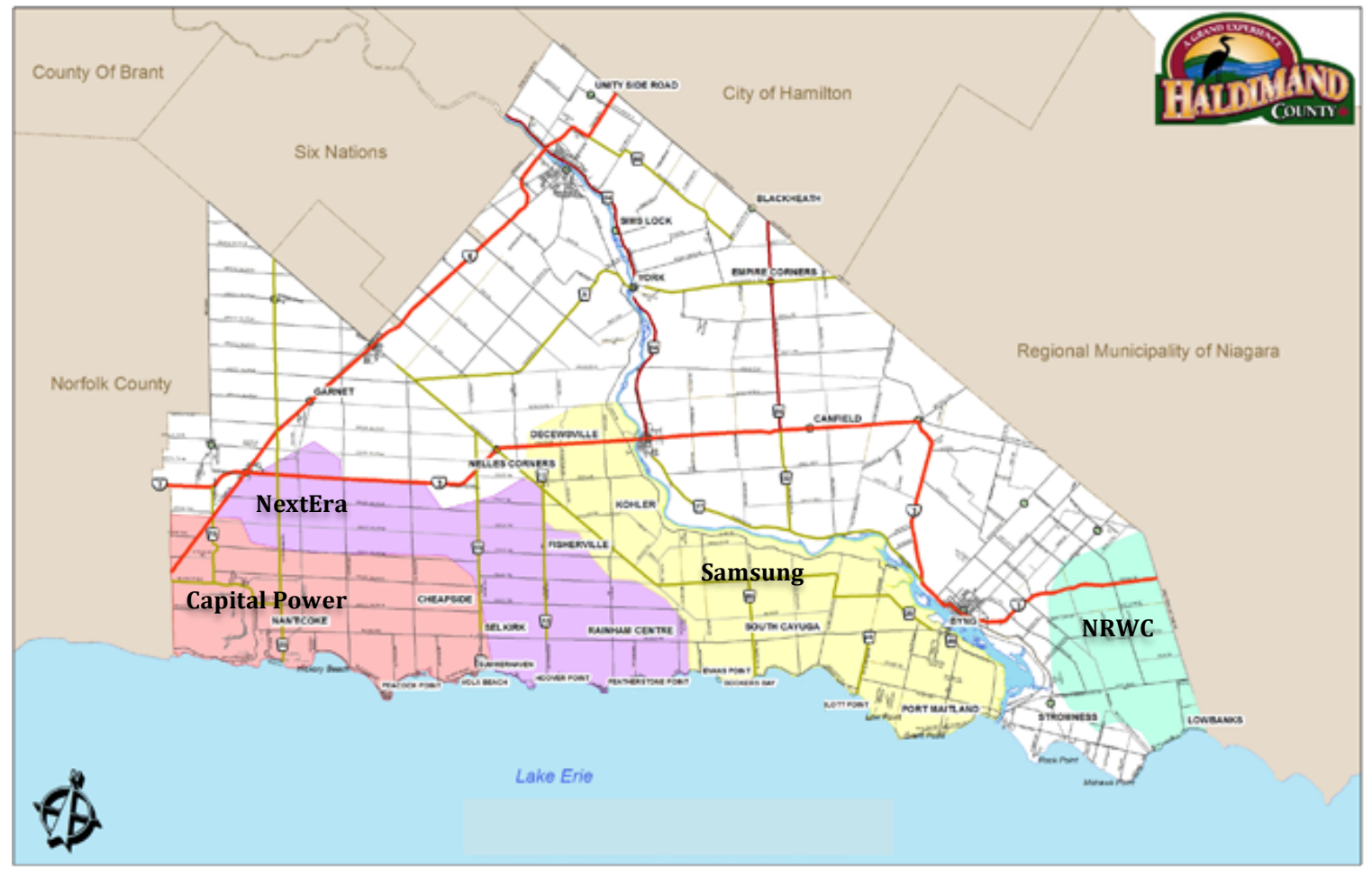

Figure 14: Haldimand Renewable Energy Projects map (adapted from Haldimand County Website) 


\section{Summerhaven Project - 2006-2013 (Intended start-up: 2011)}

The Summerhaven Project was developed by NextEra Energy, one of North America's largest renewable energy generators with more than 100 wind facilities in Canada and the United States based in Juno Beach, Florida. The project received a REA in March 2012. Subsequently, notices of appeal were filed by William Monture and Haldimand Wind Concerns in March 2012 in accordance with the Environmental Bill of Rights Act. In September 2012, the Environmental Review Tribunal accepted the withdrawal of Haldimand Wind Concerns appeal on consent of the parties on a without-cost basis. The Tribunal also dismissed the appeal of Mr. Monture because the appellant had not shown the project would cause serious harm to human health or serious or irreversible harm to plant life, animal life, or the natural environment. This wind energy project has a maximum generating capacity of 124.4 MW (59 turbines as shown in Figure 15).

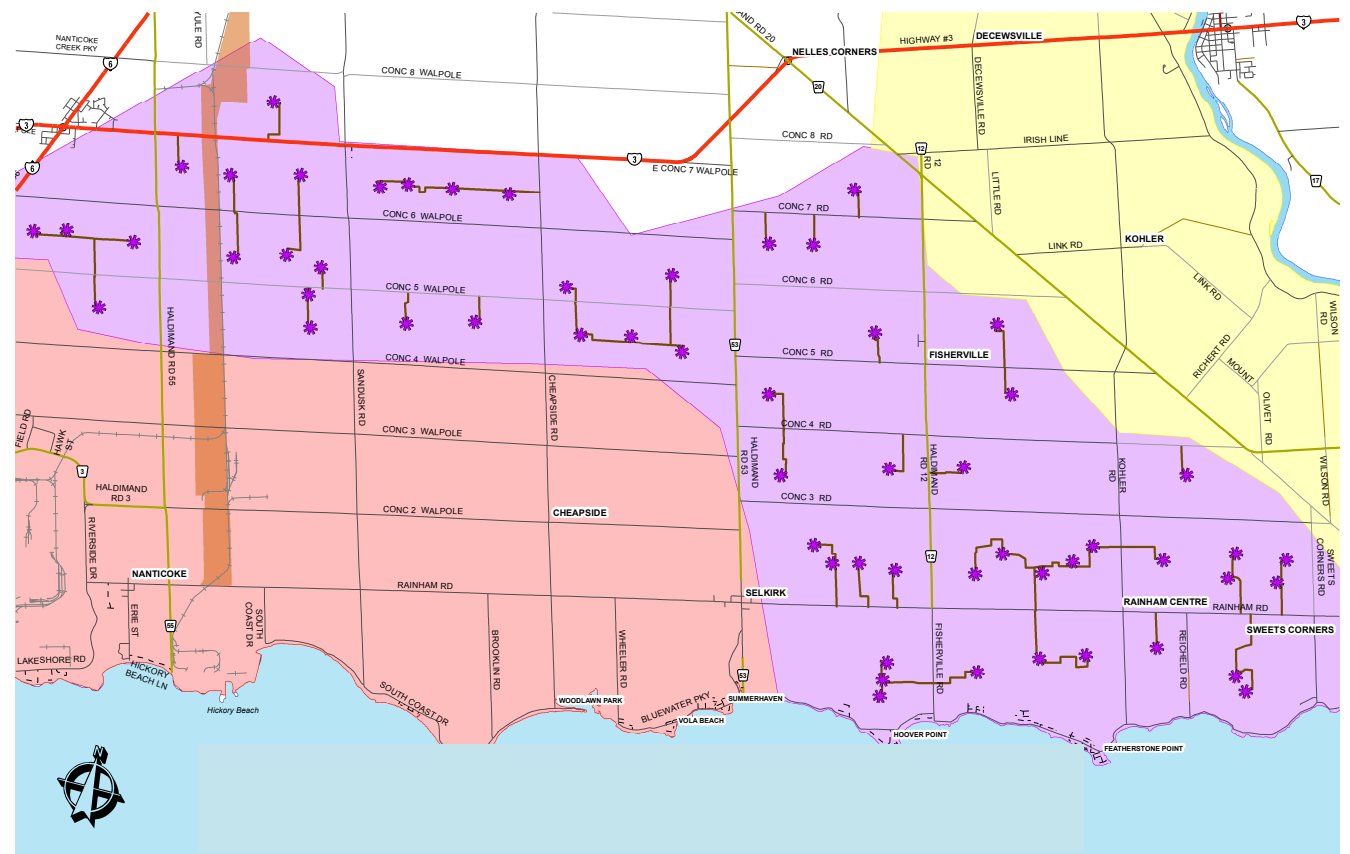

Figure 15: Summerhaven turbine map (adapted from Haldimand County Website) 
The wind farm is located in Haldimand County, Ontario. Three public meetings were held in December 2009, December 2010, and January 2011 (additional). There were also four community liaison committees (CLC) meetings from August 2012 to December 2013.

\section{Port Dover Nanticoke Wind Project (PDNW) - 2009-2013 (Intended start-up: 2012)}

The PDNW project is owned by Capital Power, an independent power producer based in Edmonton, Alberta that owns five wind facilities in Canada (three in Ontario). The project received a REA in July 2012. Capital Power's 105 MW PDNW project is located in the Counties of Haldimand and Norfolk, Ontario. The project features 58 turbines, 45 of which are located in Haldimand County (Figure 16). Three public meetings were held in both Haldimand (December 2009, June 2010 and January 2011) and Norfolk (December 2011, June 2010 and February 2011) municipalities. There were also four CLC meetings held from November 2012 to May 2014. In January 2013, the Environmental Review Tribunal dismissed the appeals filed by Haldimand Wind Concerns (filed in July 2012) and Peter Slaman (filed in August 2012), because the evidence before the Tribunal was determined to be inconclusive and contradictory, not sufficient to support a finding that the turbines caused serious and irreversible harm to plant life, animal life, or the natural environment. However, the Tribunal made some recommendations, for instance, that studies should be conducted by the appropriate agencies to monitor (pre-construction and post-construction monitoring), over time, the impact of wind turbine projects on the migratory staging and foraging habitats for tundra swans along the northern shoreline of Lake Erie. 


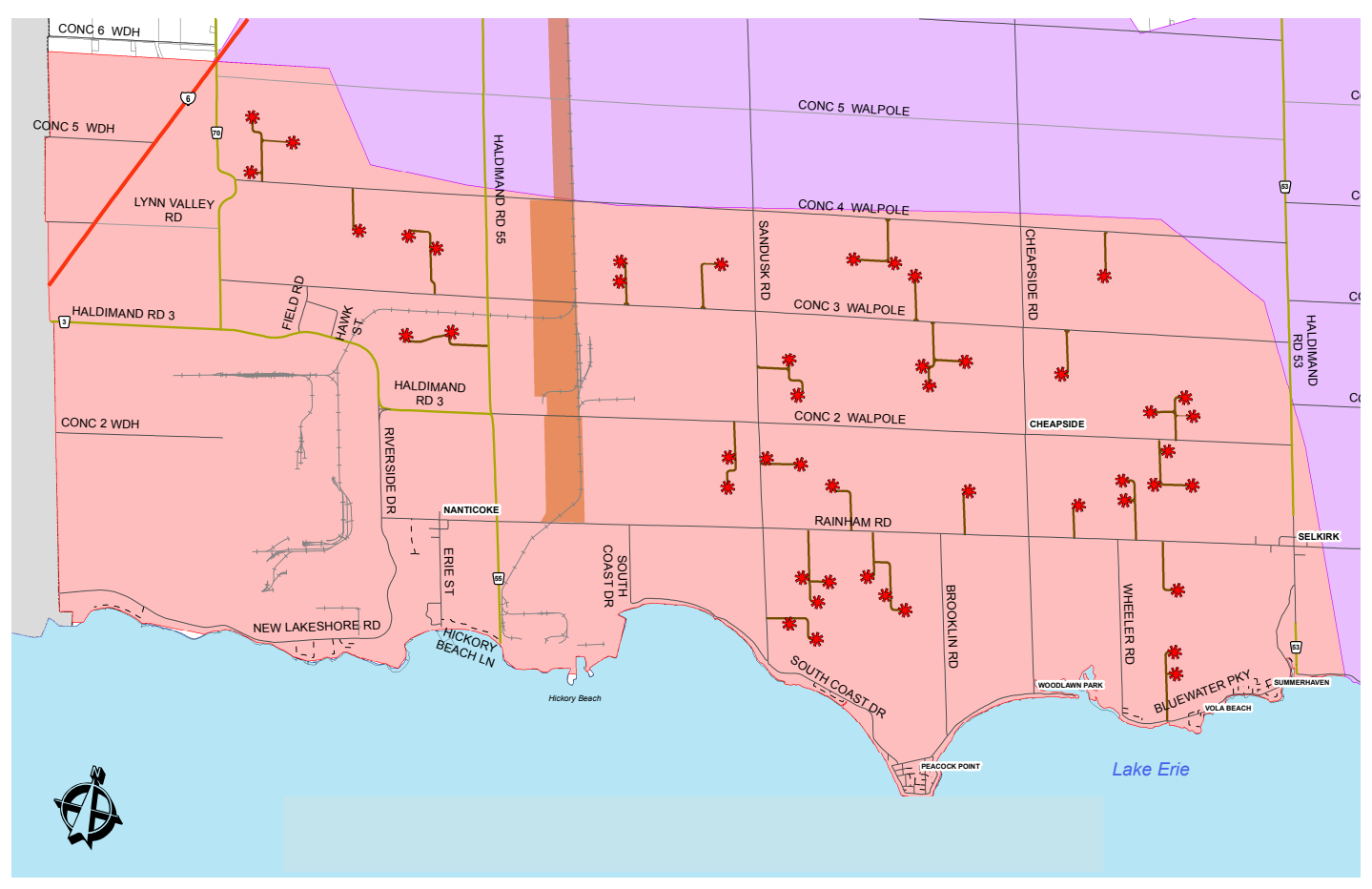

Figure 16: PDNW turbine map (adapted from Haldimand County Website)

\section{Grand Renewable Wind Project (GRW) - 2010-2015}

The GRW project was developed by Samsung, an international company based in Korea that owns five wind facilities in Ontario together with its local partner, Pattern Energy. The project received a REA in June 2012. This wind energy project has a maximum generating capacity of 150 MW (67 turbines, as shown in Figure 17). The wind farm is located in Haldimand County, ON. Two public meetings were held in July 2010 and September 2011. There were also four CLC meetings from November 2012 to November 2014. For the first time in Ontario, the developer has entered into a shared ownership with Six Nations of the Grand River. Upon completion, the Six Nations community will own $10 \%$ of the project. This project is part of what will be the world's largest cluster of wind and solar power. In December 2012, the Environmental Review Tribunal dismissed the appeals of William 
Monture (filed in June 2012), David Hyslop, and Haldimand Wind Concerns (filed in July 2012). The appeals focused on potential noise concerns and impacts on the environment. Although the appeals have not been successful, in response to some of the concerns raised by the appellants and participants, the Tribunal made some recommendations to the developer regarding the terms and conditions of the wind REA (e.g. Natural Heritage preconstruction and post-construction monitoring; reporting and review of bird and bath monitoring; Community Liaison Committee; and Aboriginal consultation).

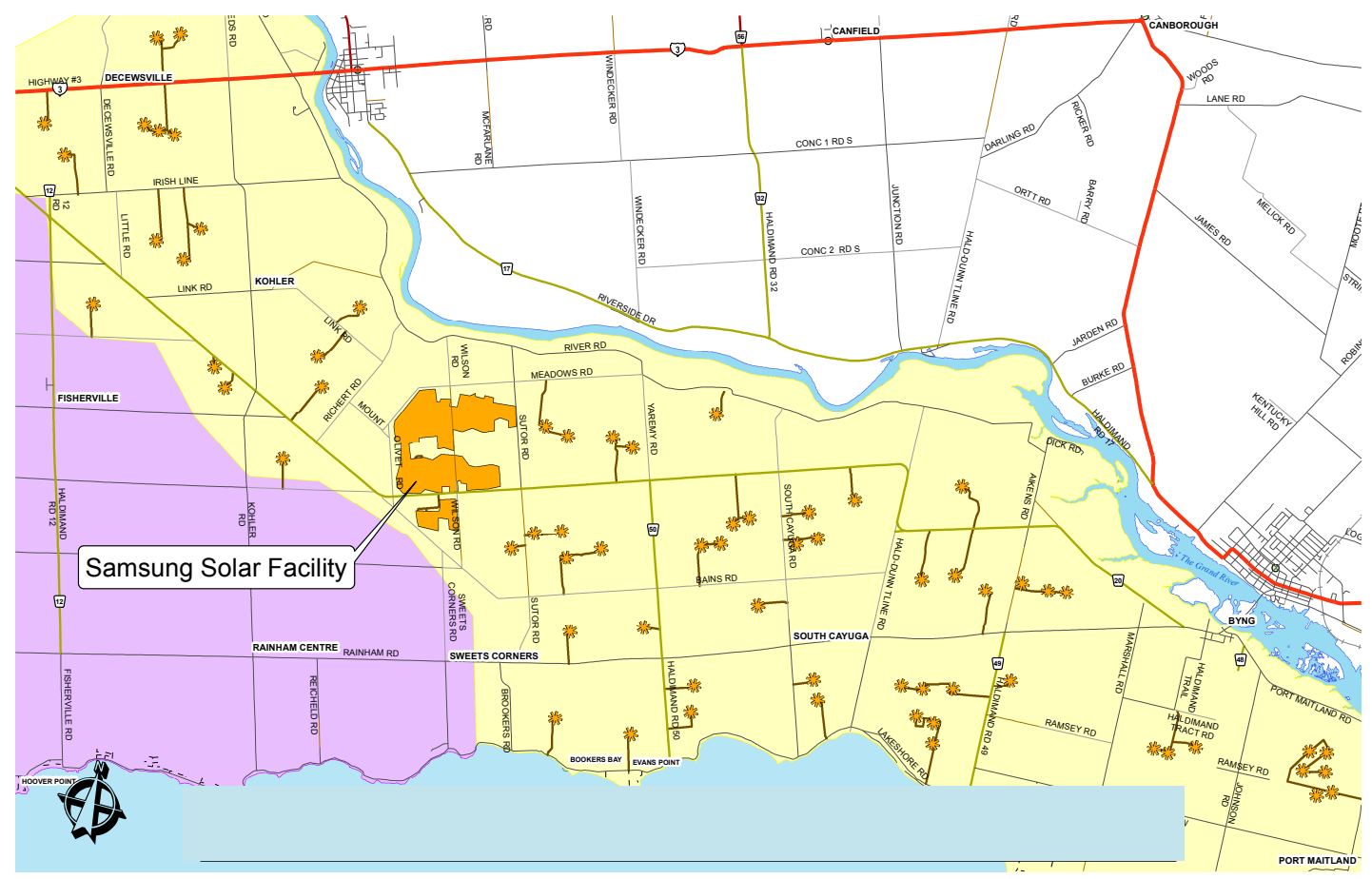

Figure 17: GRW turbine map (adapted from Haldimand County Website)

\section{Niagara Region Wind Farm (NRWF) - 2010-In progress (Intended start-up: 2014)}

The project is being developed by the Niagara Region Wind Corporation, a joint venture between Daniels Power and Renewable Energy Business. The project received a REA in November 2014. This project, with a maximum generating capacity of $230 \mathrm{MW}$, is located 
within Haldimand County and the Niagara Region (including the Townships of Wainfleet, West Lincoln and the Town of Lincoln). The Project has 77 turbines, 33 of which are located in Haldimand County (Figure 18). In May 2015, the Environmental Review Tribunal dismissed the appeal by Mothers Against Wind Turbines (filed in November 2014), which was based on the claim of serious and irreversible harm to human health, plants, animals, and the natural environment (e.g. irreversible harm to wetlands due to the close proximity of project components to wetlands; irreversible harm to the Red Mulberry; and shadow flicker). In total, four sets (from July 2011 to February 2013) of public meetings were held in 14 separate events in six municipalities.

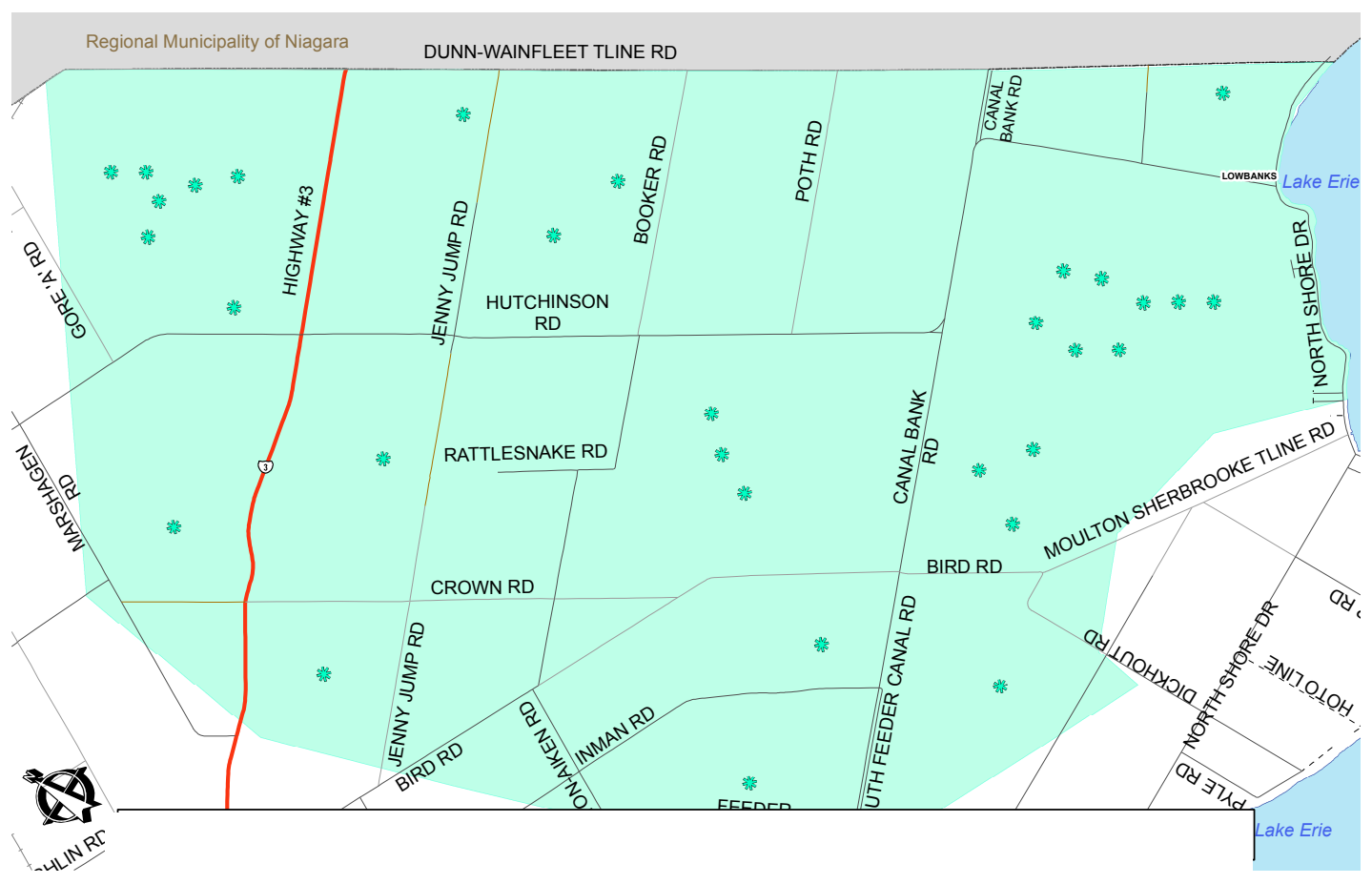

Figure 18: NRWF turbine map (adapted from Haldimand County Website) 


\section{Case \#2: Ernestown Wind Park}

Ernestown Wind Park - 2010-2014 (Intended start-up: Late 2013)

Ernestown Wind Park was developed by Horizon Legacy, a small privately-owned company based in Toronto, Ontario. The project received a REA in August 2013. This wind energy project has a maximum generating capacity of $10 \mathrm{MW}$ (5 turbines as shown in Figure 19). The wind farm is located in Loyalist Township, ON. Loyalist Township is in central eastern Ontario on the shore of Lake Ontario. The first public meeting was in June 2010 followed by a subsequent second public meeting. The developer also held six CLC meetings in 2014 (January to September). In 2011 and 2012, they went door to door to meet their neighbors and attended a number of community events in the surrounding communities of Odessa, Amherstview, Bath, and Kingston.

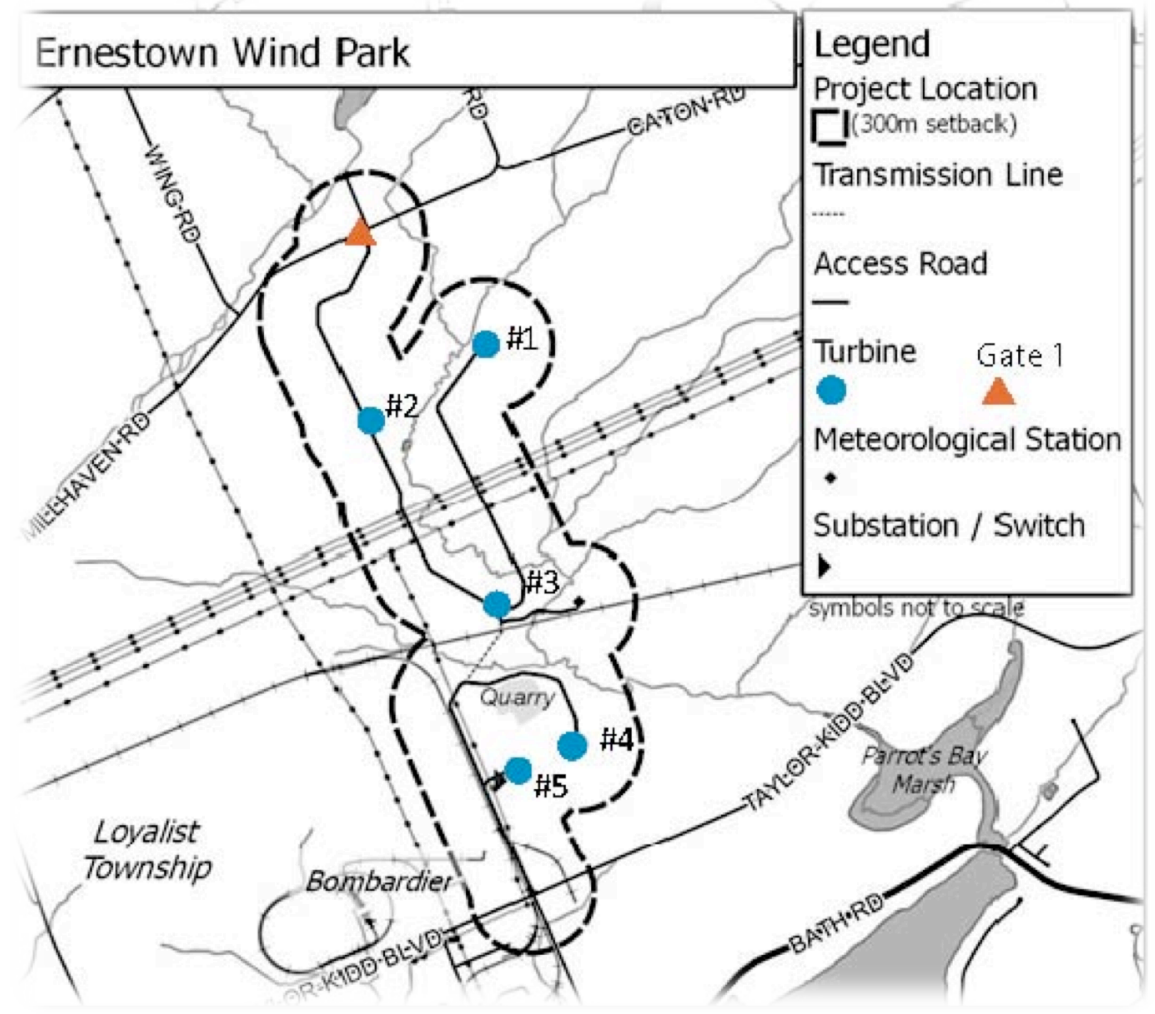

Figure 19: Ernestown Wind Park turbine map (adapted from Ernestown Wind Park website) 
In February 2014, Ontario's Environmental Review Tribunal rejected an appeal filed by Mark and Kimberly Bain (filed in August 2013). The Tribunal found that the appellants and the presenters had not established that engaging in the project in accordance with the REA would cause serious and irreversible harm to human health and animal life; in this case snapping, Blanding's or musk (stinkpot) turtles; purple martin or loggerhead shrike birds; or cattle.

\subsection{Data Analysis}

Data analysis consists of examining, categorizing, tabulating, or recombining evidence to draw empirically based conclusions. Yin (2009) recommends five techniques for analyzing case studies: pattern matching, explanation building, time-series analysis, logic models, and cross-case analysis. Explanation building is well suited for this research where a theoretical framework is developed prior to the data collection. In this technique, a final explanation is not stipulated at the beginning of the study, rather it happens gradually. In this sense, the case study is examined, the theoretical framework is revised, and the evidence is examined once again (see Figure 20). The researcher stopped repeating the cycle when the theoretical saturation was reached. Theoretical saturation is the point at which the incremental improvement is minimal (Eisenhardt 1989). 


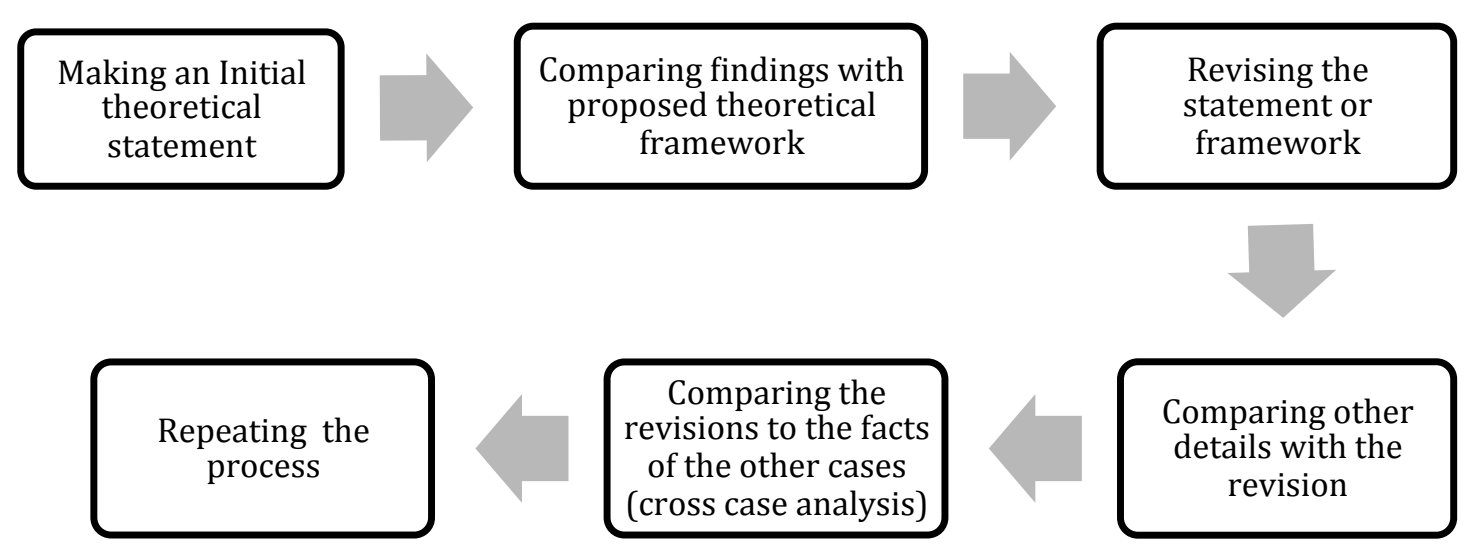

Figure 20: Explanation building process

Cross-case analysis applies specifically to the analysis of multiple cases. This technique was used in this research to find cross-case patterns. Yin (2009) suggests starting the cross-case analysis by analyzing each case separately, then using tables in a uniform framework for each case to find the similarities, differences, and overall trend. The findings of such an analysis is likely to be more robust. There is a challenge associated with this technique, as the examination of word tables relies on argumentative interpretation, not numeric properties. Therefore, the investigator should know how to develop strong, plausible, and fair arguments.

Content analysis was required to make sense of text data (i.e. interviews, observations, or documents). Content analysis is concerned with the interpretation of text data through the systematic classification process of coding and identifying themes or patterns. Patton (2002) describes that pattern and theme could be used interchangeably; however, pattern refers to descriptive findings and theme takes a more categorical or topical form. The coding process starts with organizing large quantities of text into categories. Categories are patterns or themes that are directly expressed in the text or are derived from the text 
through analysis. The next step was to identify relationships among categories (Hsieh and Shannon, 2005). Content analysis provides insight into complex models of human thought and language use. However, it is challenging to simplify the text and develop a coding scheme. Moreover, the investigator needs to be mindful when interpreting the results using automated content analysis (using computer assisted tools) and be cognizant of possible interpretive bias by the researcher (Trochim and Donnelly, 2008).

Hsieh and Shannon (2005) describe three main approaches of content analysis: conventional content analysis, directed content analysis, and summative content analysis. The key difference among these approaches is the coding system utilized. In a conventional content analysis, categories are derived from data during data analysis. In a directed content analysis, the researcher uses existing theory or prior research to develop the initial coding scheme. As analysis proceeds, additional codes are developed and the initial coding scheme is modified. Researchers employing a directed approach can extend or refine existing theory. A summative approach deals with identifying and quantifying certain words or content in text with the purpose of understanding the contextual use of the words or content (Hsieh and Shannon, 2005).

A combination of all three methods was used to get the most out of the research data. First, the directed content analysis was used for this study because the goal of directed content analysis is to validate or conceptually extend a theoretical framework (Hsieh and Shannon, 2005). The suggested theoretical framework (section 2.7) provided the initial coding scheme, helped focus the research questions, and guided the discussion of findings. However, because of the exploratory approach of the research, codes began to emerge when reading the interview transcripts (conventional content analysis). Due to the 
collection of a high volume of data, it was important to stay focused on the main topics; therefore, a summative approach of content analysis was deployed to refine the key points.

In summary, as Figure 21 indicates, the first stage of the research involved the completion of an extensive literature survey of issues related to the role of public participation and the knowledge-broker in wind project development. This was followed by formulation of a conceptual framework as a structure for the study. Data was collected through qualitative interviewing, documents, and the case meeting observation. Observing the public hearing meeting of in-progress projects served as a means of assessment for reliability, i.e. the appearance of conceptual or theoretical coherence with the developed framework. The data analysis process provided the basis for the development of conclusions and recommendations for further research.

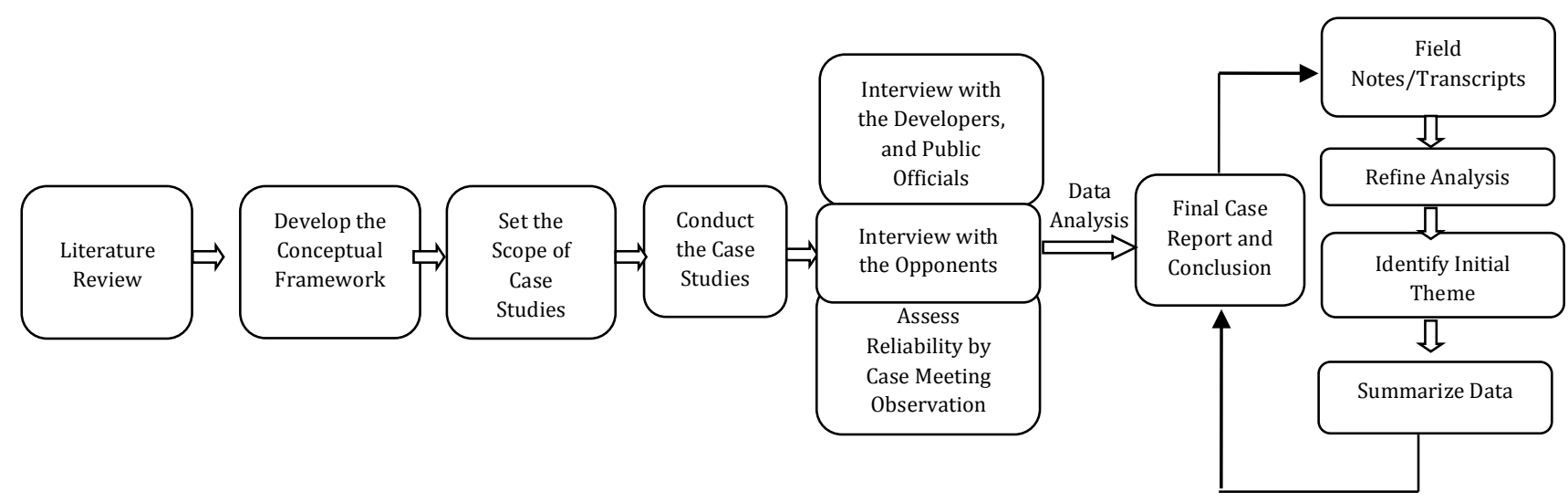

Figure 21: Stages of conducting the research and data analysis

Following Ryan and Bernard (2003), analyzing text involved several tasks: discovering themes and subthemes; sorting themes to a manageable few (involved deciding which themes are important in this research); building hierarchies of themes or codes; and linking themes into theoretical framework and research questions. In order to organize and analyze interviews, NVivo was used to classify, sort, and arrange information; examine 
relationships in the data; and find patterns. NVivo is a software tool that complements the work of qualitative researchers. NVivo enables the ingestion of various types of unstructured data, the coding of that data, and then analysis with various types of queries (Welsh, 2002). The software was invaluable in giving the researcher a means to analyzing a vast amount of collected data. The ability to code data and search for "text search" query was an interesting process that helped modify the conceptual framework and organize the data into sections. It was also helpful to make sure that nothing important was lost because of the passage of time or the researcher's memory. However, the software was only a retrieval and organizing system. As Yin (2009) argues the human mind is more capable of recognizing the most captivating comments that underline the main topics. Computerassisted tools, at most, are merely assisting tools for the human mind. 


\section{Results}

This section explains the public participation process for wind energy projects in Ontario using two cases. As previously mentioned, the selection of specific cases was guided by the following criteria: the projects were recently finished (Summerhaven, GRW, PDNW, and Ernestown Wind Park) or are underway (the only project in progress is the NRWF); there was available information through interviews, reports, and documents; the presence of a value/interest conflict; and clear traces of public involvement. To this comparative analysis, the conceptualization of public participation based on collaborative decisionmaking was applied.

In order to define the main themes, broad brush coding was utilized to organize the material into topic areas based on the conceptual framework and research questions. The coding focused on five major domains of the public participation spectrum: inform, consult, involve, collaborate and empower. Since this research takes an exploratory approach to identifying the factors which were influential in forming beliefs, attitudes, and interactions during the development of the wind projects, codes were created when reading the interview transcriptions (see Appendix 3 for more information on the coding). Based on the defined codes, a set of statements that would present the entire opinion domain was formulated. The statements included diverse viewpoints on the main concepts or themes present within the realm of the research.

Notes from observations and interview transcription were organized using theme coding by the qualitative software, NVivo. Most text was coded only once, but some text was multiple coded. Sixty-eight codes (or nodes as called in NVivo) were established and then refined to the final list of main topics including nineteen statements. The changes 
during analysis include the collapsing of codes into each other and making child codes, finding some codes fell more naturally within different domains, and recoding texts. It is important to highlight that theme identification does not produce a unique solution, which means "there is no single set of categories or themes waiting to be discovered. There are as many ways of seeing the data as one can invent. There is no magic number of developed codes that suits all the qualitative research. In theme discovery, more is better. It is not that all themes are equally important. Investigators must eventually decide which themes are most salient and how themes are related to each other" (Ryan and Bernard, 2003; pg. 103). As shown in Appendix 3, the statements are quantified based on the number of times that a respondent used a key word, phrase, or content which forms the statement. Based on these statements the main topics merged to underline factors this research seeks to investigate.

In the following section, the main topics in connection with the core question and current situation of public engagement in wind project development in Ontario are discussed, followed by the main themes based on the research sub-questions. In the concluding section, the relevance of the recommended conceptualization for a more general understanding of social support and resistance in deployment of wind power, the future of the wind industry and the recommended participatory techniques by the participants, and related regulatory policy change requirements are discussed.

\subsection{Themes Related to the Core Question}

This section discusses the findings from analyzing data - mainly interviews and in some cases the documents and notes from meeting observations. It is organized by the main topics raised by the respondents or topics that stood out from the documents based on the 
five levels of public participation spectrum in the conceptual framework. However, there is no definite border between these five levels of participation under which the research results could fall. For instance, there are topics related to "inform" which are discussed in the "consult" section. The purpose of this section is to reveal the reality of public consultation in wind project development in general and the selected cases in particular. Therefore, discussed topics are not necessarily affecting the elements of the conceptual framework in a positive way.

Unless noted otherwise, points described here were made by more than one person, even if only a single illustrative quotation is used to make the point, thereby avoiding lengthy quotes with similar content. Quotations have been presented verbatim, each identified with a code of two letters for the pseudonym initials of the respondents and a number representing the question number to ensure the identities of all participants remain anonymous.

\subsubsection{Inform}

NIMBY: Hurtful or Truthful?

As indicated earlier, generally the acceptance of wind energy remains high, but when local stakeholders are informed about specific wind developments they are often opposed. One of the most commonly referred to explanations for this gap in attitudes has been the NIMBY phenomenon. During the interviews, the opponents to wind power development criticized the use of the term NIMBY. This is consistent with the scholars' view on the use of NIMBY in the explanation of public perceptions of wind energy (Bell et al., 2005; Haggett, 2011; van der Horst, 2007; Wolsink, 2000). For instance, Bell et al. (2005) argued that the NIMBY 
concept fails to reflect the complexity of human motives and their interaction with social and political institutions. On the other hand, there will always be additional factors influencing attitudes that are unique to a locale.

The NIMBY explanation was mentioned by the respondents, mostly proponents; whereas opponents found this term insulting to the local communities. Both sides have legitimate claims regarding NIMBYism. Thus, it has become important to consider both sides of this argument, as well as those who find themselves in between. The following are some possible explanations of the NIMBY syndrome:

\section{Place-protective action}

Devine-Wright (2009) argues that NIMBY responses should be re-defined as placeprotective actions, which are founded upon the notion of place attachment and place identity. Emotional attachments to place are essential and any disruption to those attachments can affect an individual's attitude and alter their behavior. This is particularly true for wind turbines which are visible on the landscape. As this participant explains:

J.F.4: "The first concern is we live on a lakeshore which is world renowned for its beauty and so to a large extent is still unspoiled wilderness. Now it is not pristine anymore because obviously we have roads and telephone lines, electrical lines and so forth. So we're not making the claim that it's pristine. But we're saying that it's largely unspoiled wilderness to which hundreds if not thousands of visitors come every year..."

\section{Democratic deficit explanation}

Notable studies (Bell et al., 2005; Toke, 2002; Wolsink 2000) claim that while opinion polls show that the majority of people are in favor of wind power, the minority who oppose wind power control particular wind project development decision-making processes. Generally, people do not come forward with positive responses to developers' agendas. This was evident from observing the public meetings/open houses. Residents who had very strong 
views (negative) regarding wind energy were more likely to come to the open houses than those with more passive views. Interestingly, this explanation repeatedly came up in the interviews with the proponent and facilitator/consultants:

K.A.2: "Unfortunately a very small anti [wind] group or NIMBY group makes a lot more noise than people who just don't say anything or like it but they have their life to get on with and aren't going to come out. It's much easier to get people to come out and yell against you. So you have to gauge does it make sense to fight this."

Similarly:

F.M.16: “...only people that don't like something are vocal. People that are indifferent or supportive largely don't step up and say 'you know what, I'm indifferent or supportive'. So what you are hearing sometimes is like a ground swell of opposition which is in fact well-organized opposition by a handful of people and who know how to get into the media..."

Also:

P.W.6: "...I'm sure a very vocal cross section of the population spoke out against it. I don't credit them with being the majority because I don't know that. I just know that perhaps a small number of people were extremely vocal."

\section{Qualified Support}

Bell et al. (2005) and Wolsink (2000) explain that some people support wind energy under specific conditions. Those people believe that wind energy is a good idea, but they also believe there are general limits and controls (regarding the impact of developments on landscape, humans, and the nature) that should be placed on its development. A good example is the letter of one of Haldimand's residents to the Ontario Energy Board whose property is located near the Samsung GRW project (Appendix 4):

" ....I support the green energy programs, but believe it is necessary to attempt to protect my family's interests, and the equity in the property. My husband and I have planned and worked hard to create a base for our retirement...Putting my family in a cocoon of high voltage electricity, and making it impossible to sell my property, or reducing the property equity which creates all kinds of financial problems for retirement, is a deep concern. I believe a better way can be found to accomplish this transmission of electricity, not alongside roadways and in front of homes..." 


\section{Self-interest}

On the self-interest account, there is a gap between collective rationality or concern for the public good, which people will express in opinion polls when it costs them nothing, and individual rationality or self-interest because of the level of risk perception related to the distance to the site or a lack of experience with wind facilities which will motivate their behavior when the wind energy developments comes into their area. Bell et al. (2005) admit that it is not easy to differentiate between people motivated by self-interest and those who genuinely hold a general principle of qualified support. Correspondingly, this participant describes:

R.S.7: “... really I'd say the biggest thing was human health and the second thing was there were some concerns around birds and bats but in general I don't believe that was a true concern for most people, it was a political tactic, but definitely there was one person at least who was truly concerned for birds and bats and acting from the very beginning. This was a person who is involved in conservation and I think that was quite legitimate..."

\subsubsection{Consult}

Public Consultation

\section{CLC meetings}

As a condition of the REA, developers are required to establish community liaison committees (CLC) within three months of receiving the REA to provide a forum to exchange ideas, share information, and provide updates on the construction, installation, operation, maintenance, and retirement of the project with interested residents and members of the public. The CLC meeting should operate for a minimum of two years after the day it is established. Members should meet at least two times per year with the membership comprised of a limited number of participants who are selected based on certain criteria. 
These criteria narrow down the eligible population who can volunteer to serve on the committee. The following criteria were found on the developers' website (e.g. Ostrander Point Wind Energy Park): previous experience in contributing to local advisory committees; renewable energy knowledge; and a technical, science, or engineering based background or work experience. All projects had facilitators to run community liaison committee meetings. They also had consultants (i.e. environmental planners) who helped developers put together the renewable energy proposal and prepare related reports (e.g. noise impact assessment report, water assessment report, natural heritage report, archeological report, etc.). However, the role of these third parties was limited and did not go beyond facilitation or consultation.

The CLC usually consists of up to 14 individuals who are representatives of the following groups: landowners; residents within $1 \mathrm{~km}$ of the Project; Aboriginal communities; agriculture; business/industry; environment and local organizations; and representatives from government agencies. All members are required to fill out the application and to read and sign the Terms of Membership Agreement. CLC meetings are open to the public for the purpose of observing the conversation (adopted from CLC notices of the illustrative projects, see the Appendix 5). However, CLC meetings do not include matters raised during the proposal/planning stage for the project (e.g. location of a wind turbines or issues/concerns already addressed through the REA process). Therefore, CLC notices give the impression that they are rubberstamp committees in which public participation remains surficial at best. One of the participants explains this:

W.B.6: "The scope of these meetings talks about things in post decision-making. So you aren't revisiting the approval process...Now we're moving on... The overall decision-making process is complete and now we're talking about minimizing construction aspects. There's a tremendous amount of animosity left and 
confrontations at these meetings because the large decisions have already been made and settled with conditions. So the turn out to these meetings is quite lax compared to say open houses or forums and the focus is more specific, talking about specific construction schedules or mitigation."

\section{Public meetings}

It is important to note that closer examination into these projects suggests that most public participation took place after most key construction and operational decisions had been made. As discussed in section 2.5.2, the REA requires two public meetings. The first one is held following the notice of proposal and the second following the release of the REA reports. Thirty days prior to the first public meeting, the developers provide a draft of the project description report by posting the drafts on their website and making paper copies of the drafts available to the public in each local municipality (Government of Ontario, 2014). As shown in Figure 8, the public has 60 days to read, understand, and make comments on the REA reports. However, in the REA guidelines there are no suggested participatory strategies or clear guidelines that could be adopted by developers to facilitate the public participation process. It is the developers' choice as to how to manage the public meetings and prepare reports that contain the main public concerns and the results of the meetings with the Ministry of Environment and Climate Change. The regulations are ambiguous as to whether the developers are obliged to respond directly to the public regarding concerns pertaining to the proposed wind project. The responses to the question of "Do you think there is a need for more details as to how to conduct public consultation?" the participants highlighted one important point: selecting the best participatory technique is site specific, where processes may be more sympathetic or more hostile to the wind energy development application in different localities. Each project is different depending on its size and scope and the community affected: 
F.M.8: "You know what, it's very much project specific. I think the smart developers will look at the requirements under the regulations and use that as a standard for their minimum and they will go over and above and beyond and try to socialize their project..."

Similarly:

S.E.35: "The other thing is there's no one size fits all for this. Every community is different. I go to South Kent, no problems. I go to Southgate, I have very very angry people. $200 \mathrm{~km}$ away, both rural, both demographically speaking the same."

Also,

R.N.12: "I think that the key is to get in early and know your audience so we will come into an area quite early and put a plan in place that is, what's the word, not to alert, that's customized to the population. So we look at the demographic, we look at the government structure, the municipal government structure, we look at the community leaders, business associations, chamber of commerce and we look at all of them and start an outreach..."

In the studied projects, it is apparent that the developers and the local community have very different views of the proper consultation process. The developers had held a series of public meetings and felt they had made every feasible effort to consult with the fragmented communities. However, the opponents believe large open houses were not an appropriate form of communication. Even though the proponents believed the engagement was project specific, after reviewing consultation reports, attending two public meetings, and analyzing the interviews, it is evident that the developers prefer to choose the public open house format as their main participatory technique. As these participants explain:

G.V.6: "In open houses, the developers just put up a series of posters that may or may not be accurate and quite often are not accurate and that's it. That's all they have to do. They're supposed to record the comments but then it's not clear where people's comments go from there, the other thing is once an application is received, the government then posts the application document online which in the rural areas is very exclusive. Not everyone has high speed Internet; some of these documents are thousands of pages..."

Similarly: 
B.0.14: "Yes we had the two public meetings and you really should attend one of those if you haven't because it's not a public participation meeting; it's an opportunity for the proponent to provide limited information. That's what it is; it's not about participation it's about the provision of information to the general public. So they say here's the project and they always set them up in an open house format. Because you know how you go to a meeting and it's a real meeting, there's someone at the front, they present slides, there's an opportunity for questions, there's a dialogue there. That's not how they set it up. They set up a series of booths and tables and people shuffle around and look at stuff. You can ask questions of the person who is there at that particular booth but is this official? Is this recorded anywhere? Can you hold them to it? No. So it's not an entire group seeing it at the same time. So that's the issue with these public meetings because they are exclusively for providing information. They say you can write down your questions and send in my questions but they may not respond."

As demonstrated in the comments above, respondents have acute feelings of powerlessness with respect to how their concerns or questions influence the process and the outcome. In all interviews with the opponents, they claimed that there was no avenue for public participation. In their opinion, it is just ticking the box for the developers to show that they have done the public consultation. It was not perceived as sincere and there was no true back and forth communication. Statement $D$ in Appendix 3 shows the results of NVivo analysis of how participants think of the consultation process.

The experience of participants at the community consultations hosted by the developers and their negative opinion of the developers' representative answers to attendees' questions emerged as one of main triggers of opposition. Yet, while process-related issues were raised, the interviews revealed a great preoccupation with the behaviour of the developers and what they perceived as lack of transparency, dishonesty, and avoidance of concerns and question:

V.M.10: "...as a municipal politician I know what public consultation is about. You put the proposal out there, you listen to concerns and they are quite frequently valid concerns raised with the proposal, you respond to those concerns and you adjust the project and put it back out for comment, but it's that listening and responding that's missing. The town hall meeting was written questions and answers from 'experts' on 
the stage and the arrogance and dismissive responses from the wind company and their experts to perfectly valid questions actually damaged their reputation in the community and built opposition to the project... I talked about response to concerns, they just dismissed them, they ignored them, valid things."

V.M.15: “...So the process is not anywhere close to open and transparent."

Similarly:

B.0.26: "...that there is no honest dialogue. That the developers aren't...they aren't doing more than they need to do."

And

G.V.18: "You don't see any wind developers talk anywhere and in fact it sounds crazy but it's true. If you happen to know the names of executives or whoever is involved in a wind developer, you will not find them on the Internet, their entire everything is scrubbed clean, you will not find them, they will not comment to you, everything is strictly controlled by the lobby group."

Moreover, the community participants described how the plan for developing a wind facility is usually in place for several years, yet has not been communicated to them until the studies are almost done, the turbine locations have been decided, and the developer has gone to the property owners and tried to secure land (typically, before they even talk to the municipality, let alone the local community):

Z.C.7: “...it was already too late, half the environmental studies were already conducted, actually more than half, just about all of them were. We had no say at all whether we would like or not like an industrial wind turbine within our view or within $550 \mathrm{~m}$ of our property, we had no say. There was nothing, it was already done by the time they had started an active consultation process with people in our community."

And:

D.B.14: "The decision is made therefore my opinion doesn't matter. So I'm going to complain about it because that's all I can do. That's what I perceive to be the issue...In this case because the REA process is done up front, all the reports are done up front and then go to the public. The perception is that the decision is made." 


\section{Local knowledge}

These opinions demonstrate a need for different forms of involvement (procedure and method are crucial), which should occur during the early stages of the process. Several participants in response to the question: "What are some strategies that could be adopted for increasing the level of public participation?" stated that it is more about the timing of participation; instead of having it happen once a project is decided and then announcing to people what is going to be done, the developers need to back that up and have participation earlier in the process which would facilitate a smoother project process. As indicated by the respondents, this early involvement and acknowledging the democratic right of the local community have two main benefits: decreasing the level of public opposition and taking advantage of local knowledge. Citizens can be used as local experts and fully engaging them in decision-making can provide developers with a rich and contextualized knowledge of the local area, its people, and the area's political dynamics:

N.B.15: "if you treat the community with respect and you are honest and upfront with them, they may not like what you have to say and how things are unfolding. Typically they are going to understand why it's unfolding that way."

And

E.L.14: "The more people provide the input [early], the more ownership or more involved they feel in the process and I think most accepting they can become of the project. But, it is also so important because usually when these companies come in, they are outsiders. We don't know the area and it is important getting people involved and having the information. They can tell us stuff, we didn't know about. You know, for example, an unregistered airstrip. Somebody flies planes off their property, and their landing strip is too short, so is not tracked by Transport Canada. So, we would have no way of knowing about this unless somebody told us about this. So, they can point out things that we might not know about."

Similarly:

J.L.19: “...like the developer doesn't necessarily live here and hasn't lived here. We are people who have lived here for some, 150 years through their families. So they 
know the area. They have lived here. They know what happens. So that type of public participation [early engagement] is really beneficial to both the public and the developer because they can sort of iron out any detail, anything they may be missing or that may enhance things."

Therefore, decisions that do not take into account local factors, concerns, and values may raise questions, face public opposition, lead to poorly developed plans that have to be reworked in order to fix flaws, and importantly, fuel distrust. These issues can be resolved with collaborative decision-making, which considers knowledge as socially situated rather than merely the domain of the technical or scientific form of knowledge.

\section{Possible consequences}

What respondents describe above exemplifies the influence of two key dimensions and concepts related to wind energy decision-making process: transparency and early involvement. One could argue that open consultation, participation, and the social impact on the localities never took place. Rather, as indicated by some respondents, these projects were planned by the developers many years in advance as a part of the REA strategy. However, in some cases the developers paid a price for this inadequate consultation by way of substantial delays in implementation due to appeals through the Environmental Review Tribunal process or when dealing with the motions passed by municipalities. An example is the North Frontenac case in which the researcher participated in order to observe the dynamics. On June 6, 2015, the North Frontenac Council held a special council public meeting about a proposed wind project by NextEra. Representatives from NextEra explained their plan and answered questions from the Council. Few questions from the public were answered by the NextEra representatives. However, as soon as questions became more challenging and controversial topics were brought to the fore, some people started to seriously question the provided documents (questions, based on observation, 
were not answered adequately). The developer representatives then changed the format of the meeting (where they were standing in front of the room full of concerned citizens and were barraged with questions) to an open house format with posters. The opposition group was distributing leaflets (Appendix 6) outside the Community Hall and its members were encouraging people to sign a petition against the developer.

On June 10th, North Frontenac Council passed a resolution declaring the township an "unwilling host" for the NextEra wind power projects. The company had offered a $\$ 200,000$ per year for 20 years community vibrancy fund in addition to a projected increase in tax revenue of more than $\$ 100,000$ per year under one condition: the township needed to pass a motion supporting the project, thereby enabling the company to secure community support points and win the bid in the procurement process, which had been set out by Ontario's Independent Electricity System Operator (IESO). In an interview with Frontenac News, the Mayor explained the motives behind the motion:

"There were many red flags about this proposal as far as North Frontenac is concerned, starting with the fact that instead of being approached by the company we initially read about it in the newspaper in early March. It also involves major construction and conflicts with the entirely different economic development strategy we have been developing, and beyond that our residents have voiced their opposition in large numbers."

The NextEra bid to the IESO can proceed without municipal support; however, the statement that North Frontenac is not a willing host will cost NextEra valuable ranking points in the procurement process, which will make it difficult for them to compete with bidders in "willing" townships. If NextEra still wins the bid, the turbines would be built in North Frontenac. In that case all that North Frontenac Council will have accomplished by stating they were "not a willing host" will be to lose up to $\$ 10$ million in revenue over 20 years. In March 2015, the IESO launched its new Large Renewable Procurement (LRP). The 
LRP is an effort to improve the public consultation process and strike a balance between early community engagement and financial viability of projects. Proposed projects must "demonstrate site and resource due diligence" as well community engagement (IESOb, 2015). Whether or not these changes can be considered improvement in the participatory process is discussed in the next section.

\section{New Procurement Process}

During the course of interviews, participants talked about the new Large Renewable Procurement ${ }^{1}$ process and the requirement that developers secure public and municipality support for their wind projects. However, neither proponents nor opponents seem highly supportive of the new LRP. There is a community support points system: 80 points for community engagement and 20 for Aboriginal interest. There are two levels of possible support from the project community: a Municipal Support Resolution or a Municipal Agreement. If there is an agreement, but no support resolution, the proponent can receive 40 of the 80 points. Any developer that has the approval or support of the community has a better chance of securing the contract. While the municipal support provision was included

\footnotetext{
${ }^{1}$ The Large Renewable Procurement (LRP) or Large Renewable Procurement Request for Proposals (LRP I $\mathrm{RFP}$ ) is a competitive process for procuring large renewable energy projects generally larger than $500 \mathrm{~kW}$ and up to $300 \mathrm{MW}$ of On-Shore Wind, $140 \mathrm{MW}$ of Solar, $50 \mathrm{MW}$ of Bioenergy, and $75 \mathrm{MW}$ of Waterpower. In order to proceed, renewable energy projects in Ontario need to be awarded long-term contracts with the Independent Electricity System Operator. Once this contract is awarded, and prior to the commencement of construction, the projects are subject to approval (REA) from MOECC. On March 10, 2015, Ontario's new procurement process for large-scale renewable power projects was publically released. The municipal, Aboriginal, and stakeholder engagement activities are included in this new Large Renewable Procurement Process. For each Renewable Energy Proposal, a registered proponent must have a publically accessible website for the Large Renewable Project on which the registered proponent or its representative has posted the project's documents. The proponent should make sure the Large Renewable Project website is and remains available and publically accessible from the date that is at least 15 days prior to the date of the public community meeting. Section 3.2.5. of this new process is dedicated to community engagement. At least one public community meeting must be held to discuss Large Renewable Projects with members of the public in each of the project communities and one meeting must be held with the public officials $\left(\mathrm{IESO}_{c}, 2015\right)$.
} 
in the latest wind energy procurement process to provide for some local input, it does not go as far as granting municipalities any authority to approve or reject proposals. On March

11,2015 , an email was received from one of the opponents regarding the new process:

G.V.: "...The wind power development lobby got several concessions, namely: the number of public meetings required is now ONE, not two; and the percentage of adjoining landowners who must consent to a power project is now $75 \%$, not $100 \%$. It is difficult for the public to have any faith in this process when the entire thing favours the developers. Note also the timing of this process March 10-September 1 is the busiest time of year in rural communities for those involved in agriculture..."

Meanwhile, when the opinion of the proponents was asked regarding the new process, most of them believed: (1) it was a burden on the developers to go through a timeconsuming and expensive process prior to winning the bid; (2) this would result in exposing a project to additional costs and risks; (3) this mandatory consultation required by the IESO over and above that required by the MOECC for the REA process further slows down any wind developer's planning and construction schedule. As one of the participants stated:

F.M.8: "...you submit a bid, and its largely the price that you bid will determine whether you are selected as a project, but as part of this project they have almost a parallel prescriptive consultation process that you have to follow. It's to me a bit silly, it's duplicative of the REA, it's written into the rules and it's a mandatory requirement and if you don't do it, your proposal will be kicked out for consideration."

In response to the question: "What would motivate the developers to go through such a long process?" all respondents believed the FIT is a strong incentive for the developers to do all the consultation and studies because they want to win. If they are successful, they will have considerable profit over 20 years. 


\section{Inadequate Consultation Begets Inadequate Participation}

It is important to note that in some cases it is difficult to identify and address the public's interests and concerns, because people refuse to come to a meeting and get involved in a principled negotiation. Sometimes, the meeting becomes confrontational and vocal opponents come to the meetings without registering, interested only in their positions or to express their emotions. This makes it complicated for the developers to control the situation, separate the interests from the positions, and address the legitimate concerns of the community.

V.F.22: "The other problem with creating better meeting strategies or creating better forums for public involvement is that there is such an opposition lobby group that it sometimes makes public meetings unsafe. People become threatening, they physically threaten, verbally threaten. So some meetings require police presence at them."

And:

J.L.12: "At one meeting, once it was all set up, they [developer] opened up the doors and invited the people in. They didn't want to come in. They chose to stand. It was one of the coldest days of the year in December. They went and parked all around the building that was a little old church we were in; they parked as close as they could around the building, and honked their horns for 3 hours while we were having the meeting. But wouldn't come in and comment."

Furthermore, as previously mentioned, people with positive or laissez-faire responses (silent majority) generally do not come forward to support wind project development. Hence, the minority who oppose wind power can control the decision-making process. As some participants pointed out, sometimes opponents who have already made up their mind are not necessarily from the area, they are just against wind projects. There is a strong anti-wind network in Ontario; they travel around the province to support anti-wind groups in different areas.

V.F.6: "There was a public meeting and there were protesters outside the public 
meeting for the project. They refused to go into the public meeting to learn about the project. They were invited to come but they refused to sign in at the meeting. Some of the protesters were yelling at this gentleman who was for the project and were saying 'You're destroying our community how could you do this?', and he said to them 'If I recognized you and I knew where you lived, then I would actually listen to what you are saying, but this is a community of 3000, I've never seen you before in my life, you are clearly not even from here, you're just here to protest for an antiwind campaign."'

And:

E.L.24: "We have sought or found that with some projects that we have [been] working on, all within the same area, it's the exact same people that show up on all the open houses to oppose the projects. Sometimes it's easy to identify them. It's easy to identify the opposition groups. And I think it sometimes just feels discouraging, when you go out there to talk to these people and they don't want to talk to you and they just want to yell and be unreasonable."

At the stage of contacting the potential interviewees, an email (Appendix 7) was received from the spokesperson of an opposition group which endorsed the dedication of anti-wind groups to put an end to the wind energy development in Ontario. She declined to be interviewed because she believed that university-driven research rests on false premises such as wind providing a good substitute for fossil fuels and reducing greenhouse gases (GHG):

C.H.: "We are committed to the end of industrial wind factories in Ontario, and to exposing the experiment of climate fear-induced profiteering from so called, 'renewables' and the 'green' agenda. I am not sure that our objective is in any way meshing with your overview of engaging communities, consulting..."

Based on the interviews in totality, the cause of such a partisan position may be attributed to some developers undertaking a poor job with public consultation and leaving the public with no choice but to find other ways to be heard (P.W.25 and S.E.5). The opposition is grounded in experience with the existing projects. The developers kept with the "decide-announce-defend" tradition and information provision which is the bottom-line engagement approach and the minimum level allowed by law. While this is a good first 
step, the emphasis on a one-way flow of information left people having little influence or opportunity even to express themselves. Apparently, the current engagement technique in the form of public open houses is not helpful:

C.0.6: "I don't think in the open house events we hold now, there's no or very very little benefit to them because they are very contentious and very volatile and anybody that has a genuine concern or interest in the project I think they get intimidated and I think they get scared off by people out side with sticks and yelling and screaming and burning straw dolls. I've been to a lot of angry meetings and I can't see anybody who has a genuine interest ever wanting to come to one."

While the reasons for protesting against wind energy are not straightforward, what motivates many of them is the lack of opportunities that concerned people have for meaningful engagement in the decision-making process. In response to the question: "What is the trigger of public opposition?" one participant stated:

E.L.25. "I think it's because of, may be, feeling helpless like nothing they can do is going to change anything..."

If renewable energy in general and wind in particular is a main strategy for tackling GHG emission and climate change, issues related to public support and opposition have to be addressed with the public being meaningfully engaged. Seeing the public as a barrier or ignorant about climate change is unlikely to be beneficial. Instead, a better approach to understand the concerns that people have and how these might be mediated is required. In the interviews with opponents, local citizens criticized the decision-making process, feeling that the decisions had already been made and there was a lack of real consultation, which hardened their opposition against both the wind energy and the developer. Similar to the developers who should adapt more proactive approaches for meaningful engagement (early involvement, providing factual information, educating the public about both 
advantages and disadvantages of different forms of energy, transparency), the public should participate in a meaningful way:

E.L.42: "I think what I would like to see, just like, developers have responsibility to host these meetings and be there to talk to people. I kind of wish that people would see that they have a responsibility if they are upset about the project to participate in the meaningful way. Showing up at the meetings, yelling and screaming, throwing feathers at somebody, that's not meaningful. It's not helpful. I wish people could see they are not helping their cause or the project by behaving that way. In order to bring faster change or being involved in the project people need to see that they have a responsibility to participate in a certain way."

As Haggett (2011) explains, convincing people that climate change is a more critical environmental concern than the localized impact of a wind energy development is a vital element in wind energy development. This can be achieved through education. In this light, a number of participants from all categories asserted the importance of education.

J.F.5: "...people have to be truly given the facts, they have to be educated about it [wind energy]. They have to know about every source of energy generation whether its nuclear or hydro or gas or solar or wood or wind or whatever it is, you have to pay for it, there's a payment more than money..."

And:

J.L.14,16,19: “...from my perspective, there's not enough done to educate the public on wind turbines... The government agencies can do a better job of educating why or what their limits are or at least why they believe that the thresholds or limits or setbacks everything are the way they are...I think that proper education would decrease the not in my backyard argument. I really do."

The challenge is that the benefits of education may not be manifested in the short-term because people are usually more concerned about local, tangible, and immediate problems in their daily lives (i.e. dealing with the wind turbines in their backyards and being worried about the potential health effects) rather than a global issue. K.A.15 thinks it is better to start with children in school because they are more open to learning and being green. Education takes place only if the developers, the government, the Canadian Wind Energy 
Association, and the Ontario Sustainable Energy Association harmoniously work together (P.W.24 and K.A.15).

Typically, communities are inadequately informed about wind energy projects and are often excluded from decision-making and the planning process. Individuals most likely obtain information regarding wind energy from a variety of sources (Internet, friends and family, media), some sources are more reliable than others:

P.R.8,10: "Internet is an interesting component of this that really no one can control and people find what they want to find on it...The problem when these things start up is if the developer isn't going out providing information, the local neighbourhood fills it in and it may not be the correct information, but the vacuum created will be filled with something. So they go to the Internet and find out what could conceivably go wrong or have gone wrong elsewhere and go from there. I think the proactive action on the part of the proponent to go out and meet people directly..."

Similarly:

C.0.2: "I think that there has been a lot of misinformation in the public, I think there has not been an effort by the developers to get the right messages out into the public realm, so every time we go into one of these things there has been a lot of debate and a lot of the same messages, for four years the message has not changed, the people that are coming to the open houses now are saying the same things they were four years ago, so there's been no real education or change in thinking and there's still a lot of fear. So I think there's been a lot of missed opportunities in the consultation, particular in wind."

Independent research from sources people trust may facilitate the information exchange process. Most participants support the notion of a knowledge-broker who can help significantly in this regard (the role of the knowledge-broker is discussed in section 4.2.1). Moreover, participants mentioned that the existing information on the developer websites and at the library or at local municipalities was not inclusive enough due to: (1) volume: hundreds (if not thousands) pages of material in technical language, which require a lot of time and expertise to review (D.S.10, B.O.7); (2) availability: not everyone has high speed Internet, requiring people in rural areas to drive long distances to a library or municipality 
to read a copy of the documents (G.V.6, Z.C.14, V.M.13). There are solutions that some developers have deployed to overcome the problem. For instance, they have made information and reports available on CDs for the local community and/or made the summary reports available in plain language, with technical appendices:

C.0.12: "During that time people can provide comments, and I understand how difficult it is to get access to that stuff, so we quite often will say as well, it's available at the library, it's available at the municipal office, if you can't get to it or if it's difficult to access it from the Internet because I understand we are working in a lot of small communities where maybe the internet is not great, we'll take it and burn CDs for them. I'll burn a CD and send it to anybody, so there is an opportunity for anyone to get the information and as part of the process as well we have to put together summary reports and the reports under the regulation of the REA process, they are called Aboriginal summaries because they are supposed to be 2 or 3 page summaries of all the reports that you provide to the Aboriginal communities, we make those public as well. They are in plain language so they are written so people will understand what's going on."

In summary, there are stakeholders who are undecided and do not know much about the project, but they are willing to listen. In other words, they want to learn. Early, honest, and transparent communication to them through providing meaningful information will affect whether they support the project or not. It is helpful to have a productive conversation with those who are supporting the wind project. There are stakeholders with their minds made up who are against wind energy. Long-term education can affect their perception. In the end they might not support wind energy, but at least they may not actively oppose the development of these projects in their communities.

\subsection{3: Involve}

\section{Provincial and Municipality Involvement}

As previously discussed, one of the controversial provisions of the Green Energy and Green Economy Act is the exemption of renewable energy projects from municipality zoning 
approval (under the Planning Act). The situation is perceived by some of the participants (G.V.13, P.R.4) as a circumvention of a democratic decision-making process in which decisions regarding a wind project are made exclusively between developers and the province (and to a minor extent the federal authorities) through a draconian and repressive process. The rationale behind the creation of the REA was to streamline the approval process with the aims of enhancing investor's confidence and speeding up the process. While this seems admirable, there are number of important issues to take into account.

First, the responsibility of making efforts to engage the stakeholders very clearly rests with the developers. They have a duty to consult with the local community (sections 16 and a8 of the REA). The MOECC has the power to refuse an application if they deem that the developer has not complied with the requirements. But, how the developer identifies the stakeholders, how they choose to engage them, and whether they do so in ways that are meaningful is key. It is also not clear how public questions should be responded to and incorporated into the plan. As a result, some developers do make efforts in this regard to be good corporate citizens (refer to section 4.1.4) while, based on the comments made by the interviewees, many others do not have a very good track record. Many respondents believed that the province should be more involved (and available) in the process to enforce its own rules and regulations, protect the environment, and alleviate the concerns, specifically the process of Aboriginal consultation:

C.0.13: "I think they [provincial government] need to make themselves more available. I think that we always invite specific ministry people to come to our open houses because a lot of the questions are for them, they are not about the project, they are about the process and I think that if the MOECC made themselves more available, put more information on the website about how these things are determined, I think that would make people feel like the MOECC is actually a part of 
the process and not just this white ivory tower decision maker that nobody can get access to."

And:

S.E.41: "I'll start with Aboriginal first. Problem we've had in Ontario is the duty consult is supposed to be with the Crown, with the province, but that's not the way it works. Developers have to go out and consult, the government doesn't do any consulting. So the issue with that has been you have companies that are literally taking on historic problems in the form of treaty rights and you know land disputes, and ... is out there discussing these things with Six Nations, well that really to be honest is the role of the Federal and Provincial governments but they've been no where to be found in this. So, I think the Federal and Provincial governments need to really step up in an aggressive way when dealing with lands and treaties and need to consult. Because it's really been left up to the developer."

Second, when interviewing municipalities, a lot of resentment and frustration arose because they do not have any say in the decision-making process. While the municipalities are the first point of contact with the local community, they are side stepped in the process. People come to them, ask questions, or complain and the municipalities' exclusion actually puts them in a difficult position. People see the local government as being associated with the problem of a lack of public consultation when in reality they do not really have much jurisdiction as a commenting agency (not an approving agency) in the decision-making process. Meanwhile some participants talked about limited resources available at both the municipal and provincial level to inspect the documents generated for wind energy applications and thereby address people's concerns and questions:

P.R.17: "The nature of green energy projects is that in rural areas its smaller municipalities so it's hard to have that expertise available even in large municipalities let alone a small one that may have only ten or fifteen staff. So it will always be a matter of bringing in outside people for expertise on how we should deal with it."

Also:

V.M.12: "So a key piece of the whole process is you need a detailed technical review and local input of the process and that's not happening at all [at municipal level] 
and it hasn't been replaced by the province because you would need a massive bureaucracy to replace all the building departments across the province."

Third, the new approval process was not $100 \%$ successful in reducing the impact of dissent. Therefore, it seems that the REA (and the opportunities for involvement that are allowed) will likely discourage and distance people from the decision-making process. The current public participation model in Ontario for wind energy projects may be designed to satisfy legal requirements, but it is not able to incorporate a broad spectrum of the public interest, nor achieve genuine participation, and does not generally satisfy the members of the public. Practice reveals (as shown in these five projects) quite a reactive and tardy public consultation performance. The reactive nature of such public participation practices simply increases the problem of participation fatigue, limits the process of learning, and reduces power-sharing opportunities (Partidario and Sheate, 2013). The current regulatory governance process strips Ontario's municipal governments of much of their power to decide whether they want such facilities to be established in their communities. As a result, they may show their dissatisfaction by passing a "not a willing host" motion (more than 80 Ontario municipalities have formally declared themselves "not a willing host" to wind power generation projects) and passing bylaws that increases barriers to development, i.e. bylaws related to noise and shadow flicker. Councils can also refuse to grant business licenses.

V.M.6: "There is a movement across municipalities to deal with this, because a lot of municipalities feel caught in the middle, they have less powers than...well normal powers that they use to manage the location of the Tim Horton's or the Starbucks or whatever you want to use as comparable, can't be applied to wind turbines. But their constituents are screaming at them to do something and there are actually lots of things that municipalities can do and are doing to try and deal with the issue. Well the most aggressive is a by law that enables the municipality to enforce the 40 dB provincial standard." 
Similarly:

M.A.9: "So there is a lot of relevant case law where municipalities have tried to do things. I think the most current one that we were approached just this past summer was to join a consortium of about 10 different municipalities to enter into a quiet nights by law where you weren't allowed to make any noise between 9.00 p.m. and 6 a.m. and then they would hire enforcement officers to go and specifically enforce this on wind turbines and that would be a way to try to shut them down."

One important point, which was highlighted by some participants, is that developing wind energy could turn into a political issue. If there are a significant number of people in the community who oppose wind energy, getting a municipal counselor to support it becomes problematic:

F.M.6: "Unfortunately municipalities are political things and mayors are up for election every four years as are councilors, and virtually every municipality in southwestern Ontario has declared themselves an unwilling host for wind turbines."

Fourth, unlike the German system, which has established a stable regulatory framework based on strong environmental awareness, comprehensive legislation, and political commitments to renewable energy targets, Ontario suffers from weak regulatory governance (Holburn et al., 2010). Renewable energy development is tied to the Liberal party as one of their policies. In other countries, energy policy is largely established at the national level, but in Canada there is no integrated electricity market. Therefore, the future of the wind industry seems to be on a shaky ground, especially if the Ontario government shifts its focus from renewables. Most of the respondents (see statement $S$ in Appendix 3) do not see a bright future for wind projects in Ontario. The predictions range from shifting to other renewables like solar, biogas, or geothermal to enhancement of storage technologies, small-scale projects, or developing wind projects in the other provinces or more northern communities, if the transmission issue can be solved.

B.O.28: "I think if the Liberal government remains in power the wind industry is for 
some reason hand in hand with them, so they will continue to do what they want to do. If the Liberal government falls out of favour I think that will be the end of the subsidies as much as possible...."

And:

V.F.38: "I think because the government did a poor job implementing the micro FIT program and the FIT program it didn't work like they thought it would from the German side. Our system is modeled after the German incentive system, you know."

Also:

R.S.21: "We modeled it on some German policy but we shouldn't roll it out the way we roll out those German policies and the program stopped and started, so many changes..."

Finally, one fundamental misconception between what the government allowed to happen and what rural landowners and stakeholders thought that they were getting into was the scale and financial ownership of the project. Local communities did not expect that wind would develop to such a large industrial scale. They were expecting smaller, community-based renewable energy systems (W.B.13). In the interview with the former Minister of Energy who presented the GEA, he acknowledged this situation:

"When we were crafting the policy we did not properly anticipate the ease with which developers would attract capital. We rather expected the model, which we saw and liked so much in Denmark where local projects typically had hundreds of local investors, was going to be the model. We expected that developers were going to have to be more community integrated in order to raise local financial capital. I criticize my own efforts and look at the Green Energy Act and say, oh this worked and this didn't, that's one of the things that I think in our construct didn't emerge the way we had expected."

\section{Environmental Review Tribunal}

The completion period (reaching commercial operation) of the projects usually exceeded the original planned start date. All five projects were appealed by opposition groups (or individuals) through Ontario's Environmental Review Tribunal. As mentioned in section 
2.5.2, the ERT holds public hearings on appeals arising from the issuance of Renewable

Energy Approvals under the Environmental Protection Act. As this proponent believes:

A.J.21: "So Ontario has one of the most robust oversights at the provincial level and they allow municipalities, citizens, individuals to appeal the permitting process, they provide access to it and its an option, it's an ongoing process."

However, as described in section 3.4.2, all the appeals for the five projects were dismissed because the Tribunal found that the appellants and the presenters had not established that engaging in the projects in accordance with the REA would cause serious and irreversible harm to human health, plant life, animal life, and the natural environment. As these participants describe:

V.M.6: “...we've exhausted the Environmental Review Tribunal process and every project gets endorsed except one ${ }^{2}$ and we're now moving in to the courts, and that's really expensive."

Similarly,

G.V.6: "There's almost no public participation, it's really just in name only. So following that the next step is people can appeal the approval process but to date only one appeal has ever been successful, that's where we are."

After reviewing the ERT decision for all five projects, it is important to highlight: (1) The Tribunal made findings on the Environmental Test on a case-by-case basis and a circumstance that may be judged to cause serious and irreversible harm in one case will

\footnotetext{
2 Ostrander Wind Project: in December 2012, the MOECC issued a REA, authorizing Ostrander Point GP Inc. (Ostrander) to construct and operate nine wind turbines on a site in Prince Edward County. In July 2013, the ERT revoked Ostrander's REA. The ERT's decision was based on the opinion that the project would cause serious and irreversible harm to the Blanding's turtle, an endangered species, which had been identified in the area. All other grounds of appeal (i.e. impacts to human health, to other animals and plant species) by the Prince Edward County Field Naturalists (PECFN) and the Alliance to Protect Prince Edward County (APPEC) were dismissed by the ERT. The ERT's decision was significant because it was the first appeal in Ontario in which a REA was revoked. The developer took the case to the Divisional Court. In February 2014, The Divisional Court overturned the ERT's decision and reinstated the REA (this was also significant since the Divisional Court generally defers to the ERT as an expert in environmental matters and will not overturn ERT decisions lightly). PECFN appealed the Divisional Court's decision and in April 2015, the Ontario Court of Appeal overturned the Divisional Court's decision and sends the dispute back to the ERT. As a result, although the REA has now gone through three levels of judicial consideration, the status of the REA issued by the MOECC remains unresolved.
} 
not be assumed to cause serious and irreversible harm in another, where project or other elements, such as location, may differ; (2) Furthermore, the Tribunal must find that harm, if found, will be both "serious" and "irreversible"; (3) the appellant should provide a solid evidentiary foundation to establish that engaging in the specific project will cause "serious" and "irreversible" harm. For this purpose, the appellant should have either extensive knowledge and go through hundreds of pages of documents and studies or hire an expert that will require a commitment of extensive time and financial resources. As one of the participants explained:

Z.C.10: "It's very very upsetting. We have no say, it seems like our democratic rights have been taken away from us. We spend a lot of money trying to appeal these projects, we are wives, husbands, grandmas, grandpas, many of us work full time, we have young children. This is not our full time job trying to appeal this; we do this after hours, on weekends. It's very stressful and time consuming so it's really important that the proper consultation is done early on before there is any sort of investigation on which landowners my be interested."

The terms "serious" and "irreversible" are subjective and open to interpretation. Further definition is required to clarify which damages could be categorized as serious vs. nonserious or reversible vs. irreversible. This raises the questions: (1) Will the case be dismissed by the ERT if a reversible damage occurs? (2) What if there is potential harm to the environment or human health? Moreover, these terms would make the section threshold so high as to render it meaningless. Based on this concern in the Summerhaven project (by NextEra), the appellant challenged the ERT. It was the first case in which the Tribunal was required to directly address section 145.2.1 (2)(b) EPA: serious and irreversible harm (vs. potential harm). The Tribunal did not find it necessary to conduct a detailed analysis of the phrase in section 145.2.1(2)(b) in order to dispose of the case since the Tribunal believed that the evidence mentioned by the appellant predominantly raised 
questions and expressions of concern regarding the potential for harm, as opposed to evidence that harm would occur.

\subsection{4: Comparative Analysis}

The study of these five projects suggests that public participation in the respective wind project developments was limited to varying degrees to the "inform", "consult", but rarely "involve" areas of the participation ladder, depending on the decision-making issues and the size of the project. If the local input resulted in any changes to the proposal of a project, it was considered as a shift to a higher rung. Table 7 presents a comparison between the selected projects.

In the Summerhaven project, the developer set up a teleconference and ran a virtual workshop to answer public questions and concerns. In December 2012, the public advised the developer that a newly-built eagle's nest was in a tree that was scheduled to be removed due to the tree's location immediately adjacent to a proposed wind turbine. After consultation and approval from the Ontario Ministry of Natural Resources, the tree and nest were removed in early January 2013 and a team of experts were employed to install five eagle nesting platforms adjacent to the project along the Lake Erie shoreline. Subsequent observations indicate the eagles have been inhabiting these new nests. In this project, the developer worked with the public to ensure that their concerns about the need for newly-built eagle nests were directly reflected in the developed alternatives and illustrates how the provided feedback and public input influenced the project:

E.L.40: "For example there is an issue with the project where a developer received a permit to remove an eagles' nest. It was a controversial project to start with and it was upsetting to a group that eagle's nest was removed. There were a lot of reasons for doing it but people still were very upset about it. What they did was - yes we will 
remove this eagles' nest but we will construct it at eagle's platform elsewhere that the eagles might use the nest on and eagle actually went to that platform and build this nest. So it's really cool and I think they even have the little camera that they can see inside the nest. So, that's one thing you find out what people are really upset about and gives you the opportunity to address it."

Although the public participation process in Ontario wind projects is typically limited to providing notifications and informing and consulting with the public in order to meet the requirements of the REA process, it is fair to recognize that in some cases the developers are proactive by going beyond the legal requirements and holding more than two public meetings. They also attended a number of community events to share information about the project, keep people informed of the progress, and answer community members' questions about the renewable energy approval process. For example, in the case of the Ernestown Wind Park, the proponents first developed a relationship with the local community then talked about the project. Ernestown Wind Park is widely known as "the right sized wind park, in the right place". As the president of the developing company stated, they tried to plant a seed based on the lessons learned from their previous projects:

K.A.9: "In Kingston [Ernestown project], I have to hand it to my VP, she was thinking ahead, part of it was luck, found the right person and people who were local who wanted to work with us and she had to stick to it for a few years because nothing was happening but eventually slowly it was a garden that came back, so it's important. She says to me, we're going to a meeting; don't talk about the wind project. Ask them about their kids, whatever, we're just here to say hi."

It took a long time for the seed to grow for such a small project, but it was a fruitful tree. The following strategies combined to build trust and a relationship with the community which made it easier for the developer to implement the next project in the same area (a solar project). As this participant describes the time spent upfront led to using fewer resources to win the community over in the end:

R.S.22: “...so when our project was listed on the Environmental Registry, after a two 
months commenting period, we were told they had never seen a wind project with so few negative remarks ever. So that immediately made that process easier, it made it easier for the environmental registry in terms of collating all our information. It uses fewer resources on that end."

There were several strategies adopted by the developer to achieve success which have been extracted from the interviews and verified by publicly available web-based documents: (1) at the very beginning, the developer's representatives walked up and down several miles of country road, went door to door and talked to people (R.S.2); (2) in addition to the public open houses, the developer arranged coffee meetings in a local restaurant in the host community. The developer invited all neighbors in the vicinity to talk about the project in a more intimate, less intimidating venue than a public meeting. In this case, more people in support of the project attended and participated in this type of meeting because it was a more relaxed atmosphere than public meetings which could become contentious (R.S.3); (3) having the support of the council by consulting with them from the beginning of the project (K.A.2); (4) aggregating questions and answering them in the next project newsletter (published by the developer) instead of ignoring them (R.S.7); (5) starting small with a strategic choice of the site location which was quite far away from the residential area (R.S.6); (6) conducting stakeholder analysis before rushing into the community, then deciding how and when the developer team should move forward (R.S.23); (7) finally, the presence of a facilitator from the local community who entered the community with credibility, was familiar with the area, and was available to the community (R.S.14). As a result of the efforts made to positively foster community engagement, Ernestown Wind Park Inc. was awarded the 2012 SWITCH $^{3}$ Rural Initiatives Award. The

\footnotetext{
${ }^{3}$ SWITCH is a Kingston based not-for-profit organization founded in 2002 to provide support to the sustainable energy sector. The annual SWITCH Awards celebrate the best in the Southeastern Ontario region
} 
project won the award on the basis of addressing the needs and challenges of rural communities and strategic facility siting (effective land use in balance with natural resources) in the pursuit of sustainable energy goals. Therefore, it is all about transparency and building trust and relationships with the community. In this case, the developer did not assume that social license was granted merely because of the Green Energy and Green Economy Act. The developer of Ernestown Wind Park made concerted efforts to earn the social license. As emphasized by this participant:

A.J.13: "So it's just a matter of relationship building and gaining trust and I think the bigger lesson is you can't assume social license. You have to earn it and there's ways that have maybe been more successful than others but certainly having that local or permanent point of contact is important.... We can always go back on lessons learned and some of the positive ones are around how you can't assume social license, you need to earn it. So social acceptance of the wind projects come from relationship building and there are better ways to do that than others [current strategies]..."

If a developer has irritated communities all across the province, it is difficult to roll those perceptions back with the goal of achieving sustainable energy goals. It is a huge miscalculation to assume that they can walk into a process that they know is confrontational, do the bare minimum, and expect all will go well with the community. Everything the developers do affects renewable energy and its acceptance. Hence, the developers have to be careful about what they do and recognize that there is a larger goal; a larger mandate that goes beyond their own particular project.

In another project (the GRW project), from the Haldimand case, the developer entered into shared ownership with the First Nation community. Six Nations of the Grand River is comprised of the Mohawk, Seneca, Oneida, Cayuga, Onondaga, and Tuscarora nations,

in the categories of Sustainable Energy Innovation, Community Leadership, Rural Initiatives, Urban Initiatives, and Energy Conservation (http://www.switchontario.ca). 
representing the largest population of all First Nations in Canada. For the first time in Ontario, Samsung has entered into an equity partnership with the Six Nations of the Grand River who will own $10 \%$ of the GRW project, which will yield an expected gross investment revenue of $\$ 38$ million over 20 years (Holburn, 2015). This deal was reached after two years of negotiations between Samsung and the Six Nations. This was a breakthrough due to past incidents, for example, a land dispute by Mohawk Six Nations near Caledonia over a housing development which Mohawk warriors claimed is located on their land. The dispute led to the occupation of the housing development in Brantford and Caledonia. In May 2012, the Progressive Conservatives raised concerns about building a huge wind and solar farm near Caledonia. They believed adding one of the world's largest wind and solar facilities in this area could be problematic. However, Samsung managed to reach this historic agreement which is admired by many actors in the industry:

P.W.25,35: "...what they [Samsung] have done down at Six Nations, working with Six Nations which was complicated...only Koreans with respect and patience could have pulled off down there. The Koreans came to town expecting there to be a government lawyer who could answer those questions for them. They've answered those questions for the government. What they did in Six Nations, the government could not have done."

According to the Project Description Report by Stantec, there are 77 wind turbines in the Niagara Region Wind Farm, each with a capacity ranging from 2.3 to 3.0 MW. To reach the contract capacity of 230MW, the selected turbines are the ENERCON E82 (height: 135m; blade length: 38.8m) and E101 models (height: $124 \mathrm{~m}$; blade length: $48.6 \mathrm{~m}$ ). Both wind turbine models have been assessed with two hub height options: $124 \mathrm{~m}$ and $135 \mathrm{~m}$, which make them among the tallest turbines in the world. The E101 turbine has higher sound emissions and a larger blade length than the E82. The construction of wind turbines in the neighbourhood of the Gainsborough School has raised concerns from parents of students at 
the school (one school has 11 turbines surrounding it at distances of 1200 to $3000 \mathrm{~m}$ away). They are worried about the proximity of turbines being planned by Niagara Region Wind Corp. in the vicinity of the school. Due to the size of the turbines, they believe a larger distance between turbines is required to reduce noise, reduce low frequency emissions, reduce vibration, and reduce turbulence between turbines. As previously mentioned, the Ontario ERT has dismissed the appeal by Mothers Against Wind Turbines, which was brought forward on the basis of noise concerns and serious damage to human health. Therefore, there was no change in the turbines' location. This project is still under development and the proponents are moving forward. However, the ERT decision might be appealed by Mothers Against Wind Turbines; in this case, a long delay in development of the project is expected.

Also, in the PDNW project, the ERT dismissed the appeal because there was not enough evidence on the cumulative impact of wind turbine projects on tundra swans in the area. However, based on the ERT recommendation for pre- and post-construction data collection, especially during the migration time of the tundra swan, Capital Power conducted a supplementary survey to address the local community concerns. The results of this study were consistent with the primary Natural Heritage Assessment results and confirm that tundra swans roost offshore in Lake Erie and forage in agricultural fields. The monitoring shows that no swans were observed resting within the project location or within $120 \mathrm{~m}$ of project components (Stantec, 2013). 
Table 7: Comparative snapshot of third party involvement and level of public participation

\begin{tabular}{|c|c|c|c|c|c|c|c|c|c|c|c|c|}
\hline \multirow{2}{*}{\multicolumn{2}{|c|}{ Case }} & \multirow{3}{*}{$\begin{array}{c}\begin{array}{c}\text { Capacity } \\
\text { (MW) }\end{array} \\
124.4\end{array}$} & \multirow{3}{*}{$\begin{array}{c}\begin{array}{c}\text { Significant } \\
\text { feature }\end{array} \\
\begin{array}{c}\text { Eagle nest } \\
\text { dispute }\end{array}\end{array}$} & \multirow{3}{*}{$\begin{array}{c}\text { ERT } \\
\text { status } \\
\\
\text { Dismissed }\end{array}$} & \multicolumn{3}{|c|}{ Third party } & \multicolumn{5}{|c|}{$\begin{array}{c}\text { Participation } \\
\text { level }\end{array}$} \\
\hline & & & & & 䒕 & 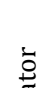 & ه্ & & \pm & 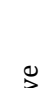 & $\stackrel{\tilde{O}}{\tilde{d}}$ & $\overrightarrow{\mathrm{\varpi}}$ \\
\hline \multirow{4}{*}{ 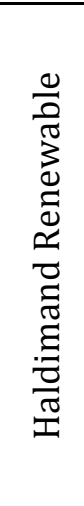 } & $\begin{array}{c}\text { Summer- } \\
\text { haven }\end{array}$ & & & & $\checkmark$ & $\checkmark$ & - & $\checkmark$ & $\checkmark$ & - & - & - \\
\hline & PDNW & 105 & $\begin{array}{c}\text { Tundra swan } \\
\text { monitoring }\end{array}$ & Dismissed & $\checkmark$ & $\checkmark$ & - & $\checkmark$ & $\checkmark$ & - & - & - \\
\hline & GRW & 150 & $\begin{array}{c}\text { Financial } \\
\text { partnership } \\
\text { with Six First } \\
\text { Nations } \\
\end{array}$ & Dismissed & $\checkmark$ & $\checkmark$ & - & $\checkmark$ & $\checkmark$ & $\checkmark$ & - & - \\
\hline & NRWF & 230 & $\begin{array}{l}\text { Large wind } \\
\text { turbines near } \\
\text { schools }\end{array}$ & Dismissed & $\checkmark$ & $\checkmark$ & - & $\checkmark$ & $\checkmark$ & - & - & - \\
\hline \multicolumn{2}{|c|}{$\begin{array}{c}\text { Ernestown Wind } \\
\text { Park }\end{array}$} & 10 & $\begin{array}{c}\text { Early } \\
\text { involvement; } \\
\text { hiring } \\
\text { facilitator } \\
\text { from the } \\
\text { community }\end{array}$ & Dismissed & $\checkmark$ & $\checkmark$ & - & $\checkmark$ & $\checkmark$ & - & - & - \\
\hline
\end{tabular}

\subsubsection{Summary of Existing Participation Levels}

As discussed in the previous sections, there are (at least) two sides in every wind dispute or conflict and multiple actors involved in every project development. Public responses are not developed in a vacuum or in the abstract, but rather in interaction with others who have an interest in a development, especially with those who are advocating and promoting it. As such, the views of the local community may emerge and shift in relation to a variety of contextual factors. In this sense, NIMBY might be a byproduct of what proponents are doing and saying and how decision-making processes are designed and enacted. Figure 22 summarizes the interaction between local communities and developers (proponents). There are different elements in Figure 22 which were extracted from interviews and 
documents including: local community or public actors; proponent's network (the developers as prominent actors); interactions between proponents and opponents; local community and developers' expectations; participatory strategies or reactions by the local community; the developers' engagement strategies, usually in fulfilling legal mandates; finally, local and provincial policy context.

Local community or public actors are situated in a particular spatial and cultural context, comprising specific locations and communities which are the focus of a wind project development proposal. The proponents are a broad category of people organized with specific roles used to support or implement a wind project including developers, consultants, facilitators, and public relation companies. These actors are operating in a network in which information and expertise is exchanged, sometimes in competition with each other, sometimes in each actor's mutual interest. CanWEA is a well-known example of a proponents' network, namely, the national industry association made up of members across the wind sector: manufacturers, developers, environmental consultants, legal, and finance consultants. The wind industry is a relatively small community in Ontario, evidenced by names repeatedly appearing on documents as reviewers or approval officials, and the same faces can be seen in public meetings, and usually the same consultant company works on multiple wind projects in Ontario. It is important to note that the public actors and the local community can also have networks that extend beyond specific places and communities. For example, Wind Concerns Ontario and Ontario Wind Resistance who make strategic connections between local groups in different places.

As shown in Figure 22, in between these two categories of actors, there is nexus: a space between the proponents (mainly developers) and public actors (mainly local community) 
where communication and the exchange of information takes place. In the current situation, the developers provide information about the project and the public reacts to such information, usually by expressing their concerns. Sometimes this opinion exchange can become confrontational. Examples of these interactions include developers' open houses, public notices, websites, protest activities, and petitions. There are also within group interactions, for instance a local community could get information from the Internet, family, friends, and media. Misinformation could occur in the absence of an efficient information provision system. There are the other opportunities for interaction within that nexus, rather than in structured, traditional, and to some degree, through familiar routines usually traversed to fulfill the legal mandates. These opportunities are provided through creative engagement strategies which occur depending upon each project. As discussed in section 4.1.4, from one case to another, variation in interactions is expected.

The interviews revealed that the "interactions" are potentially significant in shaping the "expectations" of the local community and the "future strategies" deployed by the developers. In a circular flow, these interactions affect how the dynamics of local responses evolve and how different actors react and strategically behave in relation to each other in both the short and long-term. As the local community learns about project proposals, sees media reports, attends open houses, hears about developers, and so on, their expectations may change. Sometimes, a more engaging decision-making process shifts the public expectations of the project and/or process. This may lead to limiting engagement actions by the developers in their future projects. Sometimes, there are expectations, which are more or less developed a priori and connected to a specific developer within a local, regional, or national profile, be it positive or negative. As clarified by this participant (the 
name and location of the company has been redacted):

R.S.13: "You know .... did a big project down here before, and they pissed everybody off. They upset everybody from people, community members, community groups, council, township administration, they were a nightmare and if you look at the structure of their organization, there was nobody on the ground here who was dedicated. The first person who had a community relations role didn't last long, he was out of ... The second one was very hard to get hold of and they were all working out of Toronto so there was nobody here but it was also, you know this is a very global company who does things with a very autocratic way. So community engagement, that you have to do in a real community just wasn't there as a regular way of doing business at all."

Sometimes local community expectations revolve around how they feel they should be communicated to and how the information should flow (i.e. providing meaningful information though two-way transparent communication at the early stages of the project). Finally, local community expectations might focus on distribution of benefits from a development and what a community hosting a wind project should get out of it. By some participants, this is called "economic jealousy". There are landowners adjacent to the wind turbines who have to look at the turbines every day for which they derive no financial benefit, as they do not hold the lease on them:

C.0.3: "I think that the major problem with a lot of the developments that I've seen has been that one neighbour will get great monetary benefit, anything from $\$ 15,000$ a year to $\$ 50,000$ a year to host a wind turbine, where their neighbour who could potentially be closer to the actual turbine and have more visual effect of that every day is getting nothing. So there's a lot of anger between neighbours and there's a lot of resentment that somebody has to deal with these things but is getting absolutely no benefit from it, whereas their neighbour is getting a huge amount of revenue per year from it."

It seems that Quebec has figured out a way to overcome this problem:

K.A.13: "Now in Quebec they have a system, Hydro Quebec says here is a suggestive lease, you don't have to use it but if you do in our point system you get extra points so everybody uses it, and in it is the concept that you draw a circle around the area including where the turbines are and where they aren't, and you take about half a percent and distribute it to everybody, share it. So most of the rent goes to the people who have the turbine, but their neighbours get something. Not as much but 
they get something to get them over the jealousy."

However, the concept of economic jealousy ignores the issue of fairness in terms of distribution of benefits and burdens of the project. A number of participants described that this situation - where some members of a community receive direct benefits from leases damages relationships and divides communities:

P.R.5: “...It's been very divisive, we have an area on Amherst Island where there's a proposal for a very significant development, 38 turbines and essentially it divided the island into two. There are people who don't talk to each other because they are on one side or the other of the argument. So typically it divides between people who have the leases signed and those who don't..."

The interactions also impact developer strategies on how to operate within these emotionally-charged situations and best engage a public divided into factions. Again in a circular flow, the developers' decisions about future engagement strategies are, in part, shaped by "interactions". The other influencing factors on engagement strategies are drawn from experience across multiple projects and hearing from the other developers' experience in different locations. For example, in their Thunder Bay project, Horizon Legacy deployed the same approach as Ernestown Wind Park. However, being in a different community with different expectations, the project faced significant opposition and delays; therefore, Ontario Power Authority ${ }^{4}$ terminated the contract with the developer. The Big Thunder Wind Park project was significantly delayed due to the legal challenge launched by the Fort William First Nation. The reason was that the Fort William First Nation tribe declared the developer had failed to meet its obligations to consult with

4 On January 1, 2015, the Ontario Power Authority (OPA) merged with the Independent Electricity System Operator (IESO) to create a new organization that combines the OPA and IESO mandates. The new organization carried the name Independent Electricity System Operator. The OPA was an organization created to plan the electricity system for the long term and contracts for clean electricity resources. The IESO was balancing demand for electricity against available supply through the wholesale market and directing the flow of electricity across the transmission system $\left(\mathrm{IESO}_{\mathrm{d}}, 2014\right)$. 
the First Nation as part of the REA application process. It is important to highlight that Aboriginal consultation takes place in a separate process than community consultation and that it has its own complexities. This is where most participants from the proponent category state that they expect more involvement of the provincial government in the decision-making process to resolve these types of conflicts. The Aboriginal consultation is beyond the boundaries of this research; therefore, this research has deliberately left out an analysis on the similarities and differences of the Aboriginal consultation vs. the local community consultation process.

Interactions not only affect the engagement strategies chosen by the developer, they also shape future moves. Engagement actions may be limited as the researcher found some developers chose not to become actively engaged with the local community, while for others, engagement actions were extensive. In some cases, assessment of public resistance was also found to impact the locational strategies and the developers' decision of where to situate their projects. Developers have been found to be considering moving into other renewables and/or moving to other provinces for wind energy development.

Finally, the local and provincial policy contexts are also important in determining drivers of project development; providing funding support for project development; shaping engagement strategies; and shaping local community participatory strategies or reactions. The provincial government is the owner of the REA process and provides approval and funding, whereas there is a limited input from municipalities in the REA process. However, the Climate Action Statement (signed in Ontario in July 2015) places emphasis on the leading role of both provincial and municipal governments in reducing greenhouse gas emissions; it is stated that the provincial and municipal governments need 
to work together to combat climate change and create new economic opportunities in renewable energy and clean technologies.

The nature of communities can be significant in the local policy context, shaping expectations, and forming reactions when considering socio-demographics, level of prosperity, mix of long-established and more recent incoming residents, mix of permanent residents and those who own a cottage (therefore, do not live in the area all year around), and the level of social capital. For instance, in the case of the Haldimand Renewable Energy Project, the local historical context manifested itself as a kind of ambivalence. On the one hand, the long association of the area with coal-fired power plants was linked to recognition of the reliance of the community on the jobs the wind project would provide and the extra income to land owners from leasing their property to developers. On the other hand, residents (those who opposed the project by taking their concerns to the Ontario ERT) showed little confidence that the developers would be willing or able to exercise their duty of care regarding health and ecological concerns.

In some cases, people move from big cities to the rural areas and buy their dream retirement piece of the county for a quaint rural view and its peace and quietness (B.0.1). They want to be away from the hustle and bustle and the last thing these residents want is an industrial wind facility near their property. These are typically well-educated residents, and they have time and money to fight wind development in their backyards (F.M.6, K.A.2):

R.S.7: "The people didn't want change and a lot of people out there have gone to the country because they found the city too much for them. Not because they wanted to be in the country but because they were overwhelmed and needed for health reasons to be outside the city and they saw that being threatened and it really worried them." 


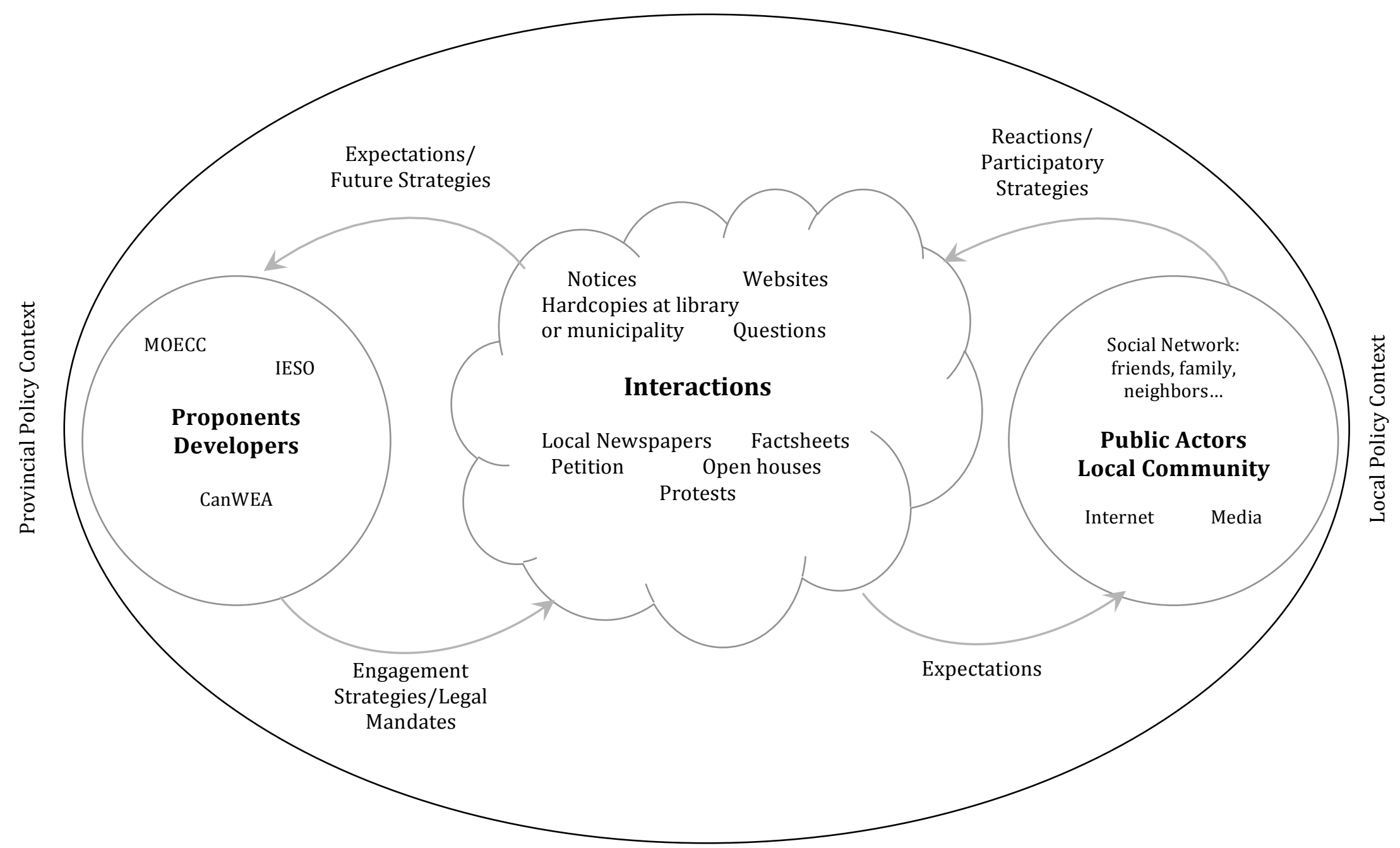

Figure 22: A summary of interactions between local community and developers 
On the other hand, the absentee landowner or cottager might be more open to having wind turbines on their land (B.0.5). Also, there are the groups who have been there longer, typically farmers with large tracts of agricultural land where wind turbines do not negatively impact growing crops or property value. They earn a living from the land and have grown crops on it; they see wind turbines as another option for producing income from the land they own (P.R.5).

These case studies have shown significantly apparent degrees of local activity, anticipation of negative impacts, and multidimensional interactions. Figure 22 demonstrates the complexity of the decision-making process with regards to a wind project. In the next section, the main themes directly related to sub-research questions and the updated conceptual framework are discussed. It is an attempt to show how the recommended framework would provide a better way of public engagement, from NIMBY to collaboration.

\subsection{Themes Related to the Sub-Questions}

In order to answer the two research sub-questions ("What are the major social conflicts of wind power development?" and "What is the role of a knowledge-broker in resolving these conflicts?"), the data was examined through the lens of the recommended conceptual framework. Before letting the data form the codes and suggest main themes, interview transcriptions were coded to organize data into targeted categories based on units of analysis and the main elements of the conceptual framework. This section presents the results of this analysis. 


\subsubsection{Collaborate}

Knowledge-Broker: Collaborative Problem-Solving

In response to the question: "How important is public engagement and securing public support for wind project development?" all respondents placed emphasis on the importance of public support for the following reasons: first, pragmatically, they believe public engagement and support can be used to increase the likelihood of successful siting. There is a requirement in the REA and LRP that the local community should be informed about the projects and that decisions should be discussed with local communities. As mentioned in section 4.1.2, in the new LRP process there is a point system for community engagement that will facilitate securing the approval of the project for the developers. Moreover, developers do not want to go to a community which is not a willing host of their project. As lack of support will make it difficult to work in that community and get the permissions or agreements on road use, entry permits, building permits etc., public support is important when the developers get into details like construction logistics. When local community and the municipalities are consulted, they are less likely to oppose (and may even support) decisions and set up roadblocks to the implementation of the project (K.A.11, F.M.20, P.R.4).

Second, the public may be engaged because in a democratic society they are deemed to have a right to participate in decisions that affect them. According to the Institute of Public Policy Research (IPPR, 2007), public engagement with energy issues is beneficial as it empowers people to help resolve problems, improve governance, deepen democracy, and build trust. The interviews reveal that trust and building a relationship (section 4.2.2) in the decision-making process about wind energy is important for addressing health and 
ecological concerns. Apparently, perceived fairness of the process and outcome are vital for encouraging meaningful engagement and acceptance. People should have the opportunity to speak and be heard:

J.F.6: "This is supposed to be a democratic country. We're supposed to have a say in the governance"

Similarly:

G.V.4,13: "Green Energy Act completely removed the democratic rights of the people of Ontario to say anything through their communities. The Green Energy Act not only laid out this regulatory regime that's very favourable to the wind industry, it also superseded 21 pieces of legislation in Ontario, that's 21 pieces of democratically developed legislation that are now not null and void, but powerless, the Green Energy Act supersedes them and that includes the Heritage Act of Ontario, the Clean Water Act, the Oak Ridges Moraine Conservation Act, the Niagara Escarpment Protection Act. The Green Energy Act supersedes all of those. Those were democratically passed pieces of legislation that now the people of Ontario cannot use to protect their communities."

Third, public engagement may lead to better or more competent decisions by the developers through taking advantage of local knowledge. It is an opportunity to receive feedback, identify issues, and thereby attempt to address those as best possible.

The aforementioned reasons resonate with the broader culture of collaborative forms of decision-making. The more people provide input, the more ownership they take or the more involved they feel in the process and as a result become more accepting of wind projects. Sometimes difficult choices have to be made regarding wind project development, but it is better to have them made with an informed and accepting public rather than by politicians at Queens' Park on their behalf. When people are involved in the decisionmaking process they learn about what can and cannot be addressed by developers and they may be more willing to acknowledge and agree on something that is the best case scenario for the public interest. Therefore, there is a need for a new way of conceptualizing public 
participation in the decision-making processes. An approach based on public participation rather than public consultation, recognizing and including all interests, and a shift from competitive interest bargaining to collaborative consensus building is required. Examples of this kind of approach include citizen juries, interactive panels, workshops, and conferences where issues are broadly considered and recommendations for decisionmakers are discussed with the presence of a knowledgeable and independent third party who facilitates the discussions.

The main concept in the proposed conceptual framework is the presence of the trusted third party, or knowledge-broker, in the decision-making process. Only one participant believed the knowledge-broker could not help improve the current decision-making process. This interviewee stated that there is a fundamental issue in wind project development which needs to be addressed:

J.F.11: "It's not a question of how you get people to buy into it or accept it, or how you make the process any more equitable or fair. The problem is a complete break down of the democratic process in the province of Ontario. That's what the problem is and you can't get to that until you have some hard factual research being done and on the table honestly and transparently and you have to understand it's not a question hiring of somebody [expert] in public relations who can put a good spin on something and who can make the public think that it's good for them."

The rest of the participants concurred that collaborative decision-making with honest and transparent communication transmitted through a knowledge-broker could be an effective two-way communication approach. However, they mentioned some challenges for that role which need to be considered and dealt with (see Table 8). 
Table 8: Participants' comments on the notion of a knowledge-broker

\begin{tabular}{|c|c|c|}
\hline Advantages & Challenges & Conditions \\
\hline $\begin{array}{l}\text { Providing factual/accurate/meaningful } \\
\text { information: plain language, finding } \\
\text { creative ways for information distribution } \\
\text { (M.A.12, G.V.15, E.L.37, J.L.22) }\end{array}$ & \multirow{3}{*}{$\begin{array}{l}\text { Filling the ideological gap: } \\
\text { dealing with the opposition } \\
\text { group who are not willing } \\
\text { to change their minds } \\
\text { (V.F.29, D.B.20) }\end{array}$} & \multirow{3}{*}{$\begin{array}{l}\text { Some sort of linkage } \\
\text { to local municipality: } \\
\text { should be hired by } \\
\text { municipality or the } \\
\text { community (D.S.16, } \\
\text { P.R.12, V.F.29) }\end{array}$} \\
\hline $\begin{array}{l}\text { Answering questions or directing people } \\
\text { to the right experts (E.L.17, C.O.15, R.S.17) }\end{array}$ & & \\
\hline $\begin{array}{l}\text { Giving feedback and how the question or } \\
\text { concern affects the project (G.V.15, R.N.8) }\end{array}$ & & \\
\hline $\begin{array}{l}\text { Diffusing the tension by listening to the } \\
\text { concerns (M.A.12, E.L.17, V.M.17) }\end{array}$ & \multirow{4}{*}{$\begin{array}{l}\text { Only if the knowledge- } \\
\text { broker could give a fair } \\
\text { shake to the project, the } \\
\text { developer will pay for such } \\
\text { a role as part of the } \\
\text { consultation process } \\
\text { (F.M.12) }\end{array}$} & \multirow{4}{*}{$\begin{array}{l}\text { A trusted third party } \\
\text { could only work in an } \\
\text { environment where } \\
\text { laws are being } \\
\text { enforced by the } \\
\text { provincial } \\
\text { government (B.0.26) }\end{array}$} \\
\hline Explaining community rights (M.A.12) & & \\
\hline $\begin{array}{l}\text { Go-between or lobbyist between } \\
\text { developers and governmental agencies } \\
\text { (K.A.21) }\end{array}$ & & \\
\hline $\begin{array}{l}\text { An independent third party explaining } \\
\text { about health myths of wind turbines } \\
\text { (K.A.22; P.R.10) }\end{array}$ & & \\
\hline $\begin{array}{l}\text { Educating people about renewable energy } \\
\text { (C.0.14) }\end{array}$ & \multirow{5}{*}{$\begin{array}{l}\text { Marketing this person to } \\
\text { the community: trust issue } \\
\text { (K.A.23, D.S.15, P.R.12, } \\
\text { V.M.17) }\end{array}$} & \multirow{5}{*}{$\begin{array}{l}\text { Should be a team of } \\
\text { experts (J.L.21) }\end{array}$} \\
\hline $\begin{array}{l}\text { Uncovering the motives (teasing out real } \\
\text { concerns) behind the opposition (K.A.28, } \\
\text { E.L.47) }\end{array}$ & & \\
\hline Alleviating those concerns (E.L.37) & & \\
\hline Gaining social license (A.J.12) & & \\
\hline $\begin{array}{l}\text { Available local resource: permanent point } \\
\text { of contact for the community (R.N.8, } \\
\text { C.0.15, R.S.17) }\end{array}$ & & \\
\hline $\begin{array}{l}\text { Relationship building and gaining trust } \\
\text { (R.N.8) }\end{array}$ & \multirow{4}{*}{$\begin{array}{l}\text { Who chooses this person? } \\
\text { And who pays for this } \\
\text { position? (Z.C.17) }\end{array}$} & \multirow{4}{*}{$\begin{array}{l}\text { Should be affiliated } \\
\text { with the developer } \\
\text { (S.E.32) }\end{array}$} \\
\hline $\begin{array}{l}\text { Helping facilitate negotiations (P.W.35, } \\
\text { Z.C.17) }\end{array}$ & & \\
\hline $\begin{array}{l}\text { Encouraging the silent majority to come } \\
\text { forward (E.L.44, P.R.9) }\end{array}$ & & \\
\hline $\begin{array}{l}\text { Effective communication: taking technical } \\
\text { information and translating it into } \\
\text { something that both the developer and the } \\
\text { public can understand. And, also trying to } \\
\text { take ministry guidelines and communicate } \\
\text { them (N.B.18) }\end{array}$ & & \\
\hline
\end{tabular}


The proposal put forward in this research is that participation in approving wind energy projects in Ontario should be collaborative and in this framework, the inclusion of a knowledge-broker assures that learning takes place, that radical tensions are defused, and conflicts are resolved through effective communication and the provision of meaningful information. The adoption of the proposed framework and the presence of a knowledgebroker may help reduce the completion period by providing for a smooth flow of information, effective communication, and decreased public opposition. In turn, this minimizes the possibility of going through the Environmental Review Tribunal process that may result in delays in implementing a project. Due to the importance of this topic, participants' responses and comments about the knowledge-broker are summarized in Table 8.

From the analysis of the interviews, it is evident that the advantages of the role of the knowledge-broker outweigh the challenges. There are always some people in the community who want to know more about the project. They want to have conversations with the proponent about the concerns; this is where the knowledge-broker can help them to come together and have an honest discussion of what can be done to clarify expectations and what the reasonable outcome could be. This participant describes how a knowledgebroker can help the decision-making process:

E.L.37: "So, what I think is it would be very helpful to have this particular person is getting to the core of, getting to roots of people's concerns. So, if you have got someone who understand the project, I don't know if they technically need to understand all the technical aspects of project. You need to understand what studies are done. You need to understand how project works. You need to know a little bit about everything. You got somebody who is so upset, and usually there is an issue, and the issue is clouded with all of this anger and hurt and sadness, so it helps to have somebody who understands how to listen to them and how to tease out that concern. Because once you can tease out that concern, you can say, 'I have got someone to talk to you about that'. Like having noise expert, you can sit down and 
talk about your concerns for noise and then it kind of helps if you have somebody trained with facilitation and communication who can talk to them but also has an understanding of project so that they know what part of the project this person is upset about. I think it would be very helpful for other reasons we talked about in the beginning. You can start to alleviate concerns people have and be happier with the end results. You can get more information from the public to help make it a better project. I really like your idea of a knowledge-broker. I think it's really cool and that could go far with how we have conversations with people in the future. It sort of seems like an expanded role from the traditional facilitator that would be at the public meetings. So I think it could really help to root people's issues and then explain to developer what that concern is and bringing people that can address it."

Some participants pointed out that the knowledge-broker should be the "right person", someone with expert knowledge about the wind projects, who is aware of the concerns about wind energy, is updated on current peer-reviewed studies, and is an expert in public relations:

E.L.25: "I just want to clarify consultants do a lot of different things. But I think it's really important for a consultant who does that job to be trained to do that because that's a very specific skill in order to mediate, in terms of facilitate discussion. I would say... it needs to be particular consultant who has the experience with consultation and may be they have done specific training and they know how to handle these situations. Not everybody can do that."

Also:

C.0.15: "... think if it's the right person it's a brilliant idea. It can backfire in that people can say 'you're paid by the company of course you are going to say this' so there is that definite pushback and maybe a bit of wariness that somebody could be on the company dime, but I think overall it is amazing to put somebody with a friendly face who happens to work with the company right in the community, definitely support it."

However, there are also some challenges highlighted by the participants:

G.V.15: "Well that's interesting because as we know the track record of the wind companies in giving accurate information is very poor.... independent knowledgebroker would be an interesting job to be presenting factual information as opposed to the wind developer who is presumably going to be making a lot of public money from the project. But as you mentioned if there is no facility, if there is no chance of the public comments going back through the knowledge-broker to be taken into account in any way, the knowledge-broker would quickly be seen as completely useless and the process would have no credibility." 
At the same time, there are also solutions to the challenges. Among the challenges, the following was brought up repeatedly: "Who is going to hire the knowledge-broker?" Local communities might not trust the developer's choice given the acrimonious history between them. On the other hand, the developers do not want to lose control over the decisionmaking process, as they believe they have internal resources, so why outsource them. The municipalities also want to have more input in the decision-making process. There are also expectations that the provincial government should take a more proactive role in the decision-making process. Therefore, the knowledge-broker could and probably should be hired by a committee which has representatives from all of the aforementioned stakeholder categories. As a part of consultation process, the developer should fund the process to cover the associated expenses of hiring a knowledge-broker. It will not add another step to the consultation process since CLC meetings are already in place and they could be used as the venue for selecting and hiring the knowledge-broker for a project. The regulations need to make it clear that in a CLC meeting there should be representatives from developers, the municipality, the local community, and the provincial government, namely MOECC, where assessing and selecting the knowledge-broker is a joint decision. Also, as suggested by some participants, the CLC meetings should be formed during the early stages of project development instead of after developers receive REA approval after decisions have already been made. In this way, the CLC meetings will reflect a continuation of positive interaction with the community: (1) by providing an ongoing opportunity for two-way communication and information sharing; (2) to assist in the identification and resolution of current and potential community issues related to the siting, construction, installation, use, operation, maintenance, and retirement of wind turbines. Afterwards, the 
selected knowledge-broker can facilitate the CLC meetings to accomplish his/her mission of effective communication through a collaborative decision-making process. It would be beneficial if the knowledge-broker could be hired locally to provide the connection between locals and the project. In this way, they walk into that community with some credibility (R.N.8, R.S.14).

As mentioned above, the credibility of knowledge-brokers regarding independence is largely a matter of the stakeholders' perception. To overcome this concern, an anonymous pool of funds could be created and administrated by the IESO or the Ontario Energy Board (OEB). As a part of the approval process, each developer would contribute to this pool; therefore, the source of money for compensating the knowledge-broker remains anonymous to some extent. In this way, knowledge-brokers are not directly paid by project developers and they will not feel "pressured" into supporting a line of reasoning at variance. The IESO (or OEB) could also accredit knowledge-brokers and certify them, then make available a list of certified knowledge-brokers. According to Leiss (2008) "universitybased experts are preferred as members of such an expert list, but exceptions to this rule are often made for good reasons." In the case of wind energy, technological, economic, social, and public factors must be taken into account along with an understanding of the interface between science and public policy. Therefore, under certain circumstances (depending on the size, location, and involved stakeholders), it could be more appropriate if a team of knowledge-brokers with different backgrounds work cooperatively on specific projects (sometimes under extreme time pressure) to reach a consensus among stakeholders. In order to do so, a spirit of good will and a willingness to find common ground without compromising on matters of principle must exist. 
Following Partidario and Sheate's (2013) recommendation and from information gained through conducting this research, it is believed that for a knowledge-broker to succeed a number of conditions must be met:

- Range of stakeholders: the appropriate range of stakeholders should be engaged to give them an opportunity to have a voice in decisions.

- Logistics: resources, time, and space should be created to provide a non-judgmental environment for healthy communication and collaboration.

- Learning environment: conditions need to be established to stimulate mutual learning and facilitate information and knowledge sharing to build social capital.

- Receptiveness of proponent for the creation of opportunities for power sharing.

- Willingness to use different forms of knowledge: integration of local knowledge with expert knowledge.

The role of a knowledge-broker will not be an easy task as one interview subject stated that it would be taxing to work on the same projects with the same intensity for several years. However, one mitigating factor is that the pressure is not constant throughout the life of the project. Moreover, so much of what the knowledge-brokers do is directed by policy. If there is strong regulatory governance in place, one that defines the role of all the stakeholders clearly in an inclusive decision-making process, then there will not be barriers in the way of collaboration. Besides, educating people pays off in the long-term and results in building social capital for future projects to proceed. Even in the case of existing fundamental disagreements in beliefs and values, the knowledge-broker could provide a venue for people to be heard and vent:

R.N.19: "...if you are approached by someone who is being confrontational you're 
best bet is to just be there to listen. You're not going to change this persons' mind. You provide the current accurate information that you have available and you encourage them to read, learn and see what's going on there but you are not going to change anybody's mind. So it's a stressful thing but you just have to kind of stand there and listen."

The knowledge-broker can make relevant research information available and accessible for planning and decision-making through interactive engagement with audiences. The process is supported by user-friendly materials and a communication strategy that enhances the credibility and reinforces key messages from the research. Key messages must be convincing and backed by rigorous research. Feedback and educational activities must be tailored to the needs and concerns of the stakeholders. Finally, the knowledgebroker should identify measurable performance objectives to evaluate the effectiveness of the process and develop the lessons learned for future wind projects which could be useful for other facility siting processes which encounter social conflicts.

\subsubsection{Empower}

\section{Main Concerns Impacting Implementation of Consensus-based Decision-Making}

This section contains the discourse of criticism of wind energy deployment and it combines

fierce opponents and conditional supporter's views, both of whom share concerns about wind turbines and the ability to empower stakeholders through the implementation of consensus-based decision-making. The focal point of public concern is concentrated on the impact of wind projects on the landscape, local interests that run counter to project development, and frustration over the project decision-making process. The issue of visual impact was only raised by one of the opponents:

J.F.8: "you have to understand the fact that visually they are very disconcerting, they are upsetting to many people and that causes them to be aggravated and upset and 
annoyed and even the Health Canada study in it's imperfection acknowledges the fact that when people are annoyed their health is impacted negatively."

This respondent also stressed the value of the area in terms of beauty and wildlife, not just for residents who live in the area, but for all Ontarians. Often, the difficulty of wind facility siting is that the best areas to develop a project are usually along shorelines. These areas are special and aesthetically valuable to the local community. The other opponents dismissed or downplayed the importance of the view. They were more concerned with the industrialization of the area by large turbines and large projects by big companies that have the support of the provincial government. They showed concern from a more pragmatic standpoint, largely around potential health impacts. While the opponents tended not to raise the aesthetic issue, they did demonstrate appreciation for natural beauty and the peacefulness of the area in which they live. Moreover, most opponents claimed that the viability and benefits of wind power are exaggerated. Many disputed claims that wind could play a significant role in phasing out coal-fired plans in Ontario:

C.H: "Denmark, with about 6400 wind turbines, has not closed a single coal fire plant ${ }^{5}$, and has not reduced its $\mathrm{CO}_{2}$ one gram. Germany produces more $\mathrm{CO}_{2}$, and has increased coal use 8\% recently, despite being a broad wind and solar promoter for many years. Ontario might do well to study these disastrous experiments."

This perspective, which was most apparent in interviews with opponents with the least support when compared with the other stakeholders, illustrates strong doubts about the public benefits of wind energy.

\footnotetext{
${ }^{5}$ American Aljazeera reports that renewables account for 43 percent of Denmark's electricity and nearly a third of the country's energy needs. Wind power is the main source of Denmark's renewable energy production. There are nine coal-fire power plants in Denmark. However, Energinet.dk, the Danish transmission system operator, predicts that Denmark will reduce capacity to produce only $700 \mathrm{MW}$ from coal in 2021 compared with 2,500 MW in 2014
} 


\section{Economic Concerns}

Opponents believed that the small amount of energy generated by wind cannot compensate for its negative impacts. In another words, they do not want renewables in their area at any cost. The opponents call the Green Energy and Green Economy Act an oxymoron because they believe the government failed to conduct a proper cost and benefits analysis. This issue elicited criticism regarding the need for subsidies through the FIT program to make wind power economically viable and produce large profits for the developers at the expense of ruining rural areas. As Statement $L$ shows (Appendix 3), one area of concern is the impact of wind projects on the local economy including the energy market (excess power and higher prices), property values, and tourism.

G.V.5: "We would like to see you do a cost benefit analysis or an impact analysis and the government never did that, and the government hasn't ever done that. The auditor general in 2012, Mr. McCarter at that point, said in his report that to this day no cost benefit analysis for how wind power was developed in Ontario has ever been done, that's what the municipalities wanted and they still don't have it."

Some participants expressed concerns that Ontario taxpayers are stuck with 20 years worth of subsidies contracts because the government basically paid the wind companies regardless of whether or not there was a need for their power. Excess power gets sold at a loss:

V.M.11: “... I mean it's not cost effective. There's billions of dollars in subsidizing hydro that we're sending to Quebec and States where [it] is busy using the cheap electricity to take jobs from Ontario. The whole thing is absurd so there's no economic benefit to it, in fact there's economic cost, stray voltage and its causing people health problems, and it kills birds, bats and all sorts of other things."

Also, some participants alluded to the term "energy poverty" which is caused by higher electricity rates:

D.B.8: "Some people on the perceived side, they don't like the FIT program and they see that those contracts are made for a higher per hour kilowatt charge on wind 
energy which they see as coming back to higher hydro rates themselves, so they don't like the governments approach to it saying that they don't support wind because they don't need higher energy costs."

And:

G.V.21: "...So you're seeing the cost, and this is another thing from Dr. Michael Trebelko of the University of Toronto when he talks about the economic effects of wind power, it has caused electricity rates to go up dramatically which in turn is having an effect on...consumers are seeing a term called energy poverty, we saw that in the United Kingdom and we now have that in Ontario..."

Concerns about decreasing property values and shrinking tourism were highlighted by some participants during the interviews. CanWEA's fact sheet about property value (usually distributed in public open house for all wind projects) clearly describes the result of studies showing no statistically relevant relationship between the presence of a wind project and negative effects on property values. One study conducted in 2010 in ChathamKent, Ontario by Canning Consultants Inc. According to the published report, in the study area, where wind farms were clearly visible, there was no empirical evidence to indicate that rural residential properties realized lower sale prices than similar residential properties within the same area that were outside of the view-shed of a wind turbine. A similar analysis by the US Department of Energy's Lawrence Berkeley National Laboratory shows the same results: researchers examined 7,500 single-family property sales between 1996 and 2007, covering a time span from before the wind farms were announced to after construction and operation. They found that proximity to wind energy facilities does not have a pervasive or widespread adverse effect on the value of nearby homes.

These studies demonstrate that the perception of dropping value of properties adjacent to the wind facilities is not reflected in reality. Also, there are studies which discuss the potential for the wind projects to create ecotourism (Devine-Wright, 2005). In response to 
the higher energy price criticism, one of the respondents described:

K.A.15: "In my view it's not because while we're paying, I don't know if we have had this discussion before, at home I'm paying about 7 or 8 cents a kilowatt hour. Our contracts are for about 12 to 14 cents, that 12 to 14 cents is locked in for about 20 years and so subject to a little bit of inflation indexing on 20\% of it, that's locked in for 20 years. It doesn't matter if there's a war in the Middle East, it doesn't matter if there's no oil or a lot of oil. I think as a citizen of Ontario that's a great contract to have because we have locked in the price at a reasonable price. That 8 cents that I'm paying today, if there's another war tomorrow that could jump up, or if there's no war I think in five or six years that price will be through 11 cents."

The above argument suggests that the narrative around economic concerns propagated by wind project opponents can be challenged. However, there is need for a deeper discussion to address this legitimate concern by the public. Presenting factual information along with education about the long-term benefits of renewables and the urgency related to climate change may have a positive impact in shifting public attitudes toward renewables. Besides, there are local economic benefits that stem from the development and operation of wind facilities in Ontario. The developer and municipality enter into a benefits agreement that sets out the financial benefit to be paid to the municipality and in turn, the municipality will use the financial benefit for community-related projects. Instead of saying "no" to renewable energy projects, some municipalities use their leverage in extraordinary ways to figure out opportunities that are to the benefit of the local community, e.g. a community vibrancy fund (CVF) and municipal property tax. For small communities with limited municipal resources, community vibrancy funds can have a significant impact on local projects. The fund will provide a stable source of support over the next 20 years (the life of the project), which will support local community, the environment, and health and wellness initiatives. Based on the Haldimand County Report (\#CAO-02-2013) of the Chief Administrative Officer on July 22, 2013, in Haldimand County, 
the annual CVF contribution by wind energy companies is $\$ 1,683,000$ (Table 9) which is extended over 20 years. Total annual property tax payments by wind power companies are estimated to be approximately $\$ 1,160,000$ in Haldimand once all proposed projects are operational in 2016.

Table 9: Haldimand County annual CVF

\begin{tabular}{|c|c|c|}
\hline Wind Project & Developer & Annual CVF \\
\hline GRW & Samsung & $\$ 610,600$ \\
\hline Summerhaven & NextEra & $\$ 435,400$ \\
\hline NRWF & NRWC & $\$ 353,500$ \\
\hline PDNW & Capital Power & $\$ 283,500$ \\
\hline
\end{tabular}

\section{Health Concerns}

Threat to human health was a predominant concern raised in the interviews. All opponents identified human health as their foremost concern. Even though the highest level of health assessment in Canada - Health Canada - has not declared any ill health effects from wind turbines, health impacts are still the main concern of the public. In July 2012, in response to public concerns about possible health effects from wind turbines, Health Canada decided to undertake a large-scale epidemiology study in collaboration with Statistics Canada. In October 2014, Health Canada announced the results of the study that found no link between wind turbines and health effects. The following issue was found to be statistically associated with increasing levels of wind turbine noise: annoyance towards several wind turbine features (i.e. noise, shadow flicker, blinking lights, vibrations, and visual impacts). The following issues were not found to be associated with wind turbine noise exposure: self-reported sleep issues (e.g. general disturbance, use of sleep medication, diagnosed 
sleep disorders); self-reported illnesses (e.g. dizziness, tinnitus, prevalence of frequent migraines and headaches); chronic health conditions (e.g. heart disease, high blood pressure and diabetes); and self-reported perceived stress and quality of life (Health Canada, 2014). By the time the report was published, the public perception about health impacts had been formed over the five years since the introduction of the Green Energy and Green Economy Act. People with negative perceptions had already been through the process, thereby tainting public perception of the decision-making process for wind projects.

According to many respondents (opponents), concerned opinions around health impacts were acquired through research and interaction with the other members of community. When asked what particular research underlay their opinions, participants frequently cited the work of Steven Cooper (Australia) ${ }^{6}$ and Internet sources. The validity of the research on wind turbines and human health emerged as an important topic in several interviews. Many opponents contested the integrity of studies conducted (or funded) by the wind industry. Some opponents compared wind energy with the tobacco industry. They believe, as occurred with cigarettes and the decades it took for governmental agencies and scientists to admit to the ill-effect of cigarettes on health, health issues related to wind turbine will ultimately manifest in the near future (G.V.3, B.O.22, V.M.17):

V.M.17: "This thing reminds me so much of the tobacco industry in the states where there was a very powerful lobby called the tobacco institute who was funding research that proved that tobacco was absolutely safe."

\footnotetext{
${ }^{6}$ Steven Cooper is an acoustics engineer who was asked to undertake an acoustic assessment by Pacific Hydro in relation to a proposed wind farm in Australia (Cape Bridgewater project). He found that there was a numerical analysis of potential noise emission levels of the wind farm, but no actual assessment of the impact to advise residents what they would experience. This was not a peer-reviewed study and Cooper asserted that there is a need for further studies to examine if the noise has direct impact on human health. Nonetheless, Cooper's study is referred to as evidence of the health effects of wind turbines by opposition groups, even in Ontario (both WCO and Ontario Wind Resistance posted the results on their websites).
} 
However, the history of wind turbines in the US dates back to 1970s. The first large (utilityscale) wind facilities were installed in 1981 (EERE, 2015). Hence, it is unlikely in a democratic society with free market and presence of the strong competitors that the health effects of wind turbines would remain secret. In this case, it is difficult to alleviate concerns because there is a lot of misinformation, fear, and mistrust making it extremely difficult to have a principled negotiation and debatable facts:

M.A.11: "... So that's part of the issue, is that you are dealing with one side [developer] a very technical and reasoned approach on based on engineering and on the other side these people who are coming forward with a very emotional appeal [public] saying that they have health impacts, or, you know concerned about their property values. And the two sides don't necessarily meet in the middle."

A knowledge-broker could be a great help in this situation, acting as an intermediary to help both sides of the argument reach a middle ground. There is also misinformation that could be addressed by the knowledge-broker. For example, there is a fear of ice-build up on blades. The response is simple: the blades are thermally heated, so there will not be any ice build up or ice flow. Besides, the setback is $550 \mathrm{~m}$ and ice pellets can only fly $100 \mathrm{~m}$ (R.S.16). People are more accepting of a project if they are in possession of the most recent information. If the proponents leave a void, misinformation, fear, and uncertainty will undoubtedly fill that void. The wind industry did not do its best in this regard and left a bad impression:

S.E.6: "...but the fact of the matter is in the beginning we didn't get in there, we didn't communicate what we were doing. Whenever you have a vacuum of communication someone going to fill it, and it was the folks who were against the project who were quite successful at doing so."

The knowledge-broker would ensure that there are studies that have been peerreviewed and from legitimate sources and provide that information to the public so that 
people can educate themselves about what is going on. With a reliance on good science, the knowledge-broker can communicate effectively and persuasively with the public. When dealing with emotional issues it is difficult to achieve clarity on a given subject, which makes it difficult to get to the root of legitimate concerns. As mentioned in section 4.2.1, a knowledge-broker can help tease out the real motives. Some participants believe there are other reasons behind the health and ecological concerns including:

- Economic jealousy: those who do not get any compensation and yet see the turbines everyday may project health effects on to themselves from the machines (i.e. F.M.5, K.A.13, N.B.41).

- Aesthetic: people do not like how the wind turbines look. They believe the beautiful countryside is spoiled by wind turbines or, as they call them, monstrosities. This reason falls back on the health concerns for justification of their position (i.e. E.L.11, P.W.20, J.L.14, V.F.8). Proper siting decisions can help to avoid any aesthetic impacts to the landscape.

- Political tactic: The ERT only accepts appeals based on serious and irreversible damage to the human health or the environment. Therefore, people justify their opposition based on theses concerns (R.S.7)

- Placebo effect: if people find an irritant and focus on an irritant over time that irritant can become a real health implication and perception becomes reality (P.W.12)

\section{Environmental Concerns}

Environmental and ecological concerns include migratory bird and bat mortality, and possible impacts on farm animals. Undoubtedly, birds can be killed through collisions with 
turbines like any other man-made structure such as meteorological towers or power lines, and also through loss of their nesting habitat. The impact of wind turbines on wildlife, most notably mortality rate of birds and bats, has been widely studied. The American Wind Wildlife Institute research found evidence of bird and bat deaths; however, the study concluded that these impacts are relatively low and do not pose a threat to species populations (AWWI, 2015). Another study conducted in Canada shows that the combined effects of collisions, nest mortality, and lost habitat on birds associated with Canadian wind facilities appear to be relatively small compared to other sources of mortality such as communication towers (Zimmerling et al., 2013). Both studies discuss mitigation measures which can reduce mortality rates including: better siting of wind turbines; advances in wind turbine technology; feathering of wind turbine blades at night during peak migration; installation of modified marine radar to detect approaching bird activity and when necessary, automatic shutdown the turbines; and keeping wind turbines motionless during times of low wind speeds which could reduce bat deaths by more than half without significantly affecting power production because bats are most active when wind speeds are low (AWWI, 2015; Zimmerling et al., 2013). However, the overall relatively low levels of bird and bat mortality caused by wind turbines suggest the mitigation measures described above might not be necessary for all projects. Mitigation strategies could be adapted depending on each project. For instance, the PDNW project where Capital Power conducted studies to monitor pre- and post-construction tundra swans activities based on the recommendation made by the Environmental Review Tribunal.

In the bigger picture, the main issue is once again the absence of municipal involvement in decision-making. If a municipality is the first point of contact with the local community 
and is provided with enough information about the project up front or is introduced to a knowledge-broker, then when constituents call them (in smaller communities people usually call the municipality before they call the developer) the municipality can provide them with the right information. This strategy should make people feel more comfortable about the project. In this way both the municipality and the local community do not feel blind-sided because they are in possession of factual information in advance and questions and concerns can be addressed early on in the process:

R.S.21: "...one of the things that was very difficult for the township and council was that people were used to being able to go to their municipal government, it's the government closest to them that they feel they have the most impact on and they feel that level of government has their voice. But they didn't because the policy is written in such a way that the local municipal government has almost no voice. It was very hard on them because people would come to them and complained and they didn't have any power. So the process, the normal democratic process was circumvented and that's a serious problem."

It seems that the fact sheets prepared by CanWEA and distributed by the developers at open houses about property values, health, and ecological concerns (Appendix 8) are not comprehensive enough to answer questions and alleviate concerns. They are too simplistic to be able to trump existing misinformation. There is a need for a better approach for information provision to address questions in a convincing way. Despite wind power being widely seen as a clean alternative to fossil fuel-based energy generation due to the perpetual abundance of the wind resource, the adaptability of wind power to existing land use, its non-polluting character, increasing cost effectiveness, and small footprint, the development of wind power has still proven to be an uphill challenge in Ontario. Increasingly, the environmental literacy of local communities will likely have a large influence on how communities shape attitudes towards a specific project. Educational programs should be established to not only educate the public concerning a specific 
planned or proposed project, but also to inform the public about all renewable technologies, climate change, and energy policy. Such an educational system should not only rely on the wind industry, but instead a larger scaled program utilizing the existing education infrastructure by incorporating the aforementioned subjects into the elementary and secondary school curriculum. Wind energy must be shown to be more than a financial investment where local people feel that their community is being appropriated by "outsiders" and their projects. By not communicating the positive aspects of wind energy to the public, many of the hidden benefits of wind energy are often left unspoken.

\subsection{Lessons Learned: A Better Future}

The conflict over developing wind facilities in Ontario is evidence of a new type of environmental controversy. One side of the argument is composed of wind proponents who advocate the environmental benefits of wind energy to tackle climate change, secure energy sources, and overcome the challenges of possible fluctuations in fossil fuel prices. Their argument is simply that the advantages of wind energy clearly outweigh its disadvantages. On the other side of the argument are the opponents who are concerned with potential health and ecological impacts. They find wind turbines too visible and disruptive. This two-sided argument is referred to as "green vs. green" debate in several studies (Groothuis et al., 2008; Kahn, 2000; Warren et al., 2005). Interviews show that the proponent's tendency to highlight the global benefits of wind energy have little influence on local public attitudes, as residents are concerned with immediate impacts in their area. In addition, the interviews show that opponents believe wind energy would not be beneficial in any way and will pose serious health and environmental risks. Evidently, the 
so-called public consultation process did not address these issues properly. Inadequate consultation results in failing to effectively answer questions and address concerns, neglecting to take local interests into account, and triggering intense feelings of resentment and frustration toward the developers and the consultation process. The developers' lawsuits $^{7}$ against opponents who were actively (sometimes aggressively) opposing wind energy development in Ontario did not help this situation and caused another backlash against wind industry. These types of lawsuits are called Strategic Lawsuit Against Public Participation (SLAPP) and are an attempt to intimidate and silence critical voices by causing them to incur legal costs during lawsuits that drag on for months or years (Shapiro, 2010). Shapiro explains that the results of a study done on SLAPPs shows that the SLAPP plaintiffs have failed to win over $80 \%$ of the cases. Therefore, the SLAPP plaintiff does not normally expect to win the lawsuit. Instead, the tactic of launching a lawsuit is to create an intimidating or chilling effect on public participation.

It is fair to acknowledge that despite the potentially significant financial benefits accruing to wind project developers, the process of developing a wind facility is complex, time consuming, and expensive. The regulatory approval process is long and several studies need to be undertaken before a project is green lit. However, there should be more

\footnotetext{
7 One prominent example is Esther Wrightman, former activist, sued By NextEra Energy despite giving up opposing the Adelaide Wind Energy Centre (60 MW project). In 2014, after six years of fighting which included being appellants in six Environmental Review Tribunal hearings, the Wrightman family moved from their hometown Kerwood, Ontario, to New Brunswick after the turbines were built. According to The Huffington Post the reason for the defamation lawsuit was that "Wrightman posted parodied versions of NextEra's corporate logo to her website, calling it 'NextTerror' to criticize wind turbine construction. The suit seeks unspecified damages and contends that Wrightman misrepresented the company in order to bolster her own crusade against wind turbines being built to provide power throughout southwestern Ontario." Many, including Robert Bryce (National Review, July 13, 2015), believe that the fact NextEra, a company with a market capitalization of $\$ 44$ billion which operates more than 100 wind projects in 19 states and Canada, could not handle the criticism and had hurt feelings because a young woman made fun of them.
} 
forbearance from the developers' side. This does not necessarily mean that the developers must agree with the anti-wind lobby, but they need to respect the formal or informal political processes available to citizens to argue their case. If not, people feel their freedom of speech has been violated and their democratic rights taken away by bullying tactics (as phrased by the Mayor of Melancthon Township in a letter to the Ontario Premier) deployed by the developers (Appendix 9):

"People are incensed by the bullying tactics employed by the developer. They have shown themselves to be overly aggressive, uncaring and frankly deceptive. The reason they can act that way, is because of [a] flawed Green Energy Act that allows them to steam roll over municipalities and individuals"

In Ontario, some efforts have been made to improve public engagement in renewable energy development decision-making processes; however, practices still remain heterogeneous and local controversies have not been settled. In other words, the outcomes from wind energy decision-making processes remain, to some extent, difficult to predict and understand. This relates not only to renewable energy, but also to facility siting much more broadly (i.e. a landfill or waste management facility). Local approval of a wind project is not only a key element to its success but also a driving factor for future wind developments in general since public attitude toward wind energy is influenced by several social factors and may be altered through a person's interaction with those who have experience with wind turbines. Because of this contingent nature of the participation processes, wind developers need to cope with local resources and singular stakes. From this perspective, developers should have different recipes for participation because generic recipes fail (i.e. open houses) to take into account the specificities of particular social factors produced by each unique project.

There is an urgent need for the provincial government and wind industry to better 
educate the public about wind energy and how it differs from conventional sources. The risk and cost associated with wind energy should be contextualized in comparison with the risks posed by the other sources (e.g. nuclear waste) and their life-cycle costs. There is an immediate need to change the public consultation process from a venue for debate about wind energy based on a vicious cycle of "decide-announce-defend" to an opportunity for gathering local community opinions and answering their questions and concerns. This would mean acknowledging and valuing local expertise; recognizing the important contribution that different stakeholders can bring; and taking into account people's attachment to places and local surroundings. For the provincial government and the developers this means framing discussions in ways that are meaningful to local people; building up long-term relationship in communities; showing interest in involving them; being socially responsible and accountable for the decisions that affect the local community; finally, employing strategies that are not exclusive, but actively seek to engage different stakeholders.

This research was an effort to shed some light on the variety of practices of public participation in wind energy projects (Table 10 presents a summary of results). The suggestion is that collaborative decision-making and a knowledge-broker could help in achieving consensus over wind project siting decisions. In response to the question "What are some strategies that could be adopted to increase the level of public participation in order to reach a consensus?" the respondents were unanimous that the current process does not have efficiency and needs to be improved. Their suggestions include: availability of the developers; being responsive, proactive, and present within the community; building relationships and trust; financial ownership of the projects by local community (partial 
Table 10: Summary of results

\begin{tabular}{|c|c|c|}
\hline Topic & Description & $\begin{array}{c}\text { Model } \\
\text { Category }\end{array}$ \\
\hline \multirow{4}{*}{ NIMBY } & Place-protective action & \multirow{5}{*}{ Inform } \\
\hline & Democratic deficit explanation & \\
\hline & Qualified support & \\
\hline & Self-interest & \\
\hline Misinformation & $\begin{array}{l}\text { Media, Internet, and interactions with friends } \\
\text { and family may play a decisive role }\end{array}$ & \\
\hline \multirow{4}{*}{ Public Consultation } & CLC meetings (rubberstamp committees) & \multirow{6}{*}{ Consult } \\
\hline & Public meetings (open houses) & \\
\hline & Local knowledge (too late to be considered) & \\
\hline & Consequences (Not a Willing Host) & \\
\hline New Procurement Process & No one has been pacified by the new LRP & \\
\hline $\begin{array}{l}\text { Inadequate Consultation Begets } \\
\text { Inadequate Participation }\end{array}$ & $\begin{array}{c}\text { Confrontational process, emotional } \\
\text { participation }\end{array}$ & \\
\hline \multirow{5}{*}{$\begin{array}{l}\text { Provincial and Municipal } \\
\text { Involvement }\end{array}$} & $\begin{array}{l}\text { The province should be more involved to } \\
\text { enforce its own rules and regulations }\end{array}$ & \multirow{7}{*}{ Involve } \\
\hline & $\begin{array}{l}\text { Municipalities: from an approving agency to a } \\
\text { commenting agency }\end{array}$ & \\
\hline & $\begin{array}{c}\text { Political Issue } \\
\end{array}$ & \\
\hline & Weak regulatory governance & \\
\hline & $\begin{array}{l}\text { Misconception: Community-based vs. large } \\
\text { industrial scale projects }\end{array}$ & \\
\hline \multirow{2}{*}{ Environmental Review Tribunal } & High threshold & \\
\hline & Dismissal & \\
\hline \multirow{14}{*}{ Knowledge-broker } & Providing meaningful information & \multirow{14}{*}{ Collaborate } \\
\hline & $\begin{array}{l}\text { Answering questions or directing people to } \\
\text { the right experts }\end{array}$ & \\
\hline & $\begin{array}{l}\text { Giving feedback and how the question or } \\
\text { concern affects the project }\end{array}$ & \\
\hline & $\begin{array}{l}\text { Diffusing the tension by listening to the } \\
\text { concerns }\end{array}$ & \\
\hline & $\begin{array}{l}\text { Go-between or lobbyist between developers } \\
\text { and governmental agencies }\end{array}$ & \\
\hline & Educating people about renewable energy & \\
\hline & $\begin{array}{l}\text { Uncovering the motives (teasing out real } \\
\text { concerns) behind the opposition }\end{array}$ & \\
\hline & Alleviating those concerns & \\
\hline & $\begin{array}{c}\text { Gaining social license } \\
\end{array}$ & \\
\hline & $\begin{array}{l}\text { Available local resource: permanent point of } \\
\text { contact for the community }\end{array}$ & \\
\hline & Relationship building and gaining trust & \\
\hline & Helping facilitate negotiations & \\
\hline & $\begin{array}{l}\text { Encouraging the silent majority to come } \\
\text { forward }\end{array}$ & \\
\hline & Effective communication & \\
\hline
\end{tabular}




\begin{tabular}{|c|c|c|c|}
\hline \multicolumn{2}{|c|}{ Topic } & Description & $\begin{array}{c}\text { Model } \\
\text { Category }\end{array}$ \\
\hline \multirow{9}{*}{ Main Concerns } & Aesthetics & $\begin{array}{l}\text { Shorelines: natural beauty and the } \\
\text { peacefulness }\end{array}$ & \multirow{9}{*}{ Empower } \\
\hline & $\begin{array}{c}\text { Ecological/ } \\
\text { Environmental }\end{array}$ & Bird and bat mortality & \\
\hline & \multirow{3}{*}{ Economic } & Energy market: higher price and need & \\
\hline & & Property value & \\
\hline & & Tourism & \\
\hline & \multirow{4}{*}{ Health } & Economic jealousy & \\
\hline & & Aesthetic & \\
\hline & & Political tactic & \\
\hline & & Placebo effect & \\
\hline
\end{tabular}

ownership, co-ops, partnership); early involvement; meaningful participation of local communities (not based on emotions); municipality engagement; a more active role for the provincial government in the decision-making process; and as R.S. asserted, collaborative decision-making: "I do not want to see support, I want to see collaboration and I want to see financial involvement, and financial reward for communities." Almost all of the participants agreed that the presence of a knowledge-broker could help the decisionmaking process and move the process from information provision to collaboration. In addition, a number of participants recommended some participatory techniques which they believed worth trying, such as: all-day open houses; forming the CLC during the early stages of the process; online engagement and using the power of social media; small meetings in a more friendly setting; telephone town-halls; citizen's reference panels or a citizen advisory panel; and public referendums.

When asked about consensus, several participants pointed out that consensus sounds like a loaded word and in the real world appears unreachable. This resonates with the criticisms toward Healy's collaborative decision-making. O'Neill (2002) believes that the viability of consensus building is hampered as those in power have the means and the will 
to sabotage such efforts while seeming to participate in the process. This situation is worsened when complex decisions are being made under tight deadlines where experts have an inbuilt position of power. This view ignores the fact that collaborative decisionmaking itself helps reduce the asymmetrical power distribution by inviting a variety of people to have input into the decision-making process instead of leaving controversial decisions up to the provincial government and the ERT processes, which slows down the implementation of projects. Besides, by definition consensus building is a conflictresolution process used mainly to settle complex, multiparty disputes that affect different groups of people with different interests (Burgess and Spangler, 2003). Inevitably, consensus building or collaborative decision-making takes time, but the involved stakeholders can establish a common understanding on how to find the best possible solution which is less likely to face problems in the implementation phase. Sager and Gastil (2006) place emphasis on the fact that consensus building differs from majority rule decision-making in that everyone involved must agree with the final decision. Sometimes people must make difficult decisions which will not make everyone happy, but much of the opposition is nullified because an agreement is reached after all interests are taken into account, all alternatives are discussed, the cost and benefits of the alternatives are analyzed, and the barriers to implementation are evaluated. The implementation may have its own difficulties as unforeseen problems may transpire, but a good collaborative decision-making process builds relationships among stakeholders, allowing the parties to work together to resolve those issues.

In order to involve all the stakeholders and define their relations, there is a need to conduct a stakeholder analysis and social network analysis. If some parties are left out or 
refuse to participate, this is likely to cause implementation problems in the end. The purpose of a stakeholder analysis and social network analysis - prior to going to the community and meetings - is to determine who comes to the meetings. Are they expressing their opinion or representing the views of others? Since the developers provide the official notification, they should also be able to identify their stakeholders. However, the depth of stakeholder analysis in identifying the interests behind positions differs depending on the size of projects. Undertaking a social network analysis is also available to the developers, but this analysis is usually not done due to the relatively high cost and time-consuming nature of it. In most interviews the question about stakeholder analysis was followed by the inquiry as to whether they think conducting a social network analysis is important. Most participants replied that conducting a stakeholder and social network analysis is up to the developers. A number of participants stated that smart and responsible developers go through the process:

N.B.17: "Sometimes. It depends on the client and what exactly they like to do. Certainly, it is something we recommend to do in sort of stakeholder analysis and understand who is out there. Now that we are 5-10 years into developing wind farms, it is fairly obvious who the main oppositions are and who the stakeholders are that are going to support the project. But that being said, the circumstances in every society are slightly different so it is a useful idea to understand that."

Also:

C.0.10: "I don't consider it to be a huge expense, they [developers] sometimes balk at it a little bit and say maybe you don't need to do that but I'll try to play it down a little bit and say we need to do something because if you don't know who you are talking to then you are talking to dead air, there's nobody to talk to."

And:

S.E.37: "To a degree, a lot of it is political check, to be perfectly honest. It's actually quite accurate, you would be surprised, based on who's there and who sends me we get a pretty good idea of what the community reaction is going to be." 
In conclusion, it is true that the level of conflict in relation to wind project development in Ontario makes the pursuit of consensus building idealistic. However, an effort should be made to develop new, mutually advantageous strategies rather than going over the same win-lose approaches and conducting business as usual. Clearly, the top-down approach to wind energy planning has created a firestorm of protest across rural Ontario. This situation requires more active engagement by all stakeholders on specific wind project development and not only based on the principles of consensus building and the deployment of other creative methods of conciliation.

\section{4: Updated Conceptual Framework}

The first version of the framework was proposed early on in the research process, drawing at that stage largely on the literature review. The conceptual framework evolved and was better formulated to capture the insights being developed through public involvement, municipality engagement, and the role of a knowledge-broker as an intermediary between different stakeholders (Figure 23). Similar to the first draft, the updated conceptual framework is organized around the procedural steps of a wind project development in Ontario and the role of a trusted third party or knowledge-broker. The updated framework incorporated the three stages of negotiation in collaborative decision-making since this was an effort to encourage the developers to improve the practice of public participation in wind energy projects by deploying a collaborative approach.

In this framework an initial involvement of interested actors starts with undertaking a stakeholder analysis to identify the main actors of the decision context, the description of social networks, and the elicitation of their views with respect to the specific decision (e.g. 
location of the site) to be made. More specifically, stakeholders' preferences are sought to identify decisional criteria to be considered, their relative importance through stakeholder feedback, and an investigation of possible solutions. The competent authority in this situation (e.g. a regulator), with the aid of a knowledge-broker would explore the existing conflicts and identify a preliminary list of alternative options. The knowledge-broker becomes a critical catalyst in the formation of collaboration by providing information that is accurate, reliable, and easy to understand.

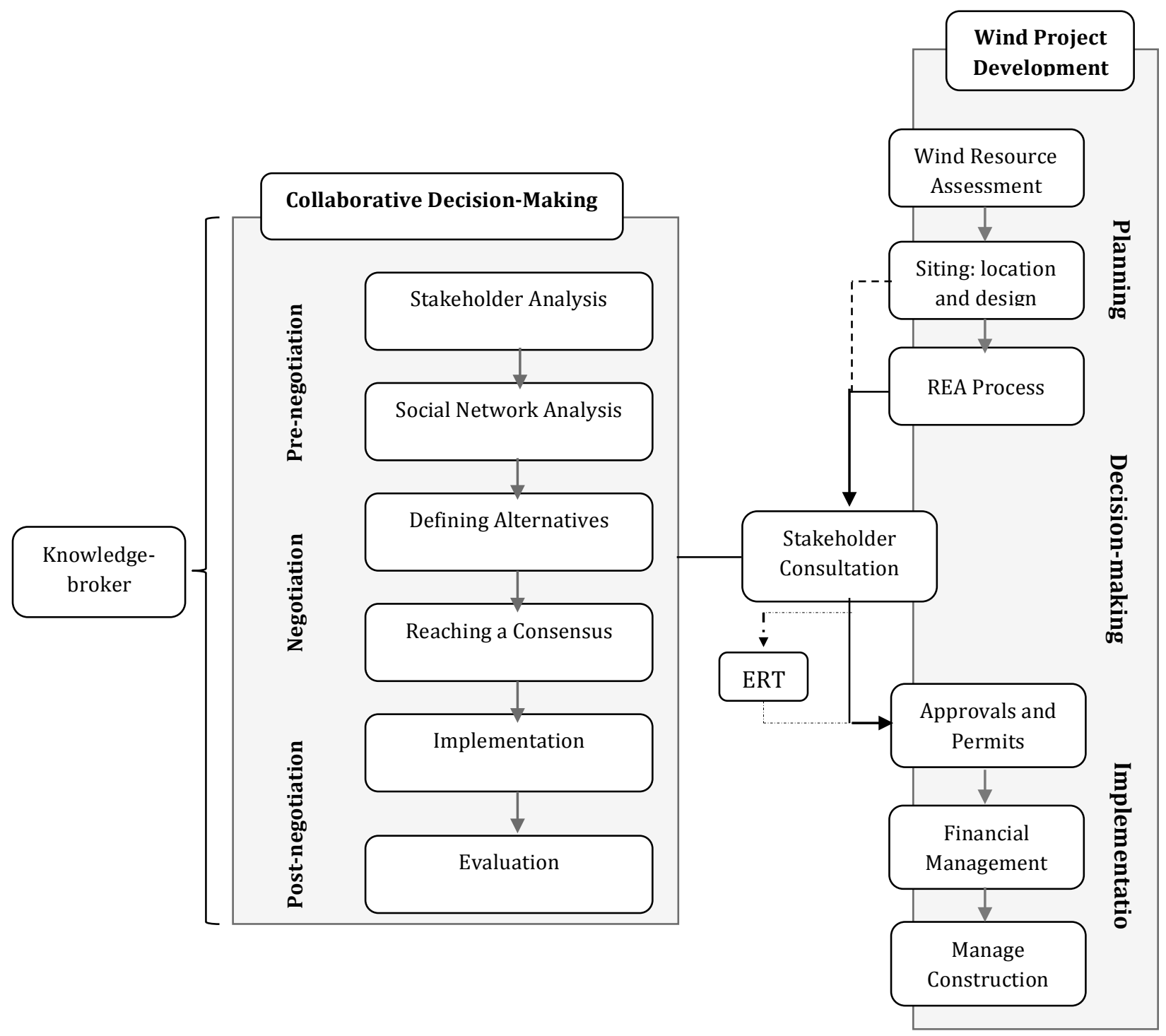

Figure 23: Updated conceptual framework 
A social network analysis is then carried out to explore the relationship among, and between, various actors and the wind energy technology itself. Social network analysis helps with understanding the formation and boundaries of networks, the relationships and interactions between actors within a network, and various elements (i.e. social, economic, political, and cultural factors) of a network that create stability. As McLaren Loring (2007) describes, the level of network stability is determined by four indicators: a strong relationship among actors within the network; immutable mobiles or the presence of documents within a network which shows the degree of organization; multiplicity or different actors with a range of identities; and critical actors who usually dedicate substantial amounts of time and effort to the process and without whom a network could not form or survive. Critical actors typically bring special skills, knowledge, or a particular conviction about the project that motivates others. Recent studies suggest that the public's concern regarding the environmental impacts of wind farms can be subjective and the sociological factors, such as a person's knowledge of the technology, exposure to particular media reports, social influences and networks (i.e. the opinion of friends and family living in the local area) are important in determining public perception of wind farms (DevineWright, 2005; Eltham et al., 2008).

These two initial steps allow for the creation of a package of assessment data, expert reports, and other research material that would be user-friendly for all stakeholders. This package would clearly articulate the relevance of the opposition network's concerns about the decision-making process and outcomes. As Bijlsma et al. (1988) explain, many social groups feel that the lack of information and the lack of opportunities to acquire knowledge are considerable barriers to public participation. Therefore, at this stage the knowledge- 
broker can play an important role in tackling this obstacle by familiarizing laypersons with certain information regarding a technical issue such as wind energy and communicating the package in a way that it is meaningful to all stakeholders. Moreover, the knowledgebroker directly works with the public throughout the involvement process to ensure public concerns and aspirations are consistently understood and considered. This allows the decision maker to structure the problem in collaboration with all interested parties and thereby establish an information exchange relationship. To establish an information exchange relationship, the following items should be determined at this stage: rules of procedure, roles and responsibilities, timelines, and logistics.

After completing a conflict assessment that evaluates the nature of the conflict and options for resolution, the interests of stakeholders can be identified by the knowledgebroker through brainstorming and idea mapping to define alternatives and encourage principled negotiation. Fisher and Ury (2011) defined four elements of principled negotiation: separating the people from the problem; focusing on interests, not positions; inventing options for mutual gain; and insisting on using objective criteria. The next step is to bind the stakeholders to an agreement, followed by implementation, and creating a monitoring process to evaluate implementation. A neutral third party (or knowledgebroker in this context) can help test assumptions and educate where perceptions differ. If emotions run high, a knowledge-broker can encourage involved stakeholders to let off steam and feel heard. As previously mentioned, where misunderstanding exists, a knowledge-broker can work to improve communication by supplying (or communicating) fact-based information and conveying feedback between and among stakeholders (Figure 6). Applying the proposed framework may result in reaching a wise agreement which, as 
defined by Fisher and Ury (2011), is a durable agreement that meets the legitimate interests of all stakeholders to the extent possible, resolves conflicting interests fairly, and takes community interests into account. Ultimately, if an REA decision is taken to the ERT, a knowledge-broker could act as the mediator.

In conclusion, in the proposed collaborative framework, local communities need to draw upon their sense of public interest rather than self-interest and should partake in a meaningful participation in order to have substantive input into the decision-making process, solve problems, and reach an agreement, which they find acceptable. The collaborative process could be carried out by a knowledge-broker who will: identify all of the stakeholders who should be involved; reframe the issues in terms of interests, which are usually negotiable, rather than positions, or values which are difficult to impossible to negotiate; and encourage the stakeholders to brainstorm alternative approaches to problems. If this collaboration happens through the early-established CLCs, the knowledgebroker can propose the mechanism of collaboration and agenda, then provide the details in cooperation with the participants. This gives the participants a sense of control of the process which is a starting point for building trust. If the participants feel they are not part of the decisions being made, consequently, it diminishes the main purpose of the meeting. Finally, both provincial and municipal governments should play a more active role to balance local policies and goals with provincial policies. In order to evolve to the next level of the participation spectrum there is a need for revision to REA legislation regarding participation and more diligent enforcement of the current REA participation requirements. 


\section{Criteria for Judging the Quality of Research}

Yin (2009) suggests four commonly used tests to establish the quality of any social science research that includes case studies: construct validity, internal validity, external validity, and reliability. Different scholars identify several tactics for dealing with these four tests. Table 11 lists these recommended tactics, which were used in this research.

Table 11: Test and tactics for establishing reliability and validity in case study research

\begin{tabular}{|c|c|c|c|c|}
\hline Test & Meaning & $\begin{array}{c}\text { Selected Case Study } \\
\text { Tactic }\end{array}$ & Stage & Source \\
\hline \multirow{3}{*}{ Reliability } & \multirow{3}{*}{ Replicable results } & Use case study protocol & Data collection & \multirow[b]{2}{*}{ Yin, 2009} \\
\hline & & $\begin{array}{l}\text { Develop case study } \\
\text { database }\end{array}$ & Data collection & \\
\hline & & $\begin{array}{l}\text { Assure the quality of field } \\
\text { notes or recordings }\end{array}$ & Data collection & $\begin{array}{l}\text { Kirk and } \\
\text { Millet, } 1986\end{array}$ \\
\hline \multirow{2}{*}{$\begin{array}{l}\text { Internal } \\
\text { Validity* }\end{array}$} & \multirow[b]{2}{*}{ Credibility } & $\begin{array}{l}\text { Do within and cross-case } \\
\text { analysis }\end{array}$ & Data analysis & $\begin{array}{l}\text { Yin, 2009; } \\
\text { Riege, 2003 }\end{array}$ \\
\hline & & $\begin{array}{l}\text { Correspondence between } \\
\text { theoretical paradigm and } \\
\text { the observations }\end{array}$ & Data analysis & Riege, 2003 \\
\hline \multirow[b]{2}{*}{$\begin{array}{l}\text { External } \\
\text { Validity }\end{array}$} & \multirow[b]{2}{*}{ Generalizability } & $\begin{array}{l}\text { Use replication logic in } \\
\text { multiple-case studies }\end{array}$ & $\begin{array}{l}\text { Research } \\
\text { design }\end{array}$ & Yin, 2009 \\
\hline & & $\begin{array}{l}\text { Compare evidence with } \\
\text { existing literature for } \\
\text { analytic generalizability }\end{array}$ & Data analysis & Riege, 2003 \\
\hline \multirow{3}{*}{$\begin{array}{l}\text { Construct } \\
\text { Validity }\end{array}$} & \multirow{3}{*}{$\begin{array}{l}\text { Correct and } \\
\text { consistent } \\
\text { operational measures }\end{array}$} & $\begin{array}{l}\text { Use multiple sources of } \\
\text { evidence }\end{array}$ & Data collection & \multirow{3}{*}{ Yin, 2009} \\
\hline & & $\begin{array}{l}\text { Establish chain of } \\
\text { evidence }\end{array}$ & Data collection & \\
\hline & & $\begin{array}{l}\text { Have key informants } \\
\text { review draft case study } \\
\text { report }\end{array}$ & $\begin{array}{l}\text { Data analysis } \\
\text { and report } \\
\text { writing }\end{array}$ & \\
\hline
\end{tabular}




\section{Limitations}

Similar to the other research methods, there are strengths and weaknesses associated with using a case study. The most frequently cited objection to the use of case studies in social science research is the issue of representativeness. In other words, the research findings may not be generalized to the wider population beyond the case study (Burton, 2000; Yin, 2009). Meanwhile, Yin (2009) puts forward a difference between statistical generalization and analytical generalization. He explains that while survey research tries to generalize findings based on a sample that generalizes to a larger population, case study findings can be generalized to some broader theory through analytic generalization. Flyvbjerg (2006) goes beyond Yin's clarification. Flyvbjerg explains that one of five misunderstandings about case study research is the generalizability issue. It is incorrect to conclude that one cannot generalize from a single case. Flyvbjerg believes it depends on the case and how it is chosen. Moreover, formal generalization is only one of many ways that people gain knowledge. However, it is overvalued as a source of scientific development (Flyvbjerg, 2006).

In order to overcome this shortcoming, comparative multiple case analysis on current wind projects was conducted to help with the issue of generalizability. The results are not only being used as part of a cross-case analysis, but also the knowledge that the researcher gained from this experience was used to develop the conceptual framework and update it while progressing with the research. Care was given to carefully choose cases that were informative and representative of other cases in Ontario (Burton, 2000). Besides, cases are not restricted to one data source and one can utilize multiple evidentiary artifacts from different sources (e.g. interviews, observation, documents). However, the findings of this 
research may not be generalizable beyond the case of wind energy development in Ontario. Ideally the findings will be compared to case explorations of wind project development in other jurisdictions or compared to other possible complementary innovations or facility sitings in Ontario.

Finally, in the case study research method, data collection procedures are not routinized. This drawback was addressed in this study by choosing the qualitative interview as a data collection approach (Burton, 2000). Despite its limitations, interviewing provides rich and worthwhile data. It offers the opportunity to listen to people's concerns and opinions about wind energy development at a level that is not accessible with a questionnaire (Stroh, 2000).

A criticism towards the interview approach, as cited in the literature, relates to the effective wording of questions; i.e. neutralizing the sense of the questions, how the improper arrangement of questions may significantly affect the results, how some topics may be difficult, controversial, or inappropriate to discuss, issues with objectivity, and how the interviewer may affect the interview process and interviewee responses (Berg, 1998; Stroh, 2000). To overcome this issue in this research, an initial interview guide was set and adopted accordingly during the course of the interview. Interview topics were planned and pilot interviews were tested, both to check the topics in the interview schedule, and also to allow for refinement of the interviewing style.

It is also important to highlight the difficulty of getting developers to participate in this research, which further supports the lack of communication from developers as a significant barrier to effective public participation. Most of the developers declined to have an interview or did not respond to the interview requests. When asked about the reason, 
the answer was one of the following: "wind energy is a sensitive topic", "it is the company's policy", "I am not comfortable to represent our company, I can talk to you as an expert in this field", or "we are not sure about the outcome of the interviews/research".

This study does not cover the Aboriginal consultation that has a separate venue from community consultation. They have similarities, but are legally and fundamentally different because Aboriginal groups have constitutionally protected rights. Those rights are embedded in the constitution, so to violate those rights would violate the constitution. 


\section{Conclusion}

\subsection{Discussion}

With increasing concern amongst scientists and policy makers about the potential consequences of greenhouse gas emissions, there has been a growing interest in many countries to increase the amount of energy generated from renewable resources. According to many scholars, wind energy technology is the most economically profitable in comparison with many other renewable energy technologies and therefore has seen the most development.

In Canada, the federal government has long resisted ambitious action on climate change. However, in June 2015, the Prime Minister signed on to a G7 commitment to deep cuts in greenhouse gas emissions by 2050 that will lower them as much as $70 \%$ from 2010 levels with an eventual stop in the use of fossil fuels by 2100. Meanwhile, in July 2015, a landmark climate statement was signed in Ontario. Until recently, the Ontario government's decision to shut down the coal-fired power plants and investing in renewables were Ontario's main contribution to reducing GHG emissions. Encouragingly, the Ontario government is preparing to take more necessary steps such as the announcement of a cap and trade program to limit the main sources of GHG emission, the establishment of a 2030 mid-term target for GHG reduction, the closure of all coal-fired power plants, and the large infrastructure investment in Ontario, which includes the electrification of the province's commuter rail network. According to the Government of Ontario's Newsroom 2015, these initiatives work towards meeting its $2050 \mathrm{GHG}$ reduction target which is to achieve a target 80\% below 1990 emissions levels. Finally, as National Observer reported on December 6, 2015, Canada surprised the COP21 (Paris climate change conference) by suggesting a 
bolder, more ambitious target for cutting greenhouse gases. Canada's Environment and Climate Change Minister wanted the Paris agreement to restrict planetary warming to just 1.5 Celsius. Eventually, on December 12, 2015, the signatories to the Paris agreement agreed to limit a temperature increase to 2 degrees Celsius. Prime Minister Justin Trudeau promised that Canada would spend $\$ 300$ million a year on clean technology innovation. However, the federal government's plan has yet to be codified. As announced by the Prime Minister, the federal government will meet with the provinces and territories to develop emission plans.

As described above, both federal and provincial governments have acknowledged that climate change is a serious issue. Consequentially, there should be a concerted effort to reduce GHG emission. Local communities need to consider "public interest" by either choosing to host a local wind facility (or the other forms of renewables) or alternatively, commit to energy conservation by reducing car dependency, source more food locally, increase recycling, etc. However, it seems that the urgency to address climate change requires both actions be done simultaneously. As the world begins to equip itself to enter a new era and end the use fossil fuels, inevitably, there will be major changes in the ways energy is produced and consumed. Consequently, this will bring new forms of technology to the landscape. Wind turbines can be seen as beautiful symbols of modern dynamism or as ugly monsters, which are too visible, disruptive, and despoilers of beautiful nature. How people perceive (local attitudes) wind energy technology will influence the future development, success, and acceptance of it, which will then determine the level of market penetration. Possible ways - through deploying renewable energy - to reach ambitious targets of a low carbon economy could be: (1) adapting new technologies to make the 
physical appearance of wind turbines less intrusive; (2) educating people that climate change is a more critical environmental concern than the localized impact of a wind energy development; (3) investing in alternative renewable energy technologies; and (4) advancements in energy storage.

Environmental attitudes and the level of public support have heavily influenced the success or failure of wind power projects. The involvement of the community in the early stages of developing a wind project should be considered in order to gain the mutual support of stakeholders, raise public awareness about the issues and complexity of balancing the various stakeholders' requirements/needs/interests, and provide information to develop a better understanding of the issue on hand and identify key local environmental knowledge. Subsequently, this mutual collaboration may lead to increased capacity of public engagement on issues of local concern (as a long term achievement) and to the reaching of decisions that are stronger, applicable, and more acceptable (short term achievement).

The recommended framework in this research (Figure 23) requires all stakeholders to reconsider their current roles in the decision-making process. The public should engage in project planning and monitor the decision-making processes to ensure that their concerns have been addressed. Developers should address public concerns through a consensus building process initiated early in their planning process. Federal and provincial governments have to reclaim their role of ongoing leadership and provide better criteria for implementation and evaluation of the public participation processes. An ideal situation would have the province establish an overall policy framework as they do for many other types of planning and within that framework the municipalities could have more input and 
proper consultation. It seems imperative that further modifications need to be made to the regulation in order to change the current course of action and thereby provide the provincial government with a framework where it can begin to work with local municipalities more directly and attempt to balance local and provincial needs and policies. Like the provincial government, local governments are elected to office to set policy and support the people who put them in these positions. If the policy is flawed, they need to work together to fix it on behalf of their constituents. Finally, the process requires a third party who is not only an intermediary, but also plays the role of a knowledge-broker to connect with stakeholders, share and exchange knowledge, and work on overcoming barriers. The knowledge-broker helps to fulfill the main requirement of the collaborative decision-making, which is effective communication.

The proposed framework challenges the assumption of some proponents towards the public including: people are polarized, volatile, emotional, and uninformed who argue based on their perceptions which may not correspond with reality. The natural response is to see the situation as a risk that needs to be managed. Hence, the developers put greater bumpers and guardrails around that interaction and constrain the kind of questions that can be asked or the amount of time for that dialogue. Therefore, all of the good intentions about transparency and genuine engagement fall by the way side because developers are afraid someone will attack their positions and destroy the viability of the project plan.

Based on the recommended collaborative framework, there is a need to look at the decision-making process with fresh eyes. Assumptions should be modified about the public to ones where they are perceived as caring, reasonable, purposeful, and curious. In this way, the public will be considered as resources rather than risks that need to be managed. 
The developers need to be better at sharing what they know and to foster co-learning around questions and concerns. Moving the dominant view of the public as "a risk to be managed" towards "a resource that can be tapped" is important for three simple reasons (if done well): increasing the legitimacy of the decision; enhancing the trust; and ideally creating an environment for the making of better decisions. To do so requires a rebalancing of the conversation. The evidence would suggest that when people are not heard through a collaborative process then it is more likely that a determined individual or group will find ways to make himself/herself/themselves heard in ways that are not only unappealing to the proponents, but can be cause for significant delays and added costs.

\subsection{Concluding Remarks}

I attempted to maintain objectivity in this research and present both sides of the argument to the extent possible. However, I would like to conclude with a personal observation about wind energy development in Ontario. As a supporter of renewable energy and public engagement in decision-making which affects people's welfare, I believe - and I stress emphatically that this is a personal view - major environmental issues could become more contentious at the public policy level. My observations suggest that both wind energy development and the decision-making process have become emotional issues on the part of general public. It is important to recognize how scientific studies can be a salient and objective input in the decision-making process. Modern technologies have a high degree of technical complexity and correspondingly have a complex set of potential impacts on human health and the natural environment. Therefore, scientific analysis is required in order to discover which type of impact may be present. As discussed above, the scientific 
studies themselves could become the subject of public controversies and bitter stakeholder conflicts as there are references to other scientific studies which appear to point to different kinds of conclusions and, sometimes, these claims advance in the ERT or a courtroom setting. Claims about "phony science", "flawed study designs" and "bias" are repeatedly brought up during the interviews. One strategy to heighten the credibility of scientific assessments (especially where significant perceived risk and benefits are involved) is to communicate the results of such assessments effectively. Moreover, there are valid economic concerns which also need to be addressed.

\subsection{Contribution and Future Research}

Most of the available literature on wind energy development discusses the economic and political barriers, while relatively little research has focused specifically on effective communication. Therefore, there is room for further research on resolving social conflicts related to wind project development. This study contributes to academic knowledge by seeking to address these gaps through a participatory framework that highlights the role of a knowledge-broker in regulatory governance. The goal of this research was to produce insight that might be valuable during the course of improvements in Ontario's REA process. As such, this research relied on participants and researcher interpretations of the current situation of wind project development in Ontario and expectations of future events. In future, in-depth, multiple case studies could be conducted to examine the applicability of the conceptual framework in a real-life situation, particularly if knowledge-brokers can be found to be part of the approval process. A comparison of this case study based on 
collaborative decision-making, along with a historical case study could yield important insights as to the usefulness of the knowledge-broker in the decision-making process. 


\section{Appendix 1: Case Study Protocol}

\section{Background}

\section{(a) Overview:}

Most available literature on wind energy development discusses the economic and political barriers, while relatively little research has specifically focused on effective communication. This study contributes to the academic knowledge base by seeking to address these gaps through providing a participatory framework, which highlights the role of knowledge-broker in the regulatory governance. To examine the role of public participation and a trusted third party in wind energy industry, there is a need to conduct in-depth exploratory case studies in real-life contexts.

\section{(b) Research Questions:}

- Core question: "How does public participation affect the public decision-making process of developing a wind energy project?"

- Sub-questions: "What are the major social conflicts of wind power development?" and "What is the role of a knowledge-broker (trusted third party) in resolving these conflicts?"

\section{Design}

This study is exploring the nature of a particular contemporary social phenomenon (public participation) within its real-life context; the communication and presence of a third party are important subjects, but have not been studied previously and there is not enough experience or information from the literature; therefore, an exploratory case study approach was selected. To explore and understand the similarities and differences within and between cases, multiple cases will be studied. The nature of the problem and the attributes of the conceptual framework lend themselves to an embedded case design that allows for multiple units of analysis.

\section{Case Selection}

The selection of specific cases is guided by the following criteria: the projects were recently finished or are underway; there was available information through interviews, secondary reports, and documents; the presence of a value/interest conflict; and clear traces of public involvement. Also, to fulfill the requirements of deliberate theoretical sampling, polar types of cases are chosen: one is a big project in southern Ontario with the presence of four national and international companies which have wind projects all over southern Ontario, the other is a small-scale project by a privately-owned company with only two projects in Ontario. 


\section{Data Collection}

(a) The data will be collected through semi-structured interviews, documents, and observing public meetings. To reveal the common narratives, representatives of key stakeholder groups will be interviewed: municipality (planning or renewable energy managers), proponents (wind project managers or public relation managers), consultants and facilitators, and opponents.

\section{(b) Data collection plan}

- Data will be recorded by audiotape or notes will be taken.

- The interviews will be in person or on the phone.

- Consent will be obtained with a written consent form.

- Electronic data will be encrypted, portable devices will be password protected, and hardcopy data (interview transcriptions) will be stored in a locked cabinet.

- Participants will be recruited through sending the following email to the potential participants identified in the project documents or through recommendations from existing participants.

Hello Mr. ...

My Name is Anahita. I'm in the midst of completing my PhD in Environmental Management at Ryerson University. My dissertation involves the examination of public participation in wind project development in Ontario. I am in the process of contacting professionals in the field who are willing to share their experiences. Following are some highlights about my research:

- The research is approved by Ryerson REB (Research Ethics Board).

- I am only seeking information that you would provide to any third party.

- The interview takes 30 minutes to 1 hour.

- Interviewee can at any time and without reason, decline to answer any individual question during the interview.

- The name of interviewee will not be revealed in the case study.

- A sample of the questions will be provided to you prior to the interview.

- Interviewee may review/edit the recordings or transcript.

- Attached, please find a summary of my research.

I am hoping you will be willing to help facilitate my research needs or direct me to a colleague who could.

Best regards, Anahita Jami

\section{(C) Interview Questions:}

The tentative research questions are listed below. However, during the course of interview (due to the semi-structured nature of the interview) follow up questions will be asked. The letters (P: Proponent; O: Opponent; M: Municipality) next to each question means that the question will be asked from that category of stakeholders. 


\section{Current situation:}

- (i) How important is public input in the decision-making process of developing a wind energy project? (ii) How important is it to have the public support? $(\mathrm{M}, \mathrm{O}, \mathrm{P})$

- How does public participation affect the public decision-making process of developing a wind energy project? $(\mathrm{M}, \mathrm{O}, \mathrm{P})$

- What are the main concerns of local communities about the wind turbines? $(\mathrm{M}, \mathrm{O}, \mathrm{P})$

- What is your suggestion to address the concerns of local communities? (M,O,P)

- (i) What are some strategies that could be adopted to increase the level of public participation and reaching a consensus? (ii) What are the current strategies? $(\mathrm{M}, \mathrm{O}, \mathrm{P})$

\section{Participatory strategies:}

- What innovative and traditional participatory tools do you use to facilitate the public participation process? (P)

- How much time and effort were put into developing a relationship by (name of the company) with the local communities? (P)

- What initiatives did (name of the company) undertake in case of a demonstrable challenge/failure? (P)

- What lessons did (name of the company) learn from that challenge/failure? (P)

\section{The importance of the right participatory strategy:}

- Do you have a formal plan for managing public engagement prior to starting your project? (P)

- How do you choose your participatory strategies? (P)

- Describe the role of government (both provincial and municipal) to construct a robust collaborative framework for renewable energy project development? $(\mathrm{M}, \mathrm{O}, \mathrm{P})$

- Are you familiar with the term "knowledge-broker"? (M,O,P)

(i) If Yes - Would a knowledge-broker be useful in educating the public about renewably energy projects and help in increasing public acceptance of the project?

(ii) If No - Would an independent person, acting as a go-between in the transfer of knowledge regarding the project between the project proponent and the public at large, be useful in educating the public and increasing public acceptance of the project? $(\mathrm{M}, \mathrm{O}, \mathrm{P})$

- Do you undertake the stakeholder analysis to inform the public? (P)

- How does the use of a social network analysis might help to consult with the public and involve them? (P) 


\section{The future of wind industry:}

- How do you see the future of wind industry in Ontario? (M,O,P)

- What will be the impact on the wind industry directly in the event the Ontario government shifts its focus from renewables? $(\mathrm{M}, \mathrm{O}, \mathrm{P})$

\section{Analysis}

Interpretation of case study findings will be done by:

- Content analysis: Summative content analysis for identifying certain words or content in text with the purpose of understanding the contextual use of the words or content to develop the main topics/concepts/themes.

- Conventional content analysis for explanation building of the main topics.

- Directive content analysis to explain how the data elements combined to address the research question.

- Cross-case analysis to find cross-case patterns.

\section{Reporting}

The outcome of this research will be a PhD dissertation and a paper will be submitted to a peer-reviewed journal.

\section{Schedule}

Following is a rough estimation for all of the major steps of the research:

\begin{tabular}{|l|l|}
\hline Tasks or Milestones & Planned Completion Date \\
\hline The REB approval & December 2013 \\
\hline Data collection & March 2015 \\
\hline Date analysis & July 2015 \\
\hline Report writing & August 2015 \\
\hline
\end{tabular}




\section{Appendix 2: Consent Form}

\section{RYERSON UNIVERSITY}

\section{CONSENT TO PARTICIPATE IN RESEARCH}

Title of the research: Investigating the role of public participation in wind energy development: the case studies of Ontario, Canada.

You are being invited to participate in a research study. Please read this Consent Form so that you understand what your participation will involve. Before you consent to participate, please ask any questions necessary to be sure you understand what your participation will involve.

\section{INVESTIGATORS}

This research study is being conducted by Anahita A.N.Jami, from the Environmental Applied Science and Management Program, Yeates School of Graduate Studies at Ryerson University.

If you have any questions or concerns about the research (e.g. applications of the study) please feel free to contact: Dr. Philip Walsh: Associate Professor, Ted Rogers School of Management, Ryerson University.

Contact info: Philip Walsh - $\underline{416.979 .5000 ~ E x t . ~} 2553$ - prwalsh@ryerson.ca

Anahita Jami - anahita.asadolahniaj@ryerson.ca

\section{PURPOSE OF THE STUDY}

This research is a case study. I intend to conduct interviews in an effort to help understand the underlying facilitators and constraints that affect public input to a renewable energy projects. In so doing I hope to provide guidance to improve the practice of public consultation in a renewable energy project development decision-making process.

\section{PROCEDURES}

If you volunteer to participate in this study, we would ask you to do the following:

Participate in an interview from 30 minutes to 1 hour.

$>$ The interview will consist of questions related to the role of public participation in developing a renewable energy project.

Sample questions:

- How important is public input in the decision-making process of developing a renewable energy site?

- How important is having public support?

$>$ Research findings will be available to participants through a published paper upon completion of the research. 


\section{POTENTIAL RISKS AND DISCOMFORTS}

$>$ I am only seeking information that you would provide any third party, however given the nature of inquiry, you may experience discomfort at providing candid answers to questions related to your job or experiences. You can at any time and without reason, discontinue the interview and/or decline to answer any individual questions during it.

\section{POTENTIAL BENEFITS TO PARTICIPANTS AND/OR TO SOCIETY}

$>$ You may not experience any direct benefits from participation in this study.

$>$ It is a sincere hope that, this case study will provide a participatory model for public participation that may help guide developers to undertake an effective and morally justified approval process for renewable energy projects.

\section{NO PAYMENT FOR PARTICIPATION}

$>$ You will not be paid to participate in this study.

\section{CONFIDENTIALITY}

$>$ Every effort will be made to ensure confidentiality of any identifying information that is obtained in connection with this study.

$>$ Identities of participants will not be revealed in the case study.

$>$ The interview might be audio recorded.

- Interviewee may review/edit the recordings or transcripts.

- The recordings will be destroyed after they have been transcribed within one month after interview.

$>$ Electronic data will be encrypted, portable devices will be password protected, and hardcopy data will be stored in a locked cabinet at Ryerson University.

$>$ Only the researchers and faculty supervisor mentioned above will have access to this information.

\section{PARTICIPATION AND WITHDRAWAL}

$>$ Participation in this study is voluntary. You can choose whether to be in this study or not. If you volunteer to be in this study, you may withdraw at any time without consequences of any kind. If you choose to withdraw from this study you may also choose to withdraw your data from the study. You may also refuse to answer any questions you don't want to answer and still remain in the study. Your choice of whether or not to participate will not influence your future relations with Ryerson University.

\section{RIGHTS OF RESEARCH PARTICIPANTS}

$>$ You may withdraw your consent at any time and discontinue participation without penalty. You are not waiving any legal claims, rights or remedies because of your participation in this research study. This study has been reviewed and received ethics clearance through the Ryerson University Research Ethics Board. If you have questions regarding your rights as a research participant, contact:

\section{Toni Fletcher, Research Ethics Coordinator Research Ethics Board Office of the Vice President, Research and Innovation}




\author{
Ryerson University \\ 350 Victoria Street \\ Toronto, Ontario M5B 2K3 \\ 416-979-5042 or toni.fletcher@ryerson.ca
}

\title{
SIGNATURE OF RESEARCH PARTICIPANT
}

I have read the information provided for the study "Investigating the role of public participation in wind energy development: the case studies of Ontario, Canada" as described herein. My questions have been answered to my satisfaction, and I agree to participate in this study. I have been given a copy of this form.

Name of Participant (please print)

Signature of Participant

Date

I agree to participate in this audio-recorded interview. I understand that such interview and related materials will be kept completely anonymous, and that the results of this study may be published in an academic journal.

Name of Participant (please print)

Signature of Participant

Date

SIGNATURE OF WITNESS

Name of Witness (please print)

Signature of Witness

Date 


\section{Appendix 3: Coding Scheme}

The coding focused on the five major levels of the public participation spectrum, which was used in the first draft of the conceptual framework. Additional codes emerged while reading the interview transcribes. Eventually, sixty-eight codes were established.

1. Following are some examples of the "inform" domain codes:

Misinformation; education; advantages and disadvantages of different sources of energy; NIMBY; availability of information; providing meaningful information; perceived health and ecological concerns; openness to change: changing people's mind; developers being more proactive

2. Following are some examples of the "consult" domain codes:

Flexibility in defining alternatives; transparency; honesty; two-way communication; feedback; representativeness: vocal minority-silent majority; meaningful consultation; meaningful participation; New LRP; local knowledge; emotionality; perceived quality of the current public engagement; predicting future of wind industry based on the current situation

3. Following are some examples of the "involve" domain codes:

ERTs; municipality involvement; provincial government involvement; financial ownerships; importance of public engagement

4. Following are some examples of the "collaborate" domain codes:

Building relationship; reaching an agreement/consensus; early engagement; the concept of knowledge-broker; adapting more collaborative techniques; building capacity; perceived advantages and challenges of a knowledge-broker; stakeholder analysis; social network analysis.

5. No obvious code could be found under "empower". It seems that the current decisionmaking process of wind energy development in Ontario is far from this level of public participation spectrum. However, there are some factors that impact the ability to empower stakeholders through the implementation of consensus-based decision-making in a negative way. Therefore, these factors are classified under "empower" in the following table.

The initial coding scheme proved to be crude when it came to the analysis of the role of the knowledge-broker in a collaborative decision-making process. There needed to be a significant refining of the coding scheme. All of the individually-coded extracts from the transcribes and notes were re-examined and recoded under the following headings (the statements are organized into topic areas or themes based on the original conceptual framework and/or research questions): 


\begin{tabular}{|c|c|c|c|c|c|c|c|}
\hline \multirow{2}{*}{\multicolumn{3}{|c|}{ Statome }} & \multirow{3}{*}{$\begin{array}{l}\text { Theme } \\
\\
\text { Inform }\end{array}$} & \multicolumn{4}{|c|}{$\begin{array}{l}\text { Number of times that } \\
\text { participants } \\
\text { mentioned a } \\
\text { statement }\end{array}$} \\
\hline & & & & \multirow{2}{*}{ 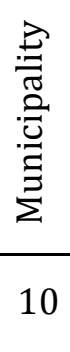 } & \multirow{2}{*}{ 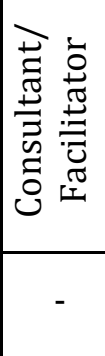 } & \multirow{2}{*}{ 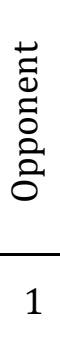 } & \multirow{2}{*}{$\begin{array}{l}\ddot{z} \\
0 \\
0 \\
0 \\
0 \\
0 \\
0 \\
6\end{array}$} \\
\hline A & \multicolumn{2}{|c|}{$\begin{array}{l}\text { As far as neighboring residents are concerned, they } \\
\text { prefer wind turbines in some other places (NIMBY) }\end{array}$} & & & & & \\
\hline B & \multicolumn{2}{|c|}{$\begin{array}{l}\text { Cost and benefit analysis: the small amount of clean } \\
\text { energy generated from wind turbines does not } \\
\text { justify its impact (higher price, potential health, and } \\
\text { ecological impacts) }\end{array}$} & Inform & 1 & - & 4 & - \\
\hline $\mathrm{C}$ & \multicolumn{2}{|c|}{$\begin{array}{l}\text { Educating local communities about renewable } \\
\text { energy and climate change has a positive impact on } \\
\text { changing people's mind }\end{array}$} & Inform & 4 & 1 & 2 & 4 \\
\hline $\mathrm{D}$ & \multicolumn{2}{|c|}{$\begin{array}{l}\text { In developing a wind facility, there is no real } \\
\text { participation, it is just ticking the consultation box } \\
\text { in RE application }\end{array}$} & Consult & 5 & 2 & 7 & - \\
\hline $\mathrm{E}$ & \multicolumn{2}{|c|}{$\begin{array}{l}\text { Involving the local community in the decision- } \\
\text { making process of wind projects at the early stages } \\
\text { will minimize the opposition }\end{array}$} & $\begin{array}{l}\text { Involve/ } \\
\text { Collaborate }\end{array}$ & 2 & 8 & 3 & 3 \\
\hline $\mathrm{F}$ & \multicolumn{2}{|c|}{$\begin{array}{l}\text { Misinformation: media, Internet, and interactions } \\
\text { with friends and family play a decisive role in the } \\
\text { decision-making process }\end{array}$} & Inform & 4 & 4 & 1 & 3 \\
\hline G & \multicolumn{2}{|c|}{$\begin{array}{l}\text { Offering financial ownership to the local community } \\
\text { is a good way to diffuse opposition }\end{array}$} & Involve & 1 & 2 & - & 9 \\
\hline \multirow{2}{*}{$\mathrm{H}$} & \multirow{2}{*}{$\begin{array}{l}\text { Ontario Environmental } \\
\text { Review Tribunal is a venue } \\
\text { for the public to raise their } \\
\text { concerns }\end{array}$} & Negative perception & \multirow{2}{*}{ Involve } & - & - & 7 & - \\
\hline & & Positive perception & & - & - & - & 4 \\
\hline I & \multicolumn{2}{|c|}{$\begin{array}{l}\text { Proponents of wind projects should value local } \\
\text { knowledge when developing a project }\end{array}$} & Consult & 2 & 3 & - & 1 \\
\hline $\mathrm{J}$ & \multicolumn{2}{|c|}{$\begin{array}{l}\text { Taking away municipality power in the REA process } \\
\text { was not a good idea, municipalities should be more } \\
\text { involved and properly consulted }\end{array}$} & Involve & 22 & 11 & 9 & 6 \\
\hline $\mathrm{K}$ & \multicolumn{2}{|c|}{$\begin{array}{l}\text { The current decision-making process of wind } \\
\text { projects is detrimental for both existing and future } \\
\text { projects }\end{array}$} & $\begin{array}{l}\text { Empower } \\
\text { (Core } \\
\text { question) }\end{array}$ & 5 & 2 & 11 & 8 \\
\hline
\end{tabular}




\begin{tabular}{|c|c|c|c|c|c|c|c|c|}
\hline \multirow{2}{*}{\multicolumn{4}{|c|}{ Stat }} & \multirow{2}{*}{ Theme } & \multicolumn{4}{|c|}{$\begin{array}{c}\text { Number of times that } \\
\text { participants } \\
\text { mentioned a } \\
\text { statement }\end{array}$} \\
\hline & & & & & $\lambda$ & & & \\
\hline \multirow{6}{*}{$\mathrm{L}$} & \multirow{6}{*}{$\begin{array}{l}\text { The main concerns } \\
\text { about wind turbine } \\
\text { are: }\end{array}$} & \multicolumn{2}{|c|}{ Aesthetics } & \multirow{6}{*}{$\begin{array}{l}\text { Empower } \\
\text { (Sub- } \\
\text { question\#1) }\end{array}$} & 4 & 5 & 1 & 3 \\
\hline & & \multicolumn{2}{|c|}{ Ecological/Environmental } & & 2 & 4 & 1 & 2 \\
\hline & & \multirow{3}{*}{ 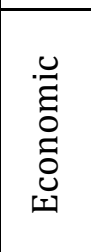 } & $\begin{array}{l}\text { Energy Market: } \\
\text { higher price/need }\end{array}$ & & 2 & 1 & 6 & \\
\hline & & & Property value & & 2 & 3 & 2 & 2 \\
\hline & & & Tourism & & - & - & 1 & \\
\hline & & \multicolumn{2}{|c|}{ Health } & & 5 & 6 & 5 & 4 \\
\hline \multirow{2}{*}{ M } & \multirow{2}{*}{$\begin{array}{l}\text { The new Large } \\
\text { Renewable } \\
\text { Procurement } \\
\text { provides more } \\
\text { opportunities for } \\
\text { community } \\
\text { involvement }\end{array}$} & \multicolumn{2}{|c|}{ Negative perception } & \multirow{2}{*}{ Consult } & - & - & 2 & 2 \\
\hline & & \multicolumn{2}{|c|}{ Positive perception } & & - & 3 & - & 3 \\
\hline \multirow{4}{*}{$\mathrm{N}$} & \multirow{4}{*}{$\begin{array}{l}\text { The notion of } \\
\text { knowledge-broker } \\
\text { helping the decision- } \\
\text { making process }\end{array}$} & \multicolumn{2}{|c|}{ Negative perception } & \multirow{4}{*}{$\begin{array}{l}\text { Collaborate } \\
\text { (Sub- } \\
\text { question\#2) }\end{array}$} & - & - & 1 & - \\
\hline & & \multicolumn{2}{|c|}{ Positive perception } & & 9 & 14 & 2 & 5 \\
\hline & & \multicolumn{2}{|c|}{ Positive under condition } & & 1 & 2 & 3 & 3 \\
\hline & & \multicolumn{2}{|c|}{ There are some challenges } & & 5 & 2 & 3 & 2 \\
\hline 0 & \multicolumn{3}{|c|}{$\begin{array}{l}\text { The problem with public input is that sometimes it } \\
\text { gets contentious }\end{array}$} & $\begin{array}{l}\text { Empower } \\
\text { (Core } \\
\text { question) }\end{array}$ & 1 & 20 & 1 & 8 \\
\hline $\mathrm{P}$ & \multicolumn{3}{|c|}{$\begin{array}{l}\text { The provincial government should be able to issue } \\
\text { directives when the stakeholders fail to co-operate }\end{array}$} & Involve & 4 & 4 & 6 & 6 \\
\hline Q & \multicolumn{3}{|c|}{$\begin{array}{l}\text { There is an economic jealousy in communities } \\
\text { where there is a wind facility }\end{array}$} & Involve & 2 & 4 & - & 5 \\
\hline $\mathrm{R}$ & \multicolumn{3}{|c|}{$\begin{array}{l}\text { Transparency and honesty are key components of } \\
\text { an effective communication }\end{array}$} & Consult & 1 & 9 & 6 & 12 \\
\hline $\mathrm{s}$ & \multicolumn{3}{|c|}{$\begin{array}{l}\text { Uncertainty about the regulatory governance in } \\
\text { Ontario will result in less investment on wind } \\
\text { energy in future }\end{array}$} & $\begin{array}{l}\text { Empower } \\
\text { (Core } \\
\text { question) }\end{array}$ & 7 & 8 & 2 & 8 \\
\hline
\end{tabular}




\section{Appendix 4: Joyce Smith's Letter to the Ontario Energy Board}

From: JEClarkSmith [mailto:jeclarksmith@aol.com]

Sent: April 21, 2011 3:58 PM

To: BoardSec; leejt@samsung.com

Subject: EB-2011-0063

Kristen Walli / John Pickernell

Ontario Energy Board

2300 Yonge Street, 27th Floor

P.O. Box 2319

Toronto, Ontario

M4P 1E4

Dear Ms. Walli, John Pickernell:

\section{RE: Intervenor Status Request, Joyce Smith for EB-2011-0063: Application for Leave to Construct Transmission Facilities for Grand Renewable Win LP}

I own the property located at $\mathbf{1 6 7}$ Haldimand Rd $\mathbf{2 0}$ and will be directly affected by the Application. I am an unrepresented lay person at this time, with limited knowledge of how to challenge this motion and or receive damages.

The purpose of this letter is to request that Intervenor Status be granted to myself and/or agent I choose to represent me, pursuant to Rule 23 of the Board's Rule of Practice and Procedure.

I support the green energy programmes, but believe it is necessary to attempt to protect my family's interests, and the equity in the property. My husband and I have planned and worked hard to create a base for our retirement.

The Transmission line, as per the information I received from you, will pass at the south side of my property. Since the correspondence did not give the exact location, size and structure of the tower/poles needed to support this line, I am very concerned about the impact this may have on my property value. In addition to the towers/poles, your information states there is to be an Interconnection Station (Connection to Hydro One) directly to the west of my property. This station's exact location, size and structure were also not included in the information correspondence. This may also impact my property value. The omission of this data, from the application, is a good enough reason to create a question as to what other information is missing. This does not promote public confidence.

I also have significant safety concerns, one regarding the choice to place the towers/poles near such a busy road. There have been numerous accidents at a number of intersections along Haldimand Rd 20 (on occasion ending up in my front yard ). What additional problems could occur with such a high voltage line being close to/or on a road allowance? Has this been studied? Another safety issue, is the location of the proposed site of the Interconnection Station, and the Transmission Line having to cross, the Trans-Northern's NPS 16 Petroleum Products Transmission Pipeline and the NPS 16 Enbridge Pipelines Inc. Pipeline a concern, if something goes wrong. Has this been studied? This problem could be in my backyard, soon. What does this do to property values?

My last and most important concern is for the health of our family. We already live near Hydro One towers but we are not wrapped around as this would do. There have been many studies done on the effects of high voltage towers on health. Anyone can pick and choose the study they 
want, to support their claims, depending on who paid for the study, and what they wanted to claim. I would not want to find out who's right by experience.

Putting my family in a cocoon of high voltage electricity, and makeing it impossible to sell my property, or reducing the property equity which creates all kinds of financial problems for retirement, is a deep concern. I believe a better way can be found to accomplish this transmission of electricity, not alongside roadways and in front of residents homes. I also believe that there are other issues that have not surfaced as yet, due to our lack of information of this matter, therefore I retain the right to address these issues, and others that may arise in the future. Please also be advised that if necessary, I will be seeking award of any and all costs, that $\mathrm{I}$ incur in this or any related further proceeding and compensation for all that is in my right to obtain by law. Not, withstanding,the aforementioned, I reserve the right to seek damages or costs related to this motion, through the honourable courts, at any further time, without further notice, subject to applicable provisions of the RULES OF CIVIL PROCEDURE etal.

I would like to be informed of all proceedings regarding this issue, as soon as the information becomes available, so that I may have more time in which to respond. Thankyou for your consideration on this matter.

Contact Information:

Joyce Smith

167 Haldimand Rd 20

RR\# 2 Hagersville ON

NOA $1 \mathrm{H} 0$

905-768-0079

jeclarksmith@aol.com

cc/email

Ontario Energy Board - boardsec@ontarioenergyboard.ca

Grand Renewable Wind LP, Mr. Jeong Tack Lee - leejt@samsung.ca

Paper copies will be sent to the above list. 


\section{Appendix 5: CLC Meeting Notices}

\section{Summerhaven Wind Energy Centre Community Liaison Committee (CLC): Meeting No. 1}

Wednesday, August 8, 2012

6:30 p.m. to 8:30 p.m.

Rainham Centre Community Hall

260 Kohler Rd., Selkirk ON

Open to the General Public - for Observation

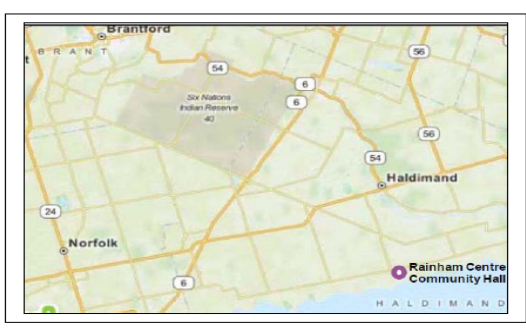

A Community Liaison Committee (CLC) has been established as a forum to exchange ideas, share information and provide regular updates on the construction, installation, operation, maintenance and retirement of the Summerhaven Wind Energy Centre ("Facility"). The CLC will not re-visit matters previously raised during the proposal/planning stage for the Facility (e.g. location of a Wind Centre in Haldimand County or the subject site, the Green Energy Act, the MOE's approval process, etc.).

A total of four (4) CLC meetings will be coordinated and facilitated by IBI Group over the next two years. All meeting materials (e.g. agendas, minutes, presentations, reports, etc.) will be made available for public review at www. NextEraEnergy Canada.com.

The CLC meetings will be open to the general public for observation. Brief depositions (up to 3 per meeting, at a maximum of 5 minutes each) may be made by members of the general public, providing the depositions pertain to items on the meeting agenda (i.e. the construction, installation, use, operation, maintenance and retirement of the Facility). Depositions will be selected at the discretion of the CLC Chair and the Company, in consultation with CLC members.

In order to be considered for a public deposition, please submit a request and the actual written deposition, at least one week in advance of a planned CLC meeting, to Amy Shepherd of IBI Group:

Email: ashepherd@ibigroup.com

Fax: 416 596-0644 (attention Amy Shepherd)

Mail: 230 Richmond Street West, Toronto, ON, M5V 1V6 (attention Amy Shepherd, IBI Group)

\section{IBI NEXTera

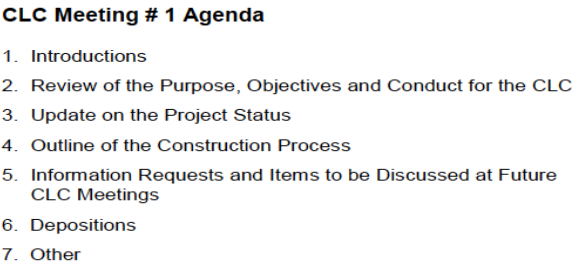

Ernestown Windpark Inc.

Community Liaison Committee Notice of $1^{\text {st }}$ Meeting

Thursday, January 30, 2014

6:30 to 8:00 PM

The Meeting Room

Odessa Fair Grounds

231 Main Street

Odessa, Ontario кон $2 \mathrm{HO}$

A Community Liaison Committee (CLC) has been established as a forum to exchange ideas, share information and provide updates on the construction, installation, operation, maintenance and retirement of the Ernestown Wind Park. The CLC will not re-visit matters related to the proposal/planning stage of the project.

The CLC meetings will be open to the general public for observation. Members of the public may submit requests for information, concerns or suggestions to be addressed at the meeting, in writing, to be received no later than 5 business days before the meeting. Please send your requests to the fax number, email or mailing addresses below. The Committee will address submissions at the meeting; the floor will not be open to members of the public to present submissions.

Meeting materials (agendas, minutes, etc.) will be made available for public review at www.ernestownwind.com.

If you would like additional information please contact Melody Tomkow, Community Relations Manager, or Bonnie Van Tassel, Project Coordinator.

Phone: 1-877-389-4099

Email: info@ernestownwind.com

Fax: 1-416-864-9568

Ernestown Windpark Inc. 2300 Yonge Street PO Box 2300 Toronto, ON M4P 1E4

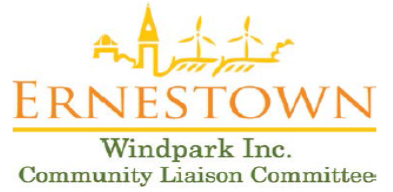

Agenda

Introductions

Review of the CLC mandate and Objectives, and member responsibilities.

Update on project status

Outline of the construction process

Information requests

Discussion - issues and concerns

Items to be discussed at future CLC meetings and action items for follow up

Other item

Ernestown - The Right Sized Wind Park in the Right Place! 


\title{
Port Dover \& Nanticoke Wind Project Community Liaison Committee
}

\author{
Tuesday, April 9, 2013 \\ 6:30 p.m. $-8: 30$ p.m. \\ Jarvis Community Centre \\ 18 James Street, Jarvis, Ontario

\section{Open to the General Public for Viewing}

A Community Liaison Committee ("CLC") has been established as a forum to exchange ideas, share information and provide regular updates regarding construction, installation, operation, maintenance and retirement of the Port Dover \& Nanticoke Wind Project ("the Project"). The 104.4 megawatt wind Project received its Renewable Energy Approval in July 2012.

Stantec Consulting Ltd. will coordinate the CLC meeting. All meeting materials (minutes, presentations, reports, etc.) will be made available for public review on the Project website at www.capitalpower.com/portdovernanticoke. The agenda for the meeting will be posted on the Project website at least one week in advance.

The CLC is open to the general public for observation. Brief depositions may be presented by members of the public. Please note that depositions will be selected at the discretion of the CLC Facilitator and Capital Power, in consultation with CLC members. To be considered for a public deposition, a written request, which must include the written deposition, must be submitted before Thursday, April 4, 2013, to the CLC Facilitator:

Herb Shields, CLC Facilitator, Stantec Consulting

Mail: 70 Southgate Drive Suite 1, Guelph, Ontario N1G 4P5

E-mail: herb.shields@stantec.com

Fax: (519) 836-2493

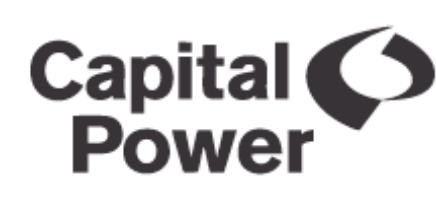

For general Project questions or comments, please e-mail PDN@capitalpower.com or phone 519-761-3969. To learn more about the proposed Project, visit our website at www.capitalpower.com/portdovernanticoke. 
Appendix 6: Sample of Leaflets and Signs Distributed by the Opposition Groups
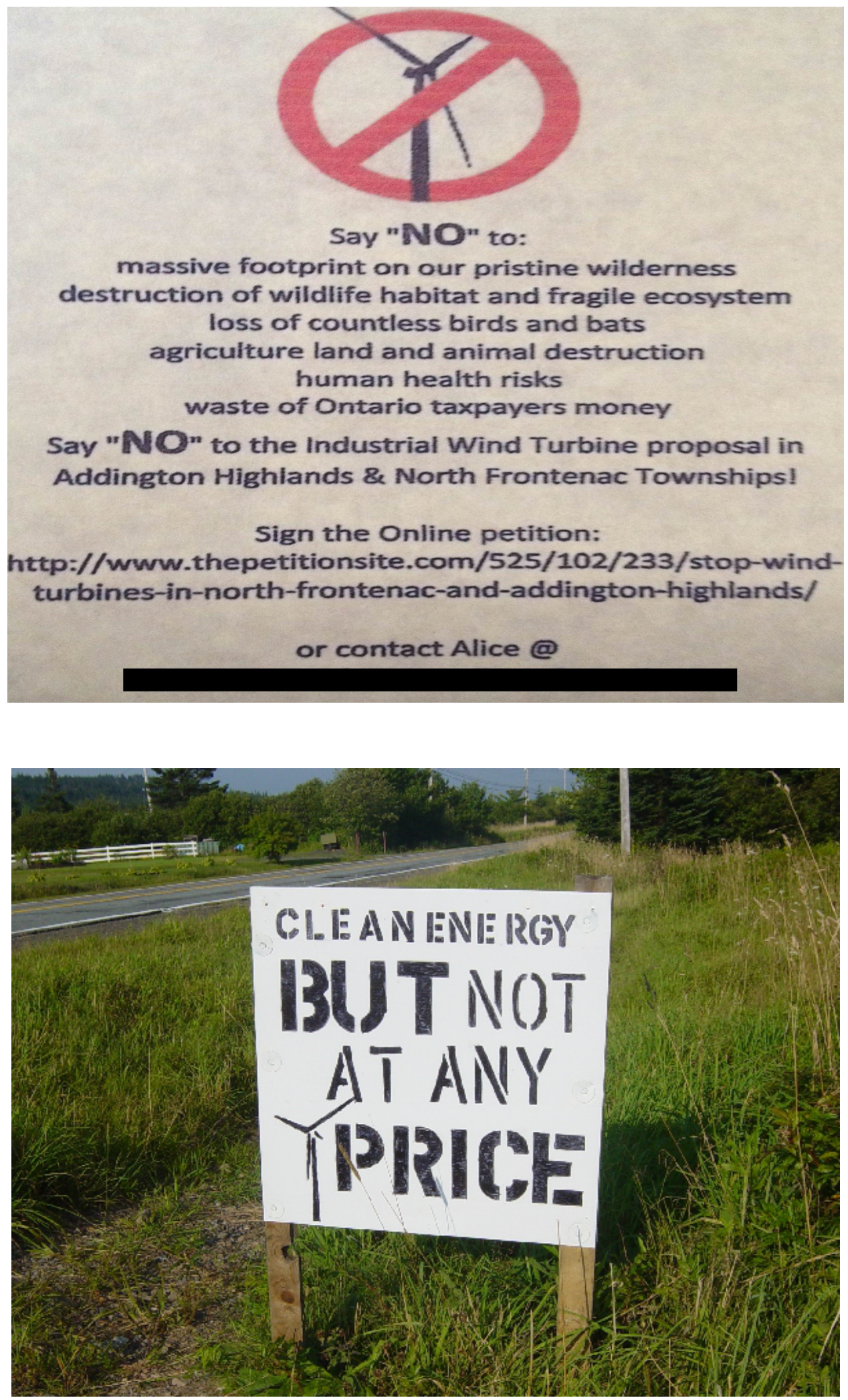


\section{Appendix 7: Email From the Spokesperson of an Opposition Group}

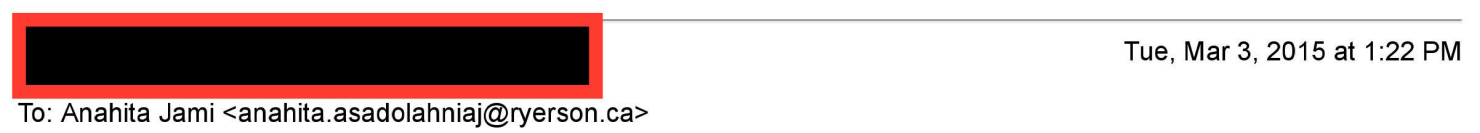

Dear Anahita,

Many thanks for your invitation to participate in your survey.

We are committed to the end of industrial wind factories in Ontario, and to exposing the experiment of climate fear induced profiteering from so called, "renewables" and the "green" agenda.

I am not sure that our objective is in any way meshing with your overview of engaging communities, consulting, or having us reflect on "visual impacts" and anticipatory negative impressions of wind power, or that we feel "not consulted." Which of course, we have not been. We are very far beyond these assertions promoted by industry and co opted by government.

If you read various websites that we and colleagues host, you will see how strong the anti wind movement has become world wide. There are, we estimate, many thousands of groups, with France itself having approximately 1500. EPAW, the European Platform, has over 850 member groups, and NA-PAW, the North American Platform, has well over 370 signatory groups, and literally thousands of other individual members.

I respectfully submit that no amount of university driven research on community participation will now be able to have any effect whatsoever to turn the tide on the outpouring of exposure of the fraud of wind power. Community consultation in the political and legal restraints we now have on us under the Green Energy and Economy Act of 2009 , is really a bit of an oxymoron.

I would add that the very first sentence in your précis is completely incorrect.

Wind Power Deployment: The Role of Public Participation in Decision-Making

Process

A wider use of renewable energy is seen as one way of meeting increasing global energy demand and fulfilling set targets for greenhouse gas reduction.

It continues to surprise us that University driven research rests on false premises of providing meaningful power, and reducing GHGs. Nothing could be further from the truth. Please see the attached documents.

World wide in 2013, a prominent study estimated that .2 of one percent, net zero, was 


\section{Appendix 8: CanWEA Fact Sheets}

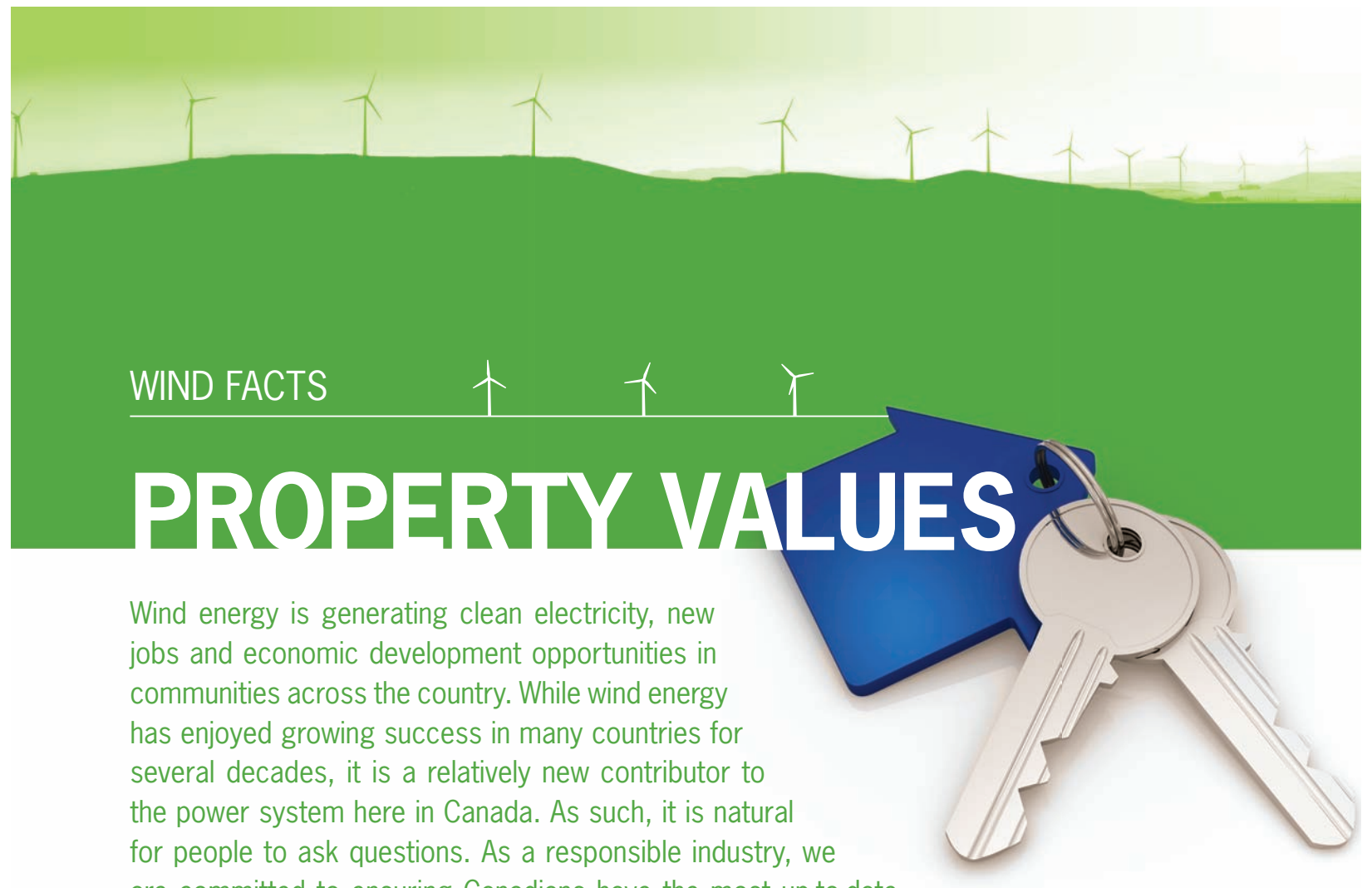

are committed to ensuring Canadians have the most up-to-date

factual information on wind energy.

\section{Wind Energy: Providing Significant Local Economic Benefits}

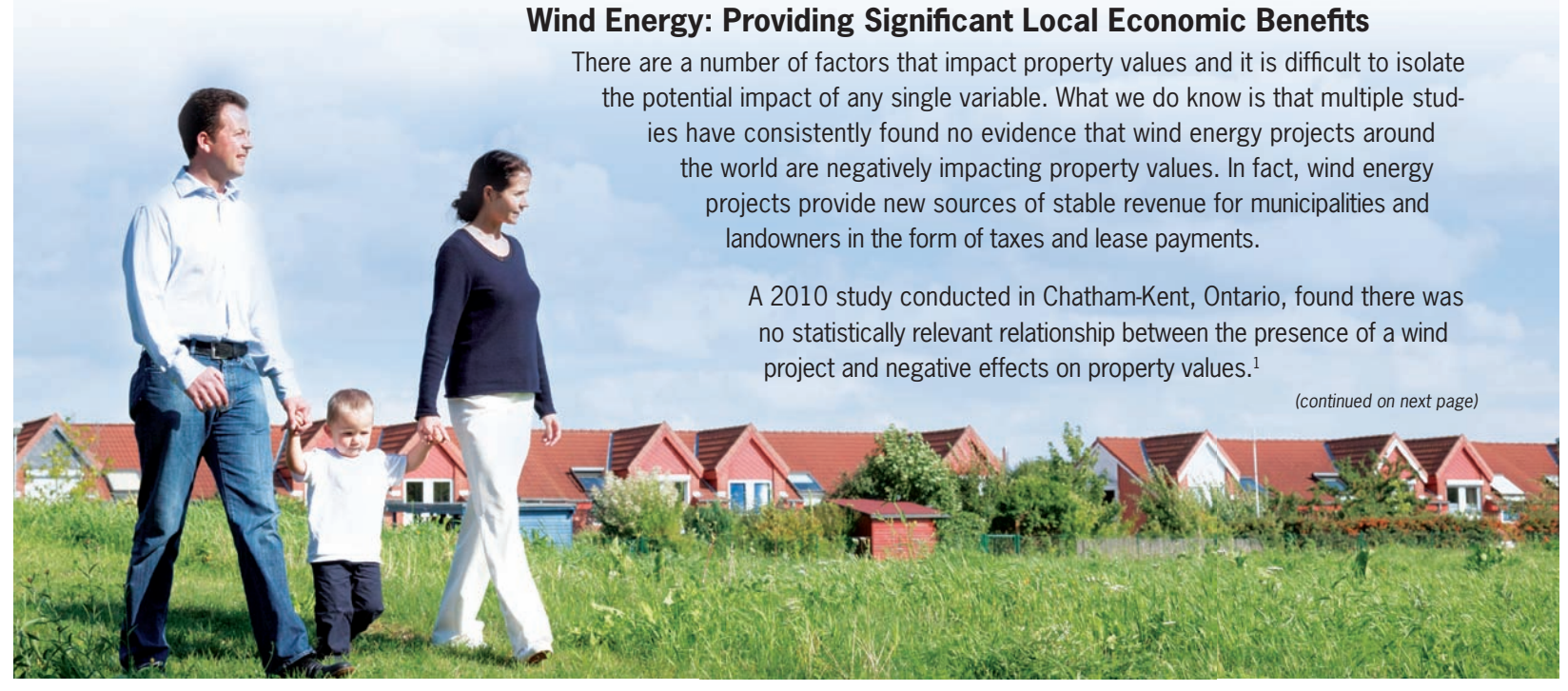


A similar analysis by the US Department of Energy's Lawrence Berkeley National Laboratory found that proximity to wind energy facilities does not have a pervasive or widespread adverse effect on the value of nearby homes. Researchers examined 7,500 single-family property sales between 1996 and 2007, covering a time span from before the wind farms were announced to well after construction

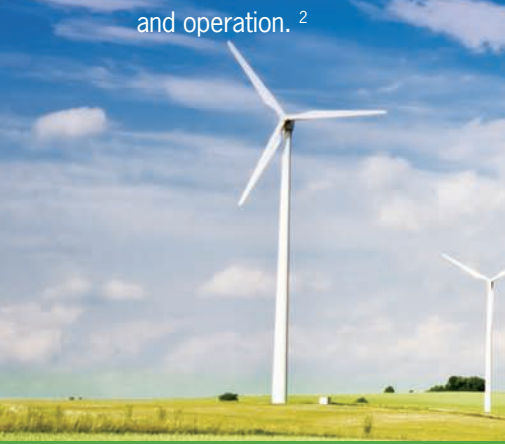

\section{WHAT DO THE EXPERTS SAY?}

"The Board finds there is no evidence to allow the Board to conclude that since the construction of the wind farm properties on what [the landowner] defines as the west side of the Island have sold for less than properties on the east side."

Assessment Review Board. Commission de révision de l'évaluation foncière. File No: WR 113994. Municipality: Township of Frontenac Islands

"In the study area, where wind farms were clearly visible, there was no empirical evidence to indicate that rural residential properties realized lower sales prices than similar residential properties within the same area that were outside the viewshed of a wind turbine."
Wind Energy Study - Effect on Real Estate Values in the Municipality of Chatham-Kent

\section{outside the vieushed of a wind turbine."}

A 2010 study looking at property values near the 396 MW Twin Groves Wind Farm in Illinois found prices were negatively affected before the wind farm was built, but rebounded after it was in place. ${ }^{3}$
"Based on the data sample and analysis presented here, no evidence is found that home prices surrounding wind facilities are consistently, measurably, and significantly affected by either the view of wind facilities or the distance of the home to those facilities."

The Impact of Wind Power Projects on Residential Property Values in the United States: A Multi-Site Hedonistic Analysis

"During the operational stage of the wind farm project, when property owners living close to the wind turbines actually had a chance to see if any of their concerns materialized, property values rebounded."

\section{Sources:}

1. Wind Energy Study - Effect on Real Estate Values in the Municipality of Chatham-Kent (Canning Consultants Inc. and John Simmons Realty Services Ltd., February 2010)

2. The Impact of Wind Power Projects on Residential Property Values in the United States: A Multi-Site Hedonistic Analysis (Ben Hoen, Ryan Wiser, Peter Cappers, Mark Thayer, and Gautam Sethi, December 2009)

3. Wind Farm Proximity and Property Values: A Pooled Hedonistic Regression Analysis of Property Values in Central Illinois (Jennifer L. Hinman, May 2010)

Wind Farm Proximity and Property Values: A Pooled Hedonistic Regression Analysis of Property Values in Central Illinois

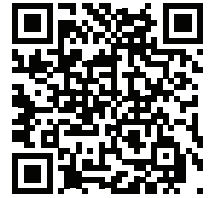

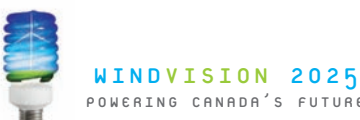

POWERING CANADA'S FUTURE www.canwea.ca canwea

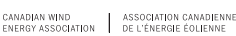


provides important protection for consumers. It is unlikely, for example, that natural gas will remain at today's low prices over the long term. Natural gas prices vary over time with changes in supply and demand - just a few years ago electricity from natural gas-fired projects was more expensive than electricity from wind.

Because wind requires no fuel, produces very little waste and consumes barely any water during operation, it also provides a hedge against the risk and uncertain costs of complying with future greenhouse gas emission restrictions and other environmental regulations.

The cost to build wind energy continues to decline while significant efficiency gains are being achieved in modern technology and siting. Wind projects also have very short construction periods and can be deployed quickly with significant positive impacts delivered to local communities. Wind energy developers absorb almost all of the upfront costs in developing their projects, which means no front-end or long-term risks to taxpayers and ratepayers.

Unlike large nuclear or natural gas plants, wind energy projects can be scaled to meet changing economic and environmental circumstances. Modern electricity systems around the world include more wind energy to reduce carbon emissions, improve grid reliability, and sustain predictable and stable electricity prices.

\section{WHAT DO THE EXPERTS SAY?}

There is an urgent need to invest in new electricity generation and infrastructure after decades of underinvestment. According to the Conference Board of Canada, \$347 billion in investment in Canada's electricity system is required between now and 2030 - and all of these costs will be passed on to consumers.

\section{r}

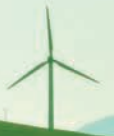

According to Power Advisory LLC, wind energy generation accounted for only 5 per cent of the total increase in the electricity bill of Ontario consumers between 2009 and $2012 .{ }^{4}$

A recent analysis by GL Garrad-Hassan of wind sites in British Columbia also found that turbine costs are down roughly 20 per cent over the past few years while productivity has increased almost 30 per cent thanks to technological advances. ${ }^{5}$

\section{Interested in learning more?}

The WindFacts website contains facts and resources that address a number of areas of key interest to Canadians: how wind works, health, community, affordability and environment and wildlife. By logging in through top social media programs, visitors can submit questions about wind energy.

windfacts.ca

\section{Sources:}

1. Mining coal, mounting costs: The life cycle consequences of coal. Centre for Health and The Global Environment, Harvard Medical School, January 2011

2. Behind the switch: pricing Ontario electricity options, The Pembina Institute, July 2011 3. Shedding Light on the Economic Impact of Investing in Electricity Infrastructure, The Conference Board of Canada, February 2012 4. Customer Bill Impacts of Generation Sources in Ontario, Power Advisory LLP, February 2013. http://canwea.ca/pdf/Customer-Bill-Impacts-ofGeneration-Sources-in-Ontario.pdf

5. Assessment of the estimated costs of wind energy in British Columbia, GL Garrad Hassan Canada, Inc., May 2012. http://canwea.ca/pdf/ Assessment_Est-Cost-of-Wind-Energy_BC.pdf

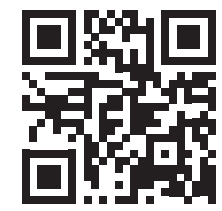

www.canwea.ca

canwea 


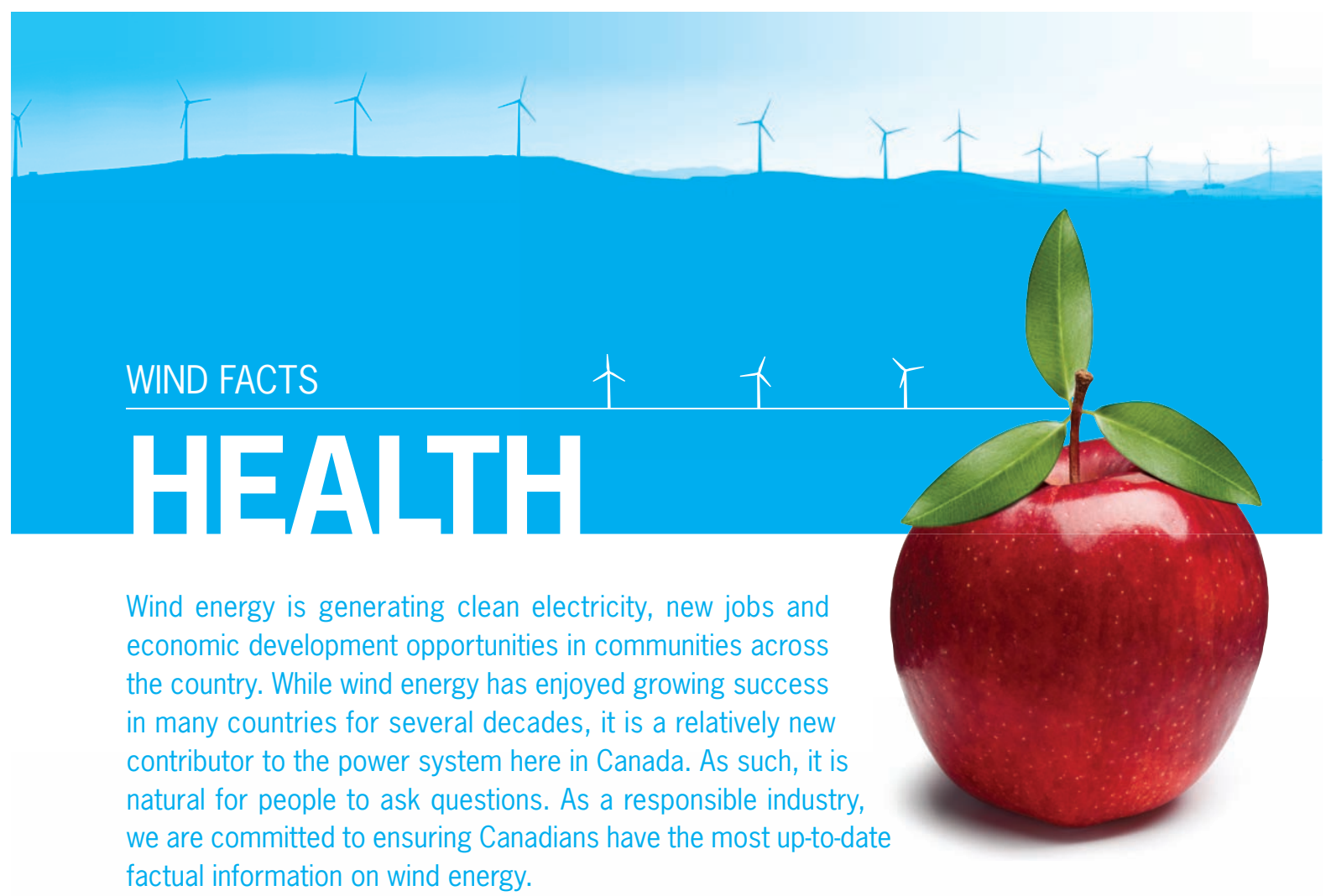

factual information on wind energy.

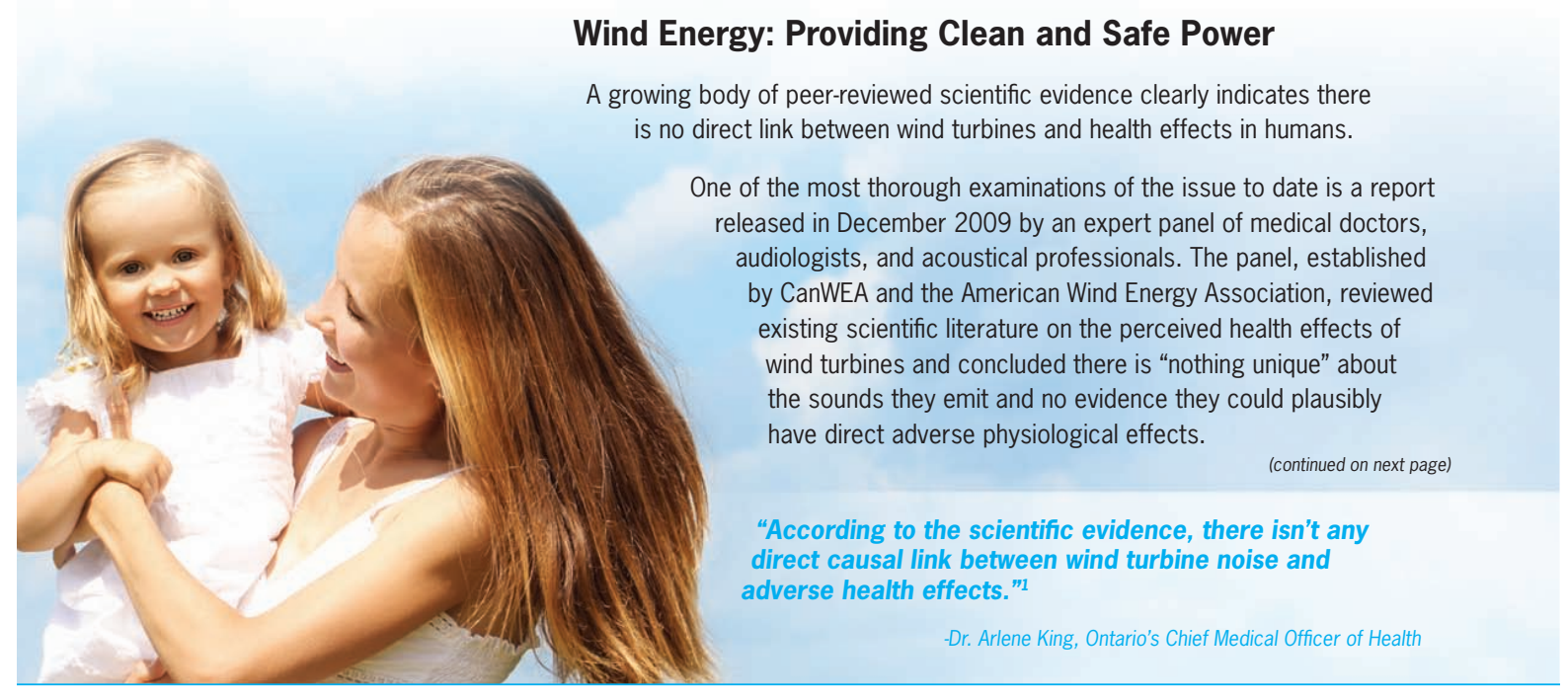


Ontario's Chief Medical Officer of Health and the National Public Health Institute in Quebec reached the same conclusion in their own independent reviews of available evidence.

Responsible siting of projects and meaningful community engagement will address any sound impacts for neighbouring homes and communities. Ontario, for example, has the most stringent regulations in Canada with its requirement that turbines be at least 550 metres from dwellings.

\section{Wind power for clean air.}

While operating, wind turbines are powered by wind, producing no greenhouse gasses or pollution.

\section{WHAT DO THE EXPERTS SAY?}

"The infrasound generated by wind turbines is not of sufficient intensity to cause health problems, or even a nuisance."
"The body of accumulated knowledge provides no evidence that the audible or sub audible sounds emitted by wind turbines have any direct adverse physiological or health effects."

Dr. Robert McCunney, Pulmonary Division Specialist in Occupational and Environmental Medicine, Massachusetts General Hospital, Wind Turbine Sound and Health Effects: An Expert Panel Review
National Public Health Institute of Québec study, 2009

"Ontario doctors, nurses and other health professionals support energy conservation combined with wind and solar power, to help us move away from coal."

2011 advertising campaign sponsored by the Ontario College of Family Physicians, Registered Nurses Association of Ontario, the Asthma Society of Canada and the Ontario Lung Association

Interested in learning more? These links will take you to PDFs:

Wind Turbine Sound and Health Effects: An Expert Panel Review

(www.canwea.ca/pdf/talkwind/Wind_Turbine_Sound_and_Health_Effects.pdf)

Executive Summary, Conclusions and Panel Member Biographies (www.canwea.ca/pdf/talkwind/Wind_Turbine_Sound_and_Health_Effects-Executive_Summary.pdf)

The Potential Health Impacts of Wind Turbines (report by Ontario Chief Medical Officer of Health) (www.health.gov.on.ca/en/public/publications/ministry_reports/wind_turbine/wind_turbine.pdf)

Wind Turbines and Public Health (study by National Public Health Institute of Québec) (www.inspq.qc.ca/pdf/publications/1015_EoliennesSantePublique.pdf)

${ }^{1}$ The Potential Health Impacts of Wind Turbines. (Ontario Chief Medical Officer of Health, May 2010)

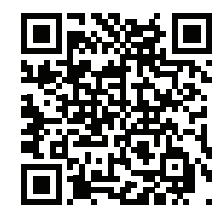




\title{
Appendix 9: Letter of Melancthon Township Mayor to the Premier of Ontario
}

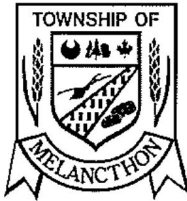 \\ The Corporation of \\ THE TOWNSHIP OF MELANCTHON \\ 157101 Hwy. 10, R.R. \# 6, Shelburne, Ontario, LON 159 \\ Denise B. Holmes, AMCT \\ CAO/Clerk-Treasurer \\ Telephone - (519) 925-5525 \\ Fax No. - (519) 925-1110 \\ Website: www.melancthontownship.ca \\ Email:info@melancthontownship.ca
}

August 13, 2013

The Honourable Kathleen Wynne

Premier of Ontario and

Minister of Agriculture and Food

Legislative Building

Queen's Park

Toronto, Ontario

M7A 1 A1

Dear Premier,

On July 23,2013 , there was another blow to democracy, and local municipal governance as a result of your Government's draconian and repressive Green Energy and Economy Act. Dufferin Wind Power Inc. (Longyuan Canada Renewables Ltd.) was successful in its' Court Application regarding the storage of turbines on a property that was not zoned for that activity within the Township of Melancthon. Our position based on solid planning advice was that the exception did not allow for the off-site storage of turbine components on a property that was not zoned for that type of use. However, Mister Justice Morawetz ruled in favour of Dufferin Wind Power Inc. concluding that the storage property does form part of the Applicant's "renewable energy undertaking." While disappointed, we accept the ruling of Mister Justice Morawetz.

Through your legislation, the Developers of wind farms may have been granted an open license to engage in any activity without being subject to the planning approval process. Surely that could not have been the intended consequence of the amendments to the Planning Act. The lack of clarity in the Green Energy Act produced this unexpected result.

On July 5, 2013, our Community and in fact the entire County, received another blow as a result of the Leave to Construct Approval that was granted. In spite of countless concerns raised by the Citizens of Melancthon and Dufferin County, the Municipalities of Melancthon, Amaranth, the 
Town of Shelburne and the County of Dufferin, the Ontario Energy Board approved the Leave to Construct Application.

Individuals and various Municipalities spent many hours and thousands of dollars preparing material to be reviewed in the Leave to Construct process. The legitimate concerns of affected individuals and Municipalities were arbitrarily dismissed. Unbelievable.

While there are many concerns about the potential health risks as a result of turbines and in the case of Dufferin Wind the $230 \mathrm{KV}$ above ground power line to be located on an old railway corridor, there are in the opinion of many, more concerns about the way Dufferin Wind conducts their business.

People are incensed by the bullying tactics employed by Dufferin Wind Power Inc. They have shown themselves to be overly aggressive, uncaring and frankly deceptive. The reason they can act that way, is because of the flawed Green Energy Act that allows them to steam roll over Municipalities and Individuals.

They have threatened our Council with expropriation, as well as the Town of Shelburne and the County of Dufferin. They have applied to expropriate land from the County, three land owners along the rail line and three Farmers in our Township.

The farmers had Agreements with Dufferin Wind Power Inc. It is my belief that Dufferin Wind Power Inc. found that wherever it may be cheaper to change where turbines would be placed, they simply approached the farmers telling them to sign amendments to Agreements or they would expropriate their land. By allowing changes to the original Agreement, the Farmers would have prime tiled drained fields ruined as the drainage equipment would be cut and dug up rendering it useless. In addition, new turbine placements would prohibit the Farmers from using existing irrigation equipment. They have now indicated that they may start digging up fields within two weeks to build roads prior to the harvest which will have a negative impact on the Farmers. I fail to understand why Landowners must adhere to Contracts, while wind farm developers are free to arbitrarily change the terms of Agreements, after the fact and to their own benefit. Once again, this could not have been the legitimate intention of your Government in passing this seriously flawed legislation.

Section 2.3.1 of the Provincial Policy Statement says that "Prime agriculture areas shall be protected for long term use for agriculture". This Policy Statement is a prime consideration in the planning approval process. It was a concern raised in the Court Application referenced above. I ask you, as Minister of Agriculture and Food, to help me understand and reconcile how destroying prime agriculture tiled drained land and not allowing crops to be irrigated helps protect 
agriculture. It does appear that your Government has chosen to favour foreign owned wind farm developers, over the interest and livelihood of Ontario farmers.

Dufferin Wind Power Inc. continues to "push" everyone for Building Permits and Road Use Permits even before any Agreements have been put in place. They have done whatever they can to avoid dealing with our Council. To that end, they have acquired private land leases to avoid using the road right of ways. This compounds the overhead line concern as there will now be parallel lines in many areas.

In the other wind farm developments in our Township, the transmission and collection lines have been buried, without a hassle from the Proponents. That was our request of Dufferin Wind Power Inc., and they refused to deal with us regarding our legitimate concerns with the transmission line. The transmission line is $13 \mathrm{~km}$ long in our Township. We advised Dufferin Wind Power Inc. that there were areas that could be above ground BUT around residences, the line should be buried. This is the same approach we have taken with other Developers. The distance is approximately 4.3 $\mathrm{km}$ of the $13 \mathrm{~km}$. Dufferin Wind Power Inc. insisted it was too expensive to bury the line. Melancthon provided them with a map outlining where they could use overhead lines in the Collection Area to offset the cost. They refused to discuss or negotiate any issues with respect to the transmission lines.

Melancthon Council are Pioneers in wind power development in Ontario when the first 45 turbines were erected by Canadian Hydro Developers, Inc. in 2005. With the approval of the Dufferin Wind Power Project there will be one turbine for every 14.82 Residents.

We have more than "done our share" and at our last Council meeting passed an "Unwilling Host" motion. While it has been sent to you, I enclose a copy with this letter.

We have sent other motions regarding Moratoriums until Health Studies have been completed. Council provided a motion outlining a "capping formula" that would allow Municipalities to calculate and determine an "acceptable" number of turbines for their communities if they want them. All of these have been ignored by your Government.

Dufferin Wind Power Inc. had been procrastinating for over a year about the Road Use Agreement and to detail those issues would take far more effort than it is worth. However, they continually claimed and stated that we were being hard to get along with by making unreasonable demands.

The Council authorized the CAO and I to sign an Agreement about two weeks ago with a different Wind Developer. The items that Council felt were important were incorporated without problems. That means that other than the Agreement with Dufferin Wind Power Inc., Melancthon Council 
$-4-$

has negotiated four Agreements without issues. We have NEVER asked Dufferin Wind Power Inc. to do more than the other four Developers have done willingly.

Dufferin Wind Power Inc. has applied under Section 41.9 of the Electricity Act to have the Ontario Energy Board decide where in the road allowances the distribution lines will be located as it has been unable to come to an agreement with Council, despite Council's continued and reasonable efforts. We believe we know where the problem is, and it is not Melancthon Council.

The reason they can do this, is again because of the flawed Legislation passed by your Government.

Reluctantly, Council directed the CAO and I to sign a Road Agreement July 31, 2013 with Dufferin Wind Power Inc. This would be the only way to retain even a modicum of control and to obtain any true financial benefit, even if it meant signing an Agreement with a Developer who does not appear to have any real interest in the interests of the Community affected by the Project. Even then, the bullying continued. Their Solicitor said they would not send the letter to the Ontario Energy Board cancelling the 41(9) process until all permits were issued. Only after our Solicitor discussed this issue with their Solicitor, did they agree to withdraw the 41(9) application. The deadline for submission was August 2, 2013 and I called an Emergency Meeting for July 31, 2013 to deal with the Agreement. Some permits were not in the control of the Township. The ones we did control were being worked on expeditiously and could not be completed in eight hours as our Office was closed Friday. The Solicitor also demanded a Preconstruction Meeting with our Engineer and Roads Superintendent within 24 hours. Although it was his day off, Staff agreed to come in, only to be told late the day before, Dufferin Wind Power Inc. did not have the reports and drawings they were to provide for the meeting.

If this is the type of business your Government is trying to attract to Ontario, it is a sad day for democracy in our Province.

As Premier, I ask you to intervene. It is imperative that further changes are made to the Green Energy and Economy Act. The tweaks that were introduced this Spring will do nothing to stop this type of aggressive behavior. County wide it has been acrimonious. There is no place in the appeal process to deal with the lack of common sense or respect. Please exercise your power and make this right.

You were not able to attend our $160^{\text {th }}$ Anniversary Celebration so I would like to extend another invitation to you to visit our Township at your convenience and to learn more about the impact your Government programs have on our Township and meet some of the affected farmers. 
On Behalf of the Council of the Corporation of the Township of Melancthon, Respectfully,

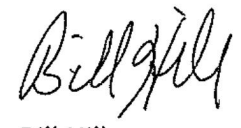

Bill Hill

Mayor

c. Honourable Bob Chiarelli, Minister of Energy

Honourable Jim Bradley, Minister of Environment

Honourable Tim Hudak, Leader PC Party

Honourable Andrea Horwath, Leader NDP Party

David Tilson, MP

Sylvia Jones, MPP

Sonya Pritchard, Dufferin County CAO

All Municipalities in Dufferin County 


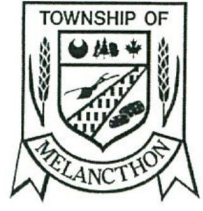

The Corporation of

\section{THE TOWNSHIP OF MELANCTHON}

157101 Highway 10, Melancthon, Ontario, L9V 2 E6

Denise B. Holmes, AMCT

CAO/Clerk-Treasurer

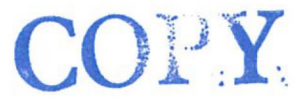

Telephone - (519) 925-5525

Fax No. - (519) 925-1110

Website: www.melancthontownship.ca Email:info@melancthontownship.ca

July 22, 2013

Premier Kathleen Wynne

Minister Bob Chiarelli, Ministry of Energy

Sylvia Jones, MPP

Association of Municipalities of Ontario

Multi-Municipal Wind Turbine Working Group

Municipalities in the County of Dufferin

Dear Sirs/Madames:

At the meeting of the Council of the Corporation of the Township of Melancthon held on July 18, 2013, the following resolution was introduced and passed:

\section{Be it resolved that:}

"Whereas the Corporation of the Township of Melancthon are the Pioneers of Wind Power Development in the Province of Ontario with the establishment of the Melancthon Wind Farm Phase I in 2005 and the development of 45 turbines;

And Whereas there were another 66 turbines in the Melancthon Wind Farm Phase II and seven turbines in the Plateau Wind Project, plus the recently approved Dufferin Wind Project of 49 turbines allowed in our Township. Therefore, the ratio of turbines is one turbine for every 14.82 residents;

And Whereas the Council of the Corporation of the Township of Melancthon has passed motions requesting moratoriums until health studies have been completed as well as a motion providing for a "capping" formula to assist municipalities to determine an allowable number of turbines in their Communities if they wish, all of which have been ignored by the Provincial Government;

And Whereas the Province's current wind power development plans are counter to the ideals set out in the precautionary principle; 
Page 2

Now therefore be it resolved that in view of the approval on July 5, 2013 of the Dufferin Wind Leave to Construct, despite numerous concerns raised by residents of Melancthon Township and Dufferin County, concerns from the Councils of the Townships of Melancthon and Amaranth, the Town of Shelburne and the County of Dufferin, the Corporation of the Township of Melancthon hereby declares that they are an unwilling host for future industrial wind turbine development. And that this resolution be sent to Premier Kathleen Wynne; Minister of Energy Bob Chiarelli; Sylvia Jones, MPP; AMO; Multi-Municipal Wind Turbine Working Group, Municipalities in the County of Dufferin."

Carried.

Yours truly,

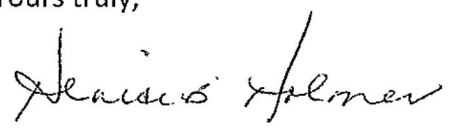

Denise B. Holmes, AMCT

$\mathrm{CAO} /$ Clerk-Treasurer 


\section{References}

Aitken, M. (2009). "Wind power planning controversies and the construction of 'expert' and 'lay' knowledges" Science as Culture, Vol. 18, No. 1, pp. 47-64.

Aitken, M. (2010). "Why we still don not understand the social aspects of wind power: a critique of key assumptions within the literature" Energy Policy, Vol. 38, No. 4, pp. 1834-1841.

Allmendinger, P. and Tewdwr-Jones, M. (2002). Planning futures: new directions for planning theory. Routledge: New York.

American Wind Wild-life Institute. Wind turbine interactions with wildlife and their habitats: a summary of research results and priority questions. Retrieved Auguest 2015, from https://awwi.org/resources/summary-of-wind-wildlife-interactions-2/\#sectionsummary-of-windwildlife-interactions.

Arnstein, S. (1969). "A ladder of citizen participation" Journal of the American Institute of Planners, Vol. 35, No. 4, pp. 216-224.

Bandura, A. (1986). Social foundations of thought and action: a social cognitive theory. Prentice Hall: Englewood Cliffs.

Baxter, P. and Jack, S. (2008). "Qualitative case study methodology: study design and implementation for novice researchers" The Qualitative Report, Vol. 13, No. 4, pp. 544-559.

Bell, D., Gray, T., and Haggett, C. (2005). "The 'social gap' in wind farm siting decisions: explanations and policy responses" Environmental Politics, Vol. 14, No. 4, pp. 460477.

Berg, B.L. (1998). Qualitative research methods for the social science (3 ${ }^{\text {rd }}$ ed.). Allyn and Bacon: Boston.

Bijlsma, J., Eijndhoven, J.V., and Turkenburg, W. (1988). "Experiences with public participation in decision-making concerning energy policy in the Netherlands" Bulletin of Science, Technology, and Society, Vol. 8, No. 4, pp. 397-404.

Breukers, S. and Wolsink, M. (2007). "Wind power implementation in changing institutional landscapes: an international comparison" Energy Policy, Vol. 35, No. 5, pp. 27372750.

Burgess, H. and Spangler, B. (2003). Consensus building. Retrieved Auguest 2015, from http://www.beyondintractability.org/essay/consensus-building.

Burton, D. (2000). "The use of case studies in social science research" in Research Training for Social Scientists, edited by D. Burton. Sage Publications: London. 
Canadian Environmental Assessment Agency. Basics of Environmental Assessment. Retrieved December 2015, from http://www.ceaa.gc.ca/default.asp?lang=En\&n=B053F859-1.

Canadian Wind Energy Association. Wind energy: building a stronger, cleaner and more affordable power system in Ontario. Retrieved August 2015, from http://canwea.ca/wind-energy/ontario/.

Cannell, C.F. and Kahn, R.L. (1968). "Interviewing" in The handbook of social psychology, Vol. 2, edited by G. Lindzey and E. Aronson. Addison-Wesley: Boston.

Charnley, S. and Engelbert, B. (2005). "Evaluating public participation in environmental decision-making: EPA's superfund community involvement program" Journal of Environmental Management, Vol. 77, No. 3, pp. 165-182.

Choi, B.C.K., Pang, T., Lin, V., Puska, P., Sherman, G., Goddard, M., Ackland, M.J., Sainsbury, P., Stachenko, S., Morrison, H., and Clottey, C. (2005). "Can scientists and policy makers work together?" Journal of Epidemiology and Community Health, Vol. 5, No. 59, pp. 632-637.

Coenen, Frans H. J. M. (2009). Public participation and better environmental decisions: the promise and limits of participatory processes for the quality of environmentally related decision-making. Springer: Dordrecht, London.

Cohen, L., Manion, L., and Morrison, K. (2000). Research methods in education (5 $5^{\text {th }}$ ed.). RoutledgeFalmer : London.

Coleby, A.M., Miller, D.R., and Aspinall, P.A. (2009). "Public attitudes and participation in wind turbine development" Journal of Environmental Assessment Policy and Management, Vol. 11, No. 1, pp. 69-95.

Cooper, A. (2010). Knowledge-brokers - a promising knowledge mobilization strategy to increase research use and its impact in education. University of Toronto: Toronto.

Corscadden, K., Wile, A., and Yiridoe, E. (2012). "Social license and consultation criteria for community wind projects" Renewable Energy, Vol. 44, pp. 392-397.

Day, J.C. and Gunton, T.I. (2003). "The theory and practice of collaborative planning in resource and environmental management" Environments, Vol. 31, No. 2, pp. 5-19.

Devine-Wright, P. (2005). "Beyond NIMBYism: towards an integrated framework for understanding public perceptions of wind energy" Wind Energy, Vol. 8, No. 2, pp. 125-139.

Devine-Wright, P. (2009). "Rethimking Nimbysim: the role of place attachment and place identity in explaining place protective action" Journal of Community and Applied Social Psycology, Vol. 19, No. 6, pp. 426-441. 
Doelle, M. and Sinclair, A.J. (2006). "Time for a new approach to public participation in EA: promoting cooperation and consensus for sustainability" Environmental Impact Assessment Review, Vol. 26 , No. 2 , pp. 185-205.

Eisenhardt, K.M. (1989). "Building theories from case study research" The Academy of Management Review, Vol. 14. No. 4, pp. 532-550.

Eltham, D., Harrison, G., and Allen, S. (2008). "Change in public attitudes towards a Cornish wind farm: implications for planning" Energy Policy, Vol. 36, No. 1, pp. 23-33.

Environmental Assessment Act. Consultation in Ontario's environmental assessment process: code of practice. Retrieved August 2014, from https://www.ontario.ca/environment-and-energy/consultation-ontariosenvironmental-assessment-process.

Environmental Review Tribunal. Environmental and land tribunal Ontario. Retrieved July 2015, from http://www.ert.gov.on.ca/english/about/index.htm.

Finnigan, D.S. (2003). An evaluation of civil society participation in collaborative land use planning in British Columbia. Simon Fraser University: Vancouver.

Fischer, F. (2009). Democracy and expertise. Oxford University Press: Oxford.

Fisher R., Ury, W., and Patton, B. (2011). Getting to yes: negotiating agreement without giving in ( $3^{\text {th }}$ ed.). Penguin Books: New York.

Fitzpatrick, P. and Sinclair, A.J. (2003). "Learning through public involvement in environmental assessment hearing" Journal of Environmental Management, Vol. 67, No. 2, pp. 161-174.

Flyvbjerg, B. (2006). "Five misunderstanding about case study research" Qualitative Inquiry, Vol. 12, No. 2, pp. 219-245.

Fullan, M.G. (1999). Change forces: the sequel. Falmer Press: London.

Gagnon, Y. (2010). The case study as research method. University of Quebec: Quebec.

George, A.L. and McKeown, T. (1985). Case studies and theories of organizational decisionmaking. JAI Press: Greenwich.

Gibson, H., Hunsberger, C.A, and Wismer, S. (2005). "Citizen involvement in sustainability centred environmental assessment follow-up" Environmental Impact Assessment, Vol. 25, No. 6, pp. 609-627.

Gipe, P. and Murphy, J. (2005). Ontario landowner's guide to wind energy. Ontario Sustainable Energy Association: Toronto.

Government of Ontario. (2014). Renewable Energy Approval. Retrieved August 2014, from http://www.e-laws.gov.on.ca/html/regs/english/elaws_regs_090359_e.htm\#BK51. 
Green, L.W. and Kreuter, M.W. (1999). Health promotion planning: an educational and ecological approach ( $3^{\text {rd }}$ ed.). Mayfield Publishing Company: Mountain View.

Groothuis, P.A., Groothuis, J.D., and Whitehead, J.C. (2008). “Green vs. green: measuring the compensation required to site electrical generation windmills in a viewshed" Energy Policy, Vol. 36, No. 4, pp. 1545-1550.

Haggett, C. (2011). “Understanding public responses to offshore wind power" Energy Policy, Vol. 39, No. 2, pp. 503-510.

Healey, P. (1998). "Collaborative planning in a stakeholder society" The Town Planning Review, Vol. 69, No. 1, pp. 1-21.

Health Canada. Wind turbine noise and health study: summary of results. Retrieved August 2015, from http://www.hc-sc.gc.ca/ewh-semt/noise-bruit/turbineeoliennes/summary-resume-eng.php.

Hersh, M.A. (1999). "Sustainable decision-making: the role of decision support systems" IEEE Transactions on Systems, Man, and Cybernetics, Part C (Applications and Reviews), Vol. 29, No. 3, pp. 395-408.

Hiscock, J. (2012). The case of distributed electricity storage in Ontario's electricity system. Ryerson University: Toronto.

Holburn, G. (2015). The local economic benefits of wind power development and operation: $a$ case study of Haldimand County and neighbouring Aboriginal groups, Ontario. Retrieved August 2015, from http://www.nexteraenergycanada.com/pdf/summerhaven/HaldRegion_EconBenefi ts-Feb2015.pdf.

Holburn, G., Lui, K., and Morand, C. (2010). "Policy risk and private investment in Ontario's wind power sector" Canadian Public Policy, Vol. 36 , No. 4 , pp. 465-486.

Holstein, J.A. and Gubrium, J.F. (2001). Handbook of interview research: context and method. Sage Publications: Thousand Oaks.

Hsieh, H-f. and Shannon, S.E. (2005). "Three approaches to qualitative content analysis" Qualitative Health Research, Vol. 15 No. 9, pp. 1277-1288.

Independent Electricity System Operator ${ }_{\text {a }}$ Current Supply Mix. Retrieved December 2015, from http://www.ieso.ca/Pages/Power-Data/Supply.aspx.

Independent Electricity System Operator ${ }_{\mathrm{b}}$. Large Renewable Procurement. Retrieved August 2015, from http://www.ieso.ca/Pages/Participate/Generation-Procurement/LargeRenewable-Procurement/default.aspx.

Independent Electricity System Operator ${ }_{\mathrm{c}}$. Request for proposals for the procurement of up to 565 MW of new large renewable energy projects. Retrieved July 2015, from 
http://www.ieso.ca/Documents/generation-procurement/lrp/lrp-1-final/LRP-IRFP.pdf.

Independent Electricity System Operator. Merger of the OPA and the IESO. Retrieved December 2015, from http://fit.powerauthority.on.ca/programupdates/newsroom/newsroom-2014/December-18-merger.

Innes, J.E. and Booher, D.E. (2004). "Reframing public participation: strategies for the 21st centry” Planning Theory \& Practice. Vol. 5. No. 4, pp. 419-436.

International Association for Public Participation. IPA2 public participation spectrum. Retrieved February 2013, from http://www.iap2.org.au/documents/item/84.

IPPR. (2007). Positive energy: harnessing people power to prevent climate change. Institute for Public Policy Research: London.

Irvin, R.A. and Stansbury, J. (2004). "Citizen participation in decision-making: is it worth the effort?" Public Administration Review, Vol. 64, No. 1, pp. 55-65.

Jacobsson, S. and Lauber, V. (2006). "The politics and policy of energy system transformation: explaining the German diffusion of renewable energy technology" Energy Policy, Vol. 34, No. 3, pp. 256-76.

Kahn, R. (2000). "Siting struggles the unique challenges of permitting renewable energy power plants" The Electricity Journal, Vol. 13, No. 2, pp. 21-33.

King, N. and Horrocks, C. (2010). Interviews in qualitative research. Sage Publications: London.

Kirk, A. and Miller, M.L. (1986). Reliability and validity in qualitative research. Sage Publications: London.

Kramer, D.M. (2002). From knowledge transfer to knowledge transformation: a manufacturing workplace intervention study. University of Toronto: Toronto.

Kumar, A. and Paddison, R. (2000). "Trust and collaborative planning theory: the case of the Scottish planning system" International Planning Studies, Vol. 5, No. 2, pp. 205-223.

Langniss, O. and Wiser R. (2003). "The renewables portfolio standard in Texas: an early assessment" Energy Policy, Vol. 31, No. 6, pp. 527-35.

Leiss, W. (2008). Development of the expert panel process in Canada, 1995-2005. Retrieved January 2016, from https://www.rscsrc.ca/sites/default/files/pdf/DevelopmentofExpertPanelProcessInCanada.pdf. 
Lewicki, R.J., Weiss, S.E., and Lewin, D. (1992). "Models of conflict, negotiation and third party intervention: a review and synthesis" Journal of Organizational Behavior, Vol. 13, No. 3, pp. 209-252.

McCallum, D.B. and Santos, S.L. (1997). "Comparative risk analysis for priority setting" Human and Ecological Risk Assessment, Vol. 3, No. 6, pp. 1215-1234.

McLaren Loring, J. (2007). "Wind energy planning in England, Wales and Denmark: factors influencing project success" Energy Policy, Vol. 35, No. 4, pp. 2648-2660.

Nishimura, K. (2012). "Grassroots action for renewable energy: how did Ontario succeed in the implementation of a feed-in-tariff system?" Energy, Sustainability and Society, Vol. 2, No. 1, pp. 1-11.

OECD. (2009). Focus on citizens public engagement for better policy and services. OECD Publishing: Paris.

O'Faircheallaigh, C. (2010). "Public participation and environmental impact assessment: purposes, implications, and lessons for public policy making" Environmental Impact Assessment Review, Vol. 30, No. 1, pp. 19-27.

Office of Energy Efficiency and Renewable Energy. History of wind energy. Retrieved August 2015, from http://energy.gov/eere/wind/history-wind-energy.

O'Neill, J. (2002). "The rhetoric of deliberation: some problems in Kantian theories of deliberative democracy" Res Publica, Vol. 8, No. 3, pp. 249-268.

Partidario, M.R. and Sheate, W.R. (2013). "Knowledge brokerage - potential for increased capacities and shared power in impact assessment" Environmental Impact Assessment Review, Vol. 39, pp. 26-36.

Pasqualetti, M.J., Gipe, P., and Righte, R.W. (2002). Wind power in view: energy landscapes in a crowded world. Academic Press: San Diego.

Patton, M. (1987). How to use qualitative methods in evaluation. Sage Publications: Los Angeles.

Patton, M. (2002). Qualitative research and evaluation methods (3 $3^{\text {rd }}$ ed.). Sage Publications: Thousand Oaks.

Prystupa, M. (2015). Canada shocks COP21 with big new climate goal. Retrieved January 2016, from http://www.nationalobserver.com/2015/12/07/news/canada-shockscop21-big-new-climate-commitment.

Renewable Energy Facilitation Office. Renewable energy development: a guide for municipalities. $\quad$ Retrieved August 2014, from http://www.energy.gov.on.ca/en/files/2014/09/RenewableEnergyDevelopment.pd f. 
Richards, G., Noble, B., and Belcher, K. (2012). "Barriers to renewable energy development: a case study of large-scale wind energy in Saskatchewan, Canada" Energy Policy, Vol. 42, pp. 691-698.

Riege, A.M. (2003). "Validity and reliability tests in case study research: a literature review with 'hands-on' applications for each research phase" Qualitative Market Research: An International Journal, Vol. 6, No. 2, pp. 75-86.

Rogers, E.M. (2003). Diffusion of innovations (5 ${ }^{\text {th }}$ ed.). Free Press: New York.

Rowe, G. and Frewer, L.J. (2000). "Public participation methods: a framework for evaluation" Science, Technology, and Human Values, Vol. 25, No. 1, pp. 3-29.

Rowe, G. and Frewer, L.J. (2004). "Evaluating public participation exercises: a research agenda" Science, Technology, and Human Values, Vol. 29 No. 4, pp. 512-556.

Ryan, G.W. and Bernard, H.R. (2003). "Techniques to identify themes" Field Methods, Vol. 15, No. 1, pp. 85-109.

Sager, K.L. and Gastil, J. (2006). "The origins and consequences of consensus decisionmaking: a test of the social consensus model" Southern Communication Journal, Vol. 71, No. 1, pp. 1-24.

Salganik, M. and Heckathorn, D. (2004). "Sampling and estimation in hidden population using respondent-driven sampling" Sociological Methodology, Vol. 34, No. 1, pp. 193239.

Savan, B., Gore, C., and Morgan, A. (2004). "Shifts in environmental governance in Canada: how are citizen environment groups to respond?" Environment and Planning, Vol. 22, No. 4, pp. 605-619.

Schutter, J. and Riemer, M. (2009). Participatory decision-making models in the context of environmental justice: are they working? Retrieved March 2014, from http://www.earthsystemgovernance.org/ac2009/papers/AC2009-0151.pdf.

Seawright, J. and Gerring, J. (2008). "Case selection techniques in case study research" Political Research Quaterly, Vol. 61, No. 2, pp. 294-308.

Seidman, I. (2006). Interviewing as qualitative research (3 ${ }^{\text {rd }}$ ed.). Teachers College Press: New York.

Shapiro, P. (2010). "SLAPPs: intent or content? Anti-SLAPP legislation goes international" Review of European Community \& International Environmental Law, Vol. 19, No. 1, pp. 14-27.

Silverman, D. (1997). Qualitative research: theory, method and practice. Sage Publications: Thousand Oaks. 
Sinclair, A.J. and Diduck, A.P. (2001). "Public involvement in EA in Canada: a transformative learning perspective" Environmental Impact Assessment Review, Vol. 21, No. 2 , pp. 113-136.

Stake, R.E. (1995). The art of case study research. Sage Publications: Thousand Oakes.

Stantec. (2013). Port Dover and Naticoke Wind Project : supplementary terrestrial monitoring program. Retrieved July 2015, from http://www.capitalpower.com/community/consultationengagement/Documents/P DN/Supplementary\%20Terrestrial\%20Surveys\%20July\%202013.pdf.

Stroh, M. (2000). "Qualitative interviewing" in Research training for social scientists, edited by D. Burton. Sage Publications: London.

Toke, D. (2002). "Wind power in UK and Denmark: can rational choice help explain different outcomes?" Environmental Politics, Vol. 11, No. 4, pp. 83-100.

Trochim, W.M.K. and Donnelly, J.P. (2008). The research methods knowledge base (3 ${ }^{\text {rd }}$ ed.). Thomson Custom Publication: Mason.

van der Horst, D. (2007). "NIMBY or not? Exploring the relevance of location and the politics of voiced opinions in renewable energy siting controversies" Energy Policy, Vol. 35, No. 5, pp. 2705-2714.

Wall, J.A. and Blum, M.W. (1991). "Negotiations” Journal of Management, Vol. 17. No. 2, pp. 273-303.

Warren, C.R., Lumsden, C., O’Dowd, S., and Birnie, R.V. (2005). “Green on green: public perceptions of wind power in Scotland and Ireland" Journal of Environmental Planning and Management, Vol. 48, No. 6, pp. 853-875.

Webler, T. and Tuler, S. (2006). "Four perspectives on public participation process in environmental assessment and decision-making: combined results from 10 case studies" The Policy Studies Journal, Vol. 34, No. 4, pp. 699-722.

Wells, M. (2009). Overcoming wind resistance: enhancing community acceptance of wind projects in Ontario. Simon Fraser University: Vancouver.

Welsh, E. (2002). "Dealing with data: using NVivo in the qualitative data analysis process" Qualitative Social Research, Vol. 3. No. 2, pp.26-34.

Wesselink, A., Paavola, J., Fritsch, O., and Renn, O. (2011). "Rationales for public participation in environmental policy and governance: practitioners' perspectives" Environment and Planning, Vol. 43, No. 11, pp. 2688-2704. 
Wolsink, M. (2000). "Wind power and the NIMBY-myth: institutional capacity and the limited significance of public support" Renewable energy, Vol. 2, No. 1, pp. 49-64.

Wolsink, M. (2007). "Wind power implementation: the nature of public attitudes: equity and fairness instead of 'backyard motives"' Renewable and Sustainability Energy Reviews, Vol. 11, pp. 1188-1207.

Wolsink, M. and Breukers, S. (2010). "Contrasting the core beliefs regarding the effective implementation of wind power: an international study of stakeholder perspectives" Journal of Environmental Planning and Management, Vol. 53, No. 5, pp. 535-558.

Wouters, M., Hardie-Boys, N., and Wilson, C. (2011). Evaluating public input in national park management plan reviews: facilitators and barriers to meaningful participation in statutory processes. Retrieved March 2012, from http://www.doc.govt.nz/Documents/science-and-technical/sfc308entire.pdf.

Wright, Z. (2012). "A voice for the community: public participation in wind energy development" Dalhousie Journal of Interdisciplinary Management, Vol. 8, No. 1, pp. 117.

Yin, R. (2003). Case study research: design and methods (3 ${ }^{\text {rd }}$ ed.). Sage Publications: Los Angeles.

Yin, R. (2009). Case study research: design and methods (4th ed.). Sage Publications: Los Angeles.

Zartman, I.W. (1975). "Negotiations theory and reality". Journal of International Affairs, Vol 29 , No. 1 , pp. $69-77$.

Zimmerling, J.R., Pomeroy, A.C., d'Entremont, M.V., and Francis, C.M. (2013). "Canadian estimate of bird mortality due to collisions and direct habitat loss associated with wind turbine developments" Avian Conservation and Ecology, Vol. 8. No. 2, http://dx.doi.org/10.5751/ACE-00609-080210. 